\title{
RESILIENCE IN FAMILIES IN WHICH A MEMBER HAS BEEN DIAGNOSED WITH SCHIZOPHRENIA
}

\section{MELANIE BISHOP}

Thesis presented in fulfilment of the requirements for the degree of Master of Science (Psychology) at the University of Stellenbosch

\author{
Supervisor: Prof. A.P. Greeff \\ Department of Psychology \\ Faculty of Arts and Social Sciences
}

April 2014 


\section{Declaration}

By submitting this dissertation electronically, I declare that the entirety of the work contained therein is my own, original work, that I am the owner of the copyright thereof (unless to the extent explicitly otherwise stated) and that I have not previously in its entirety or in part submitted it for obtaining any qualification.

December 2013

Copyright (C) 2014 Stellenbosch University

All rights reserved 


\section{SUMMARY}

The primary aim of this study was to identify family resilience qualities that families use to adapt after a member has been diagnosed with schizophrenia. Family resilience refers to the family's ability to adjust and adapt after a crisis. A secondary aim of this study was to determine whether there are significant differences between groups with regard to biographical variables (i.e. relationship to the ill member, home language, racial groups, family structure, and annual household income) and potential resilience variables. The primary theory utilised in this study was proposed by McCubbin and McCubbin (1996a), namely the Resiliency Model of Family Stress, Adjustment and Adaptation, and the secondary theory utilised is the Family Resilience Framework described by Walsh (2012). Qualitative and quantitative data were collected and analysed in order to answer the research question. Data were collected from 51 participants, who represented 42 families. Families were recruited from three support groups within the Western Cape, South Africa. Qualitative data were obtained through an open-ended question in which the participant was asked to indicate the strengths and resources used by the family to adapt after a member had been diagnosed with schizophrenia. Resilience qualities within the qualitative data were identified through a process of thematic theme analysis. Quantitative data were collected using seven self-report questionnaires, which collectively gave an indication of possible family resilience qualities within the family. Quantitative data were analysed using a mixed model repeated measures analysis of variance (ANOVA), Pearson's product-moment correlations, and a bestsubset regression analysis. Ten statistically significant correlations were found between independent variables and family adaptation. Nine of these variables had a significant positive correlation with family adaptation, namely family income; the degree to which the family finds support in their community; special events and family time; the style of communication during crises; positive communication patterns during crises; family hardiness; the ability of the family to work together and their internal strengths; positive reframing and ability to learn; and the internal locus of control within families. Only one negative correlation with family adaptation was found, namely incendiary communication during times of crisis. The quantitative results were compared with the qualitative themes, and additional findings from the qualitative data were reported. An additional theme that emerged from the qualitative analyses was factors relating to the diagnosed family member, and a subtheme, namely passive appraisal of a crisis. Differences were also found between groups with regard to the measured variables. It is evident from the findings that the 
identified qualities and resources may be used in interventions to strengthen other families in which a member has been diagnosed with schizophrenia. 


\section{OPSOMMING}

Die primêre doel van hierdie studie was om gesinsveerkragtigheidskenmerke te identifiseer wat gesinne gebruik om aan te pas nadat 'n gesinslid met skisofrenie gediagnoseer is. Gesinsveerkragtigheid verwys na die gesin se vermoë om verstellings te maak en aan te pas ná 'n krisis. 'n Sekondêre doelstelling van hierdie studie was om vas te stel of daar beduidende verskille tussen groepe is ten opsigte van biografiese veranderlikes (verhouding met gediagnoseerder lid, huistaal, ras, gesinstruktuur, en jaarlikse huishoudelike inkomste) en potensiële veerkragtigheidsveranderlikes. Die primêre teorie onderliggend aan hierdie studie is dié van McCubbin en McCubbin (1996a), naamlik die "Resiliency Model of Family Stress, Adjustment and Adaptation". Die sekondêre teorie wat gebruik is, is die "Family Resilience Framework" beskryf deur Walsh (2012). Kwalitatiewe en kwantitatiewe data is ingesamel en ontleed ten einde die navorsingsvraag te beantwoord. Data is vanaf 51 deelnemers wat 42 gesinne verteenwoordig het, ingesamel. Gesinne is verkry by drie ondersteuningsgroepe in die Wes-Kaap, Suid-Afrika. Kwalitatiewe data is met 'n oop-einde vraag ingesamel waarin die deelnemende gesinslid gevra is om in sy/haar eie woorde te beskryf watter hulpbronne/kwaliteite/eienskappe die gesin as 'n eenheid gebruik het om aan te pas nadat die lid met skisofrenie gediagnoseer is. Veerkragtigheidseienskappe in die kwalitatiewe data is deur 'n proses van tematiese tema-ontleding geïdentifiseer. Kwantitatiewe data is met behulp van sewe self-rapporteringsvraelyste ingesamel wat gesamentlik 'n aanduiding verskaf van moontlike gesinsveerkragtigheidseienskappe. Kwantitatiewe data is met behulp van gemengde-model herhaalde metings variansieontleding (ANOVA), Pearson produkmomentkorrelasies, en beste-substel regressieontledings ontleed. Tien statisties beduidende korrelasies is tussen onafhanklike veranderlikes en gesinsaanpasbaarheid gevind. Nege van hierdie veranderlikes het 'n positiewe korrelasie met gesinsaanpasbaarheid gehad, naamlik gesinsinkomste; die mate waartoe gesinne ondersteuning van hul gemeenskap kry; spesiale geleenthede en gesinstyd; die kommunikasiestyl tydens 'n krisis; positiewe kommunikasie-patrone tydens 'n krisis; gesinsgehardheid; die vermoë van die gesin om saam te werk en hulle interne sterktes; positiewe herformulering en die vermoë om te leer; en 'n interne lokus van kontrole binne die gesin. Slegs een negatiewe korrelasie met gesinsaanpasbaarheid is gevind, naamlik die gebruik van opruiende kommunikasie. Die kwanitatiewe resultate is met die kwalitatiewe temas vergelyk en bykomende bevindinge vanuit die kwalitatiewe data is gerapporteer. 'n Bykomende tema wat in die kwalitatiewe ontledings na vore gekom het, is kenmerke van die gediagnoseerde gesinslid, asook 'n 
subtema, naamlik passiewe aanvaarding van 'n krisis. Verskille tussen groepe is ook vir die gemete veranderlikes gevind. Dit volg uit die bevindinge dat die geïdentifiseerde kenmerke en hulpbronne in intervensies gebruik kan word om ander gesinne waarin 'n lid met skisofrenie gediagnoseer is, te versterk. 


\section{ACKNOWLEDGEMENTS}

First and foremost, I would like to thank all of the families who were willing to participate in the research project. Their time and efforts in completing all the questionnaires are much appreciated.

Secondly, I would like to thank all of the group facilitators and chairpersons who were willing to take the time to listen to the project and who gave me the opportunity to approach the members of each group at their monthly support group meetings. Without the support of these gatekeepers, I would not have been able to approach these groups. For this I am grateful.

Thirdly, I would like to thank Prof. Martin Kidd, the senior statistician from the Centre for Statistical Consultation at Stellenbosch University.

Lastly, I would like to thank my supervisor, Prof. Greeff, for his assistance and continuous support throughout the project. 


\section{CONTENT}

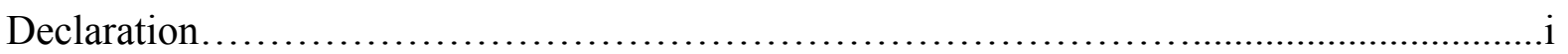

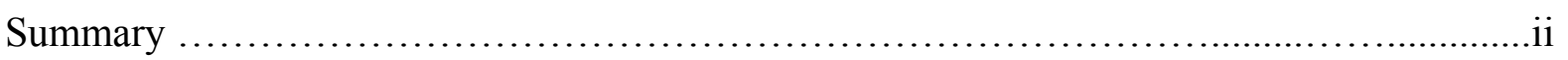

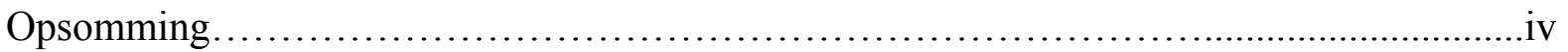

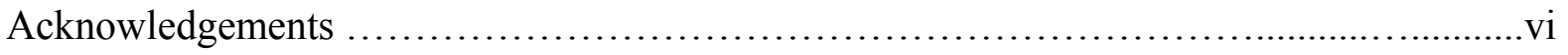

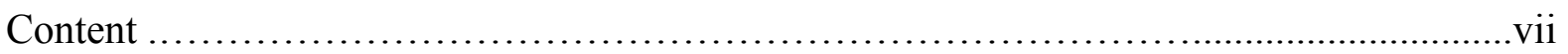

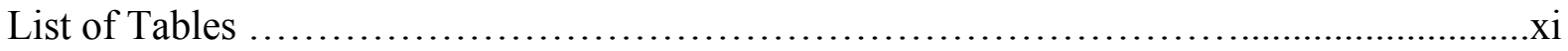

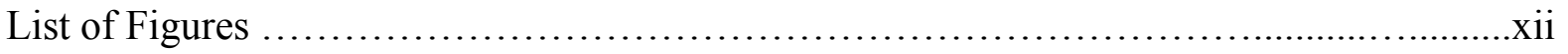

CHAPTER 1: INTRODUCTION, MOTIVATION AND AIMS OF THE STUDY …............1

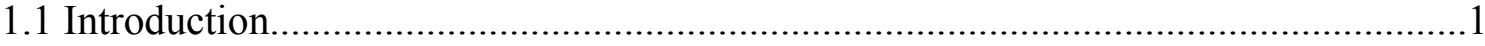

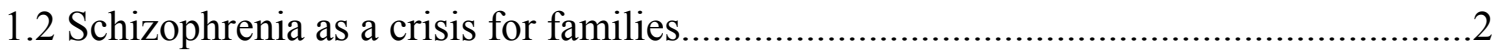

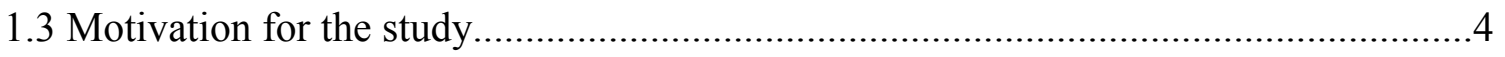

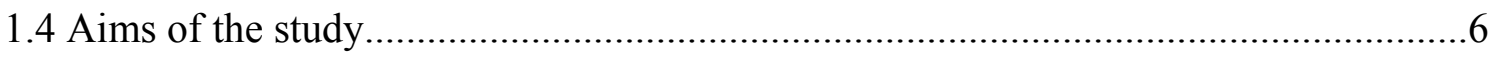

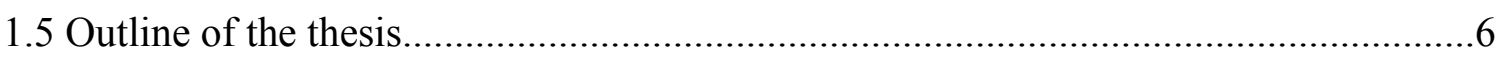

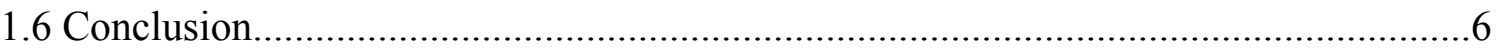

CHAPTER 2: THEORETICAL FRAMEWORK..............................................................

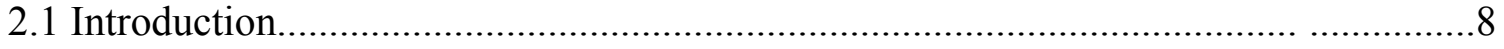

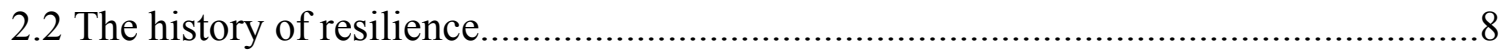

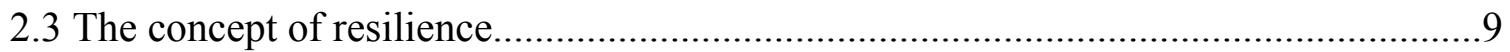

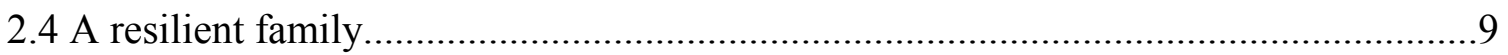

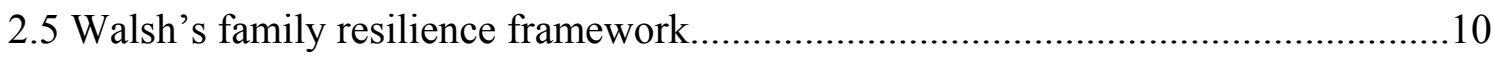

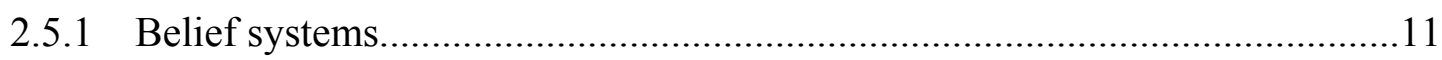

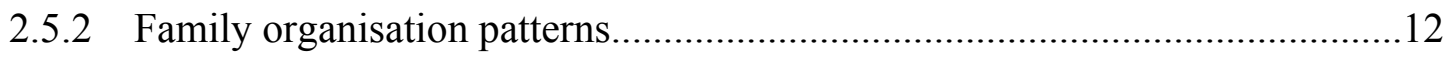

2.5.3 Communication/Problem solving processes................................................13

2.6 The Resiliency Model of Family Stress, Adjustment and Adaptation........................15

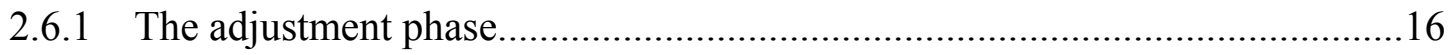

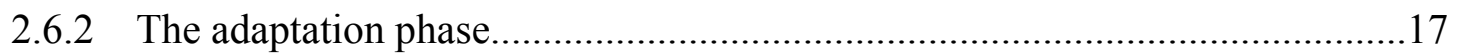

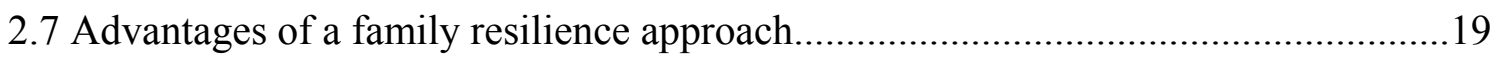

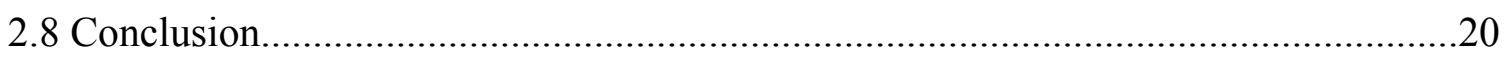




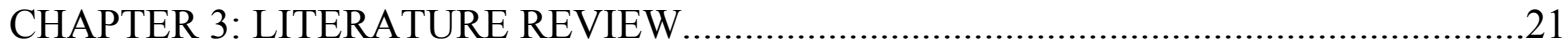

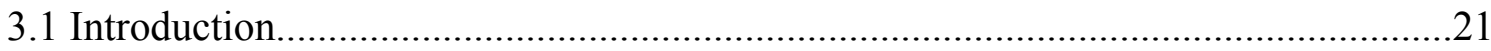

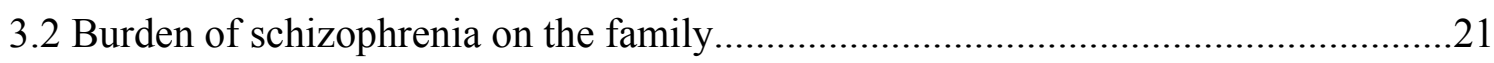

3.3 International studies of resilience in families.......................................................22

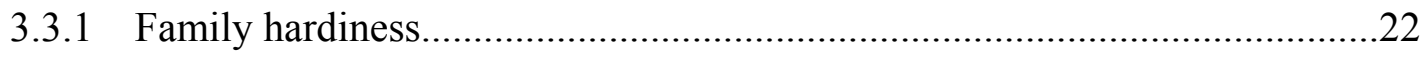

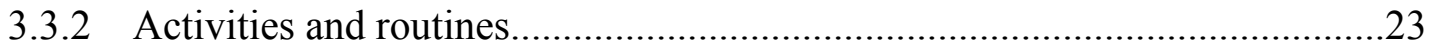

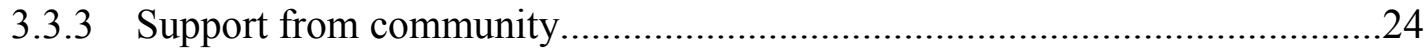

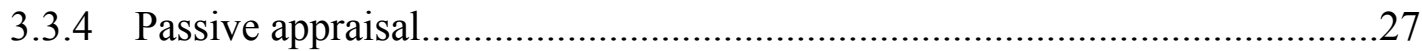

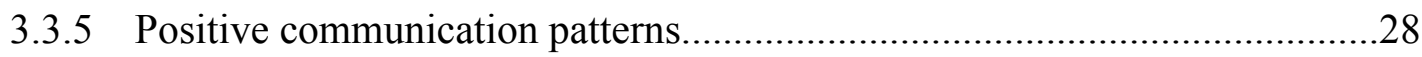

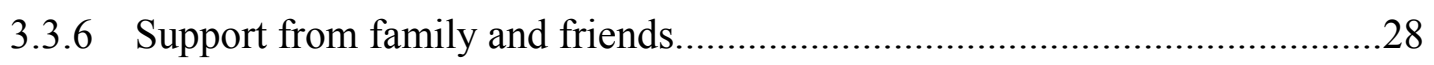

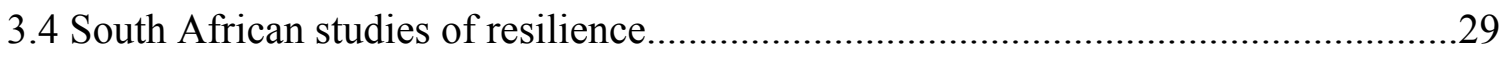

3.4.1 Families in which a member has been diagnosed with schizophrenia...........29

3.4.2 Families in which a member has been diagnosed with a mental disorder.....30

3.4.3 Resilience in families facing different adversities.....................................31

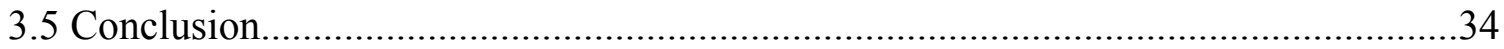

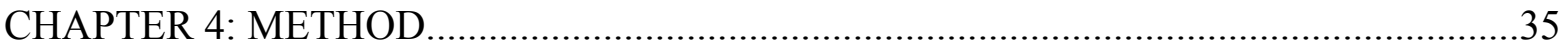

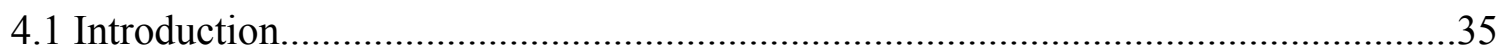

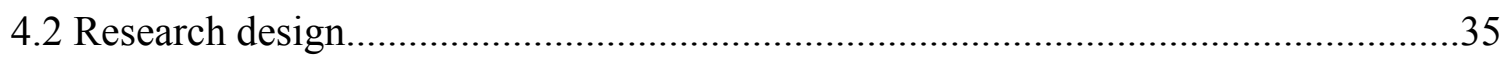

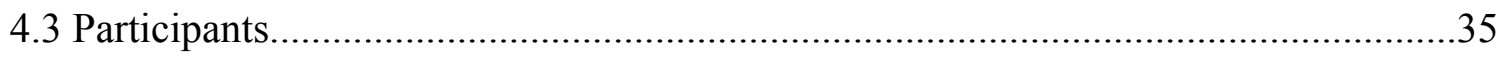

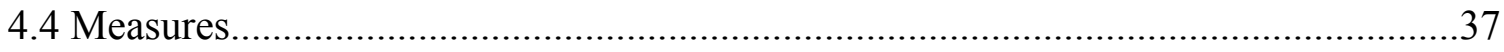

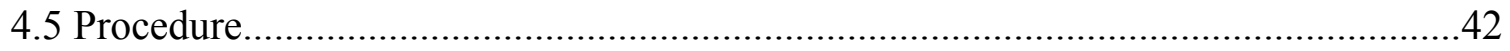

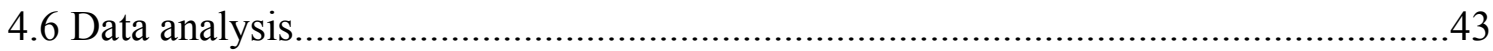

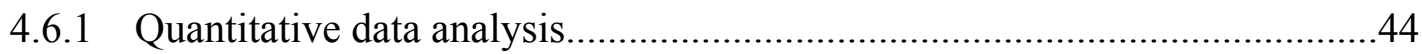

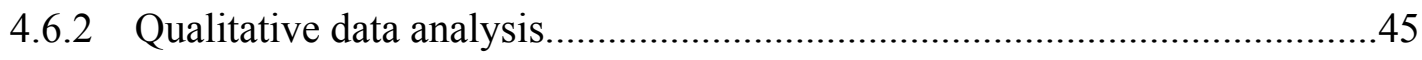

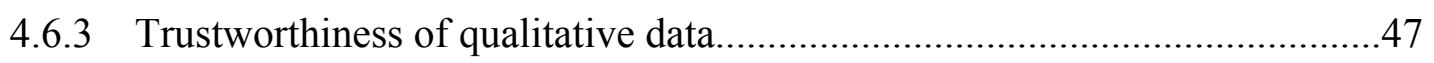

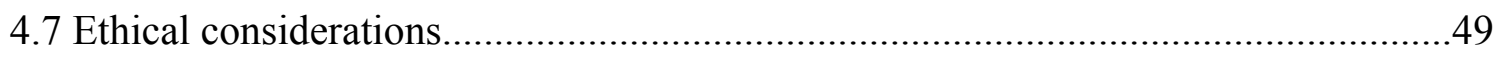

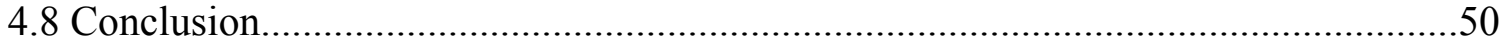

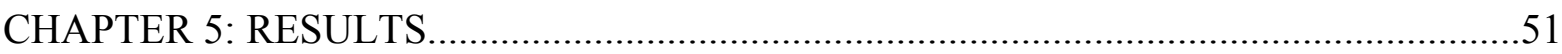

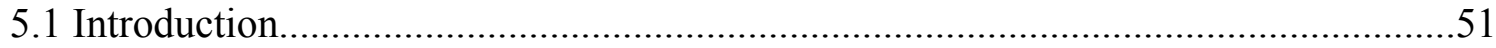

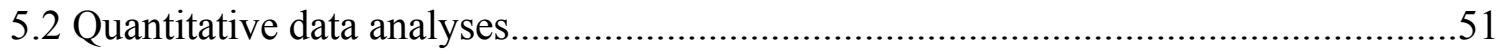

5.2.1 Mixed model repeated measures analysis of variance......................52

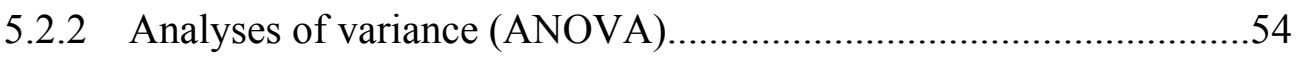


5.2.3 Correlations between the dependent and independent variables .60

5.2.4 Best-subset regression analysis .62

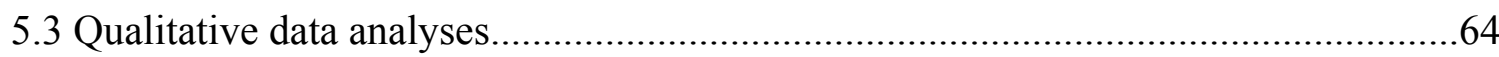

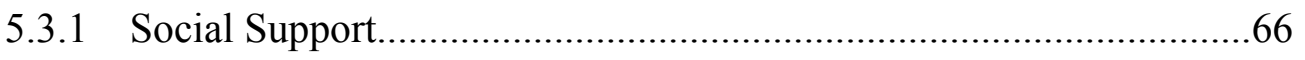

5.3.2 Characteristics and resources within the family.............................71

5.3.3 Factors relating to the diagnosed family member............................74

5.4 Quantitative results supported by the qualitative results........................................77

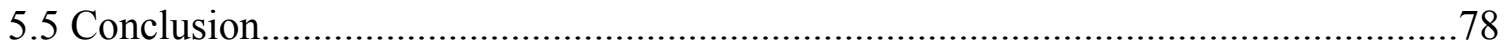

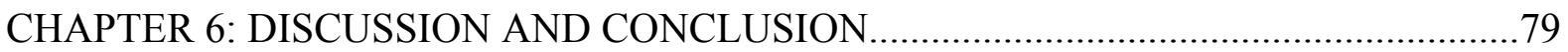

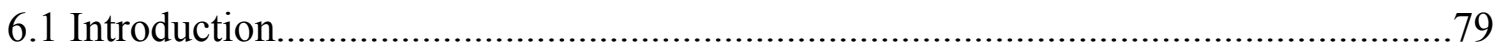

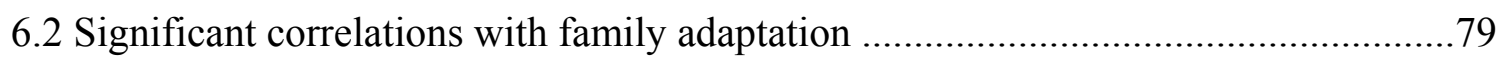

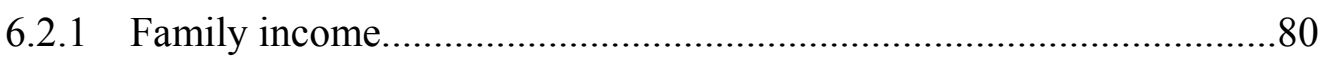

6.2.2 Degree to which the family find support in their community..............80

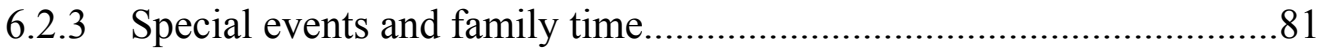

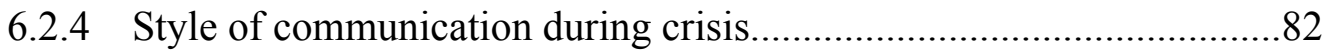

6.2.5 Positive, supportive communication during crises............................82

6.2.6 Negative, inflammatory communication patterns during crisis...........83

6.2.7 Family hardiness: The internal strengths and durability of the family.83

6.2.8 Ability to work together and internal strengths................................84

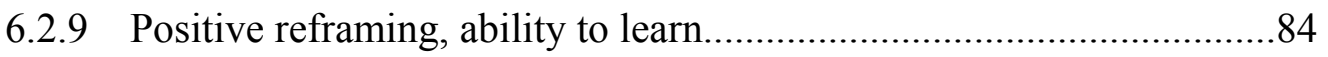

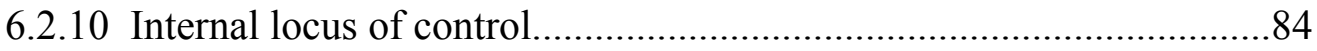

6.3 Additional findings from the best-subset regression analyses...............................85

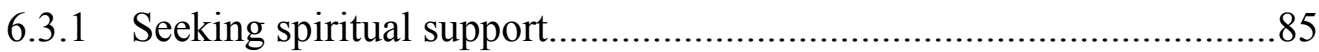

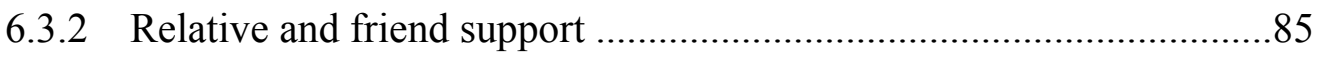

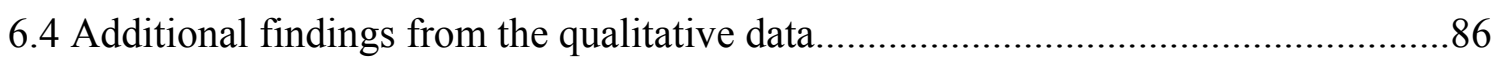

6.4.1 Factors relating to the diagnosed family member............................86

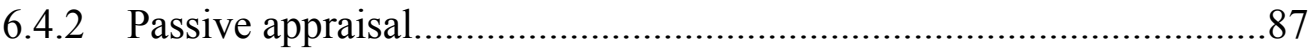

6.5 Differences between groups with regard to the measured variables..........................87

6.5.1 Differences in the use of coping strategies (F-COPES scores)............87

6.5.2 Differences with regard to family time and routines (FTRI scores)....89

6.5.3 Negative, inflammatory communication patterns during times of crisis

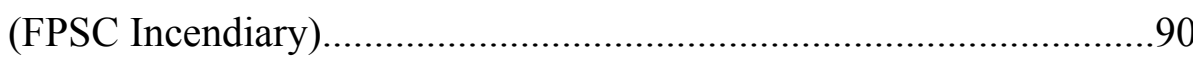

6.5.4 Internal locus of control (FHI Control).........................................90 
6.5.5 Family attachment (FACI8 Attachment)......................................91

6.5.6 Family adaptation (FACI8 Total score)....................................... 91

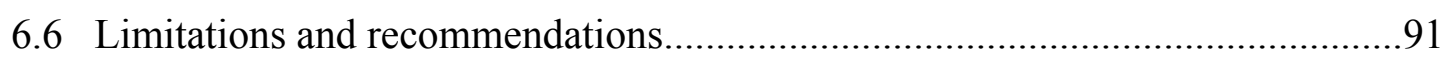

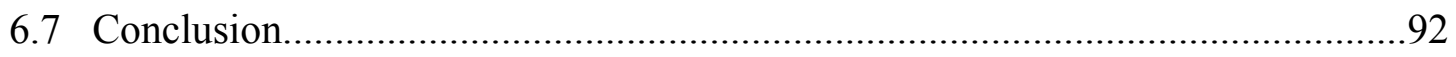

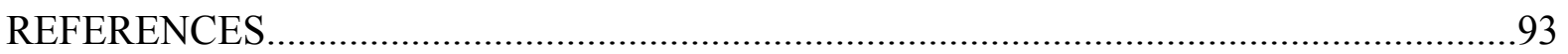

\section{APPENDICES}

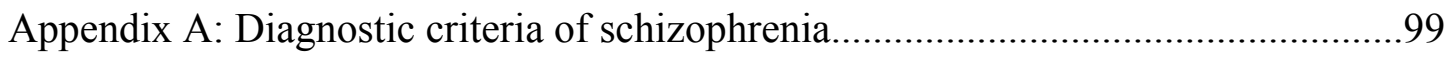

Appendix B: Biographical Questionnaire (English \& Afrikaans).............................102

Appendix C: Informed Consent (English \& Afrikaans)...........................................106

Appendix D: Instructions (English \& Afrikaans)..................................................110

Appendix E: Figures of results from the mixed model repeated measures ANOVA, and the ANOVA. 


\section{LIST OF TABLES}

1. Table 5.2.1 Results of the mixed model repeated measures ANOVA.........................52

2. Table 5.2.2 Results of ANOVAs for differences between groups within biographical variables. 55

3. Table 5.2.3 Pearson product-moment correlations between demographic variables, independent variables and family adaptation (FACI8 Total score)............................61

4. Table 5.2.4 Results of the best-subset multiple regression analysis...........................63

5. Table 5.3 Family resilience themes and subthemes that emerged from the qualitative data analyses. .65 


\section{LIST OF FIGURES}

\section{A. Theoretical Framework figures}

1. Figure 2.6.1 The adjustment phase of the Resiliency Model of Family Stress, Adjustment and Adaptation (adapted from McCubbin \& McCubbin, 1996a).... .16

2. Figure 2.6.2 The adaptation phase of the Resiliency Model of Family Stress, Adjustment and Adaptation (adapted from McCubbin \& McCubbin, 1996a). .18

B. Figures of results from the mixed model repeated measures ANOVA and

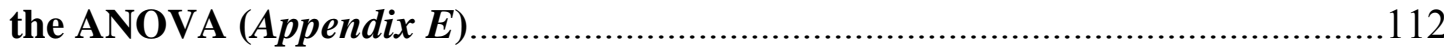

3. Figure 5a Differences at the F-COPES subscale: Family mobilization......................112

4. Figure 5b.1: Differences at the FTRI Couple togetherness subscale.........................112

5. Figure 5b.2: Differences at the FTRI Meals together subscale................................113

6. Figure 5b.3: Differences at the FTRI Parent-child togetherness subscale..................113

7. Figure 5b.4: Differences at the FTRI: Family management subscale.........................114

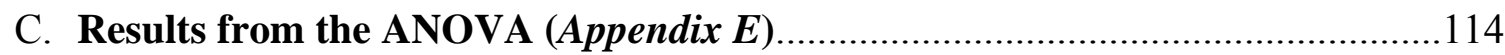

8. Figure 1.1 Difference at the F-COPES Social support subscale...............................114

9. Figure 1.2 Difference between language groups at the F-COPES Reframing subscale.

10. Figure 1.3.1 Difference between race groups at the F-COPES Spiritual support subscale.

11. Figure 1.3.2 Difference between language groups at the F-COPES Spiritual support subscale.

12. Figure 1.3.3 Differences between family structures at the F-COPES Spiritual Support subscale.

13. Figure 1.3.4 Differences between household income groups at the F-COPES Spiritual support subscale...

14. Figure 1.4 Difference between language groups at the F-COPES Family mobilization subscale.

15. Figure 1.5.1 Differences between race groups at the F-COPES Passive appraisal subscale.

16. Figure: 1.5.2 Difference between language groups at the F-COPES Passive Appraisal subscale 
17. Figure 1.5.3 Difference between the income groups at F-COPES Passive appraisal subscale.

18. Figure 2 Differences between family structures at the FTRI Important. 119

19. Figure 3 Differences between language groups at the FPSC Incendiary subscale....120

20. Figure 4.1 Difference between language groups at the FHI Control subscale. 120

21. Figure 4.2 Differences between family structures at the FHI Control subscale. 121

22. Figure 4.3 Difference between income groups at the FHI Control subscale. 121

23. Figure 5.1.1 Difference between languages at the FACI8 Attachment subscale .122

24. Figure 5.1.2 Difference between family structures at the FACI8 Attachment subscale.

25. Figure 5.1.3 Difference between the two income groups at the FACI8 Attachment subscale

26. Figure 5.2 Difference between the two income groups at the FACI8 Total scale.....123

\section{Results from the Best-subset Regression Analysis}

27. Figure 5.2.4 Histogram showing the presence of independent variables in the 20 best models 


\section{CHAPTER 1}

\section{INTRODUCTION, MOTIVATION AND AIMS OF THE STUDY}

\subsection{Introduction}

Schizophrenia has been diagnosed in 1\% of the world's population (Sadock \& Sadock, 2007; Sawa \& Snyder, 2002). Deinstitutionalisation occurred during the 1950s and, due to the closure of mental hospitals and the release of patients to their community, many families had to care for their mentally ill family member. Approximately 50 to $90 \%$ of chronically ill mental patients live with their families (Honkonen, Saarinen \& Salokangas, 1999; Rossler Salize, Cucchiaro, Reinhard \& Kernig, 1999). South Africa has also seen a shift away from institutionalisation towards community care (Kritzinger, Swartz, Mall \& Asmal, 2011). In South Africa there are 3460 outpatient mental health-care facilities and 80 day-treatment facilities (World Health Organization [WHO], 2007). Furthermore, 41 psychiatric inpatient facilities in general hospitals offer 2.8 beds per 100000 population; 63 community residential facilities offer a total of 3.6 beds per 100000 population; and 23 mental hospitals provide a total of 18 beds per 100000 population. Due to the chronic course of schizophrenia, many people need to be admitted to a mental health-care facility. It is evident that there are not enough resources for mentally ill people in health-care facilities, and families therefore need to take care of their ill relatives.

Caring for a family member with a mental illness (Fujino \& Okamura, 2009; Maurin \& Boyd, 1990; Potasznik \& Nelson, 1984; Solomon \& Draine, 1996; Tsang, Tam, Chan \& Chang, 2003), and specifically schizophrenia (Awad \& Voruganti, 2008; Chan, 2011; Glanville \& Dixon, 2005; Lefley, 1989; Rammohan, Rao \& Subbakrishna, 2002a), may place a burden on the family and many families are forced to adapt their lifestyle and coping skills during a potentially stressful period. This stressful experience can be recognised as a crisis (Jones \& Hayward, 2004). To overcome a crisis, it is believed that the family should adjust and adapt, hence be resilient as a family unit (McCubbin \& McCubbin, 1996a).

The current study focuses on resilience in families in the Western Cape, South Africa in which a member has been diagnosed with schizophrenia. In this chapter I will discuss the background and context of the study, followed by a discussion of schizophrenia as a crisis within the family, with reference to the study's potential benefits. Furthermore, the aims of 
the study will be presented, followed by an outline of the thesis and, lastly, a conclusion to this chapter. In the next section, the diagnosis of schizophrenia as a facilitator for creating a crisis within the family is discussed.

\subsection{Schizophrenia as a crisis for families}

Schizophrenia is a severe and usually long-lasting clinical disorder that affects all cultural and social classes and involves disturbances in the ill person's cognitive functioning, emotions, perceptions and other behavioural aspects (Sadock \& Sadock, 2007). The ages of onset are different for men and women, namely between 10 and 25 years for men and between 25 and 35 years for women. Both the patient and family are affected by this disorder (Sadock \& Sadock, 2007). In order to understand how the diagnosis of schizophrenia can cause a crisis within the family, it is important to refer to the diagnostic criteria and the symptoms of the illness, specifically to the diagnostic criteria of schizophrenia according to the Diagnostic and Statistical Manual of Mental Disorders (DSM-IV-TR) (American Psychiatric Association [APA], 2000) (see Appendix A). As can be seen from the diagnostic criteria, there are major social and occupational dysfunctions in a person diagnosed with schizophrenia (APA, 2000). These dysfunctions can cause social isolation and difficulty with being independent. Furthermore, this chronic illness' duration is usually lifelong, or it causes at least continuous difficulties for the diagnosed person over his/her life (Sadock \& Sadock, 2007). The social and occupational dysfunction of the ill member, as well as the duration of the illness, may contribute to a crisis within these families (Jones \& Hayward, 2004).

The symptoms of schizophrenia are divided into two clusters, namely positive symptoms and negative symptoms. The positive symptoms include delusions, hallucinations and bizarre thoughts (Sawa \& Snyder, 2002). The negative symptoms include social withdrawal with affective flattening/restriction, poor motivation, apathy, poverty of thought, and anhedonia (Andreasen \& Carpenter, 1993). Living with a person with these symptoms can be difficult for the family to manage. Most families do not know how to deal with these unusual behavioural patterns (Jones \& Hayward, 2004). Although schizophrenia is diagnosed in individuals, the illness has an influence on the whole family (Jones \& Hayward, 2004). In addition to placing a potential burden on the family, this mental illness can also cause stigmatisation of and discrimination against the family (González-Torres, Oraa, Arístegui, Fernández-Rivas \& Guimon, 2007; Kritzinger et al., 2011; Lefley, 1989; Tsang et al., 2003). 
It seems that families in which a member has been diagnosed with schizophrenia have a need to understand the concept of expressed emotion and the contribution of expressed emotion in the relapse of the ill relative (Kritzinger et al., 2011). The concept of expressed emotion is used to evaluate the role that communication plays in the family (Becvar \& Becvar, 2003) and was first described in 1972 by Brown as the manner in which the family connect with the member diagnosed with schizophrenia. Expressed emotion refers to the hostile or overinvolvement of parent(s) with their children (Sadock \& Sadock, 2007), and is also characterised by excessive criticism (Gabbard, 2005; Henry, Rendell, Green, McDonald \& O'Donnell, 2008; Ward, 2008). This communication between family members is often due to a misunderstanding of the mentally ill relative and the illness (Ward, 2008). This may also cause the family members to feel frustrated, which results in expressed emotion (Ward, 2008). The concept of expressed emotion is not used to give blame to the family members, but rather to illustrate how the illness can affect family life (Gabbard, 2005). By using hostile communication, being over-involved and excessively criticising towards the ill family member, the family may indirectly contribute to the relapse of this person. Many studies have found that there is an increase in relapse when a person diagnosed with schizophrenia lives with a family in which high levels of expressed emotion are present (Gabbard, 2005; Sadock \& Sadock, 2007). The ill member is advised to be in an environment where there are low levels of expressed emotion (Ward, 2008). Therefore it is important for the family to understand the concept of expressed emotion and lower their levels of expressed emotion in order to better care for their mentally ill member (Ward, 2008).

Ward (2008) demonstrates several strategies that the families can use and suggests that there should be a balance within the family between over-stimulation and under-stimulation of the ill member, and that a better understanding of the illness may decrease levels of expressed emotion. The environment should be supportive and predictable, there should be clear boundaries and the families should make use of their social support systems.

Literature on what helps families to adapt will be discussed in Chapter 3. In addition to identifying this diagnosis as a crisis, the motivation for this study is given in the subsequent section. 


\subsection{Motivation for the study}

Families worldwide are affected by mental illnesses. With approximately $1 \%$ of the world's population diagnosed with schizophrenia, it is clear that many families will be affected (Sadock \& Sadock, 2007; Sawa \& Snyder, 2002; Walsh, 2012). Many of these families have to care for their ill family member at home due to the release of patients from institutions to the community (Honkonen et al., 1999; Rossler et al., 1999). Due to the extensive focus of the literature on the burden placed on families in which a member has been diagnosed with a mental illness, such as schizophrenia, there is a need to identify factors that may help these families to be resilient and adapt to their crisis. There is growing literature in South Africa on resilience in families facing adversities (Greeff \& Du Toit, 2009; Greeff \& Fillis, 2009; Greeff \& Lawrence, 2011; Greeff \& Thiel, 2012; Greeff \& Van der Walt, 2010; Greeff \& Wentworth, 2009; Jonker \& Greeff, 2009)., but only one study was found that focused specifically on the resilience of families in which a member had been diagnosed with schizophrenia (Haddad, 2008). Another study that is also relevant is a thesis by Sellmeyer (2003), who researched the needs of families in which a member has been diagnosed with schizophrenia. Due to this limited available research literature, the current study will contribute to the literature about resilience in families in which a member has been diagnosed with schizophrenia, and also provide a more comprehensive look at resilience in these families. Through this study a contribution is made with regard to factors and resources that are associated with resilience in families in which a member has been diagnosed with schizophrenia.

The research results of this study could be used in various ways. Firstly, the information obtained from this study could be used to inform professionals in clinical practice about possible interventions for families living with a member with schizophrenia. Secondly, the information could be used to normalise the experience of the family and, lastly, it may be used to facilitate support groups. These different contributions will be discussed briefly. Firstly, the possible contribution of this research to clinical practice will be highlighted.

The information obtained from this study could be used to inform professionals about how to accurately and effectively help families living with an individual with schizophrenia (Walsh, 2012). McCubbin and McCubbin (1996a) argue that interventions should make use of models that identify the strengths and capabilities of the family. The family resilience framework can be used within the therapeutic relationship to enable the family to find new solutions to 
problems and adapt to change. Vulnerability and risk can be decreased if this framework is used to identify and use these strengths (Walsh, 2012). Rather than focusing on the failures of the past, the family can be encouraged to focus on their strengths. By identifying strengths within the family, the family can be better equipped to manage future challenges. In this light, Walsh (2012) describes resilience as a preventative measure. Furthermore, the practitioner can assist the family to create support within the family system, which may enable them to overcome a crisis. According to Walsh (2012), resilience-oriented interventions will empower the family by increasing hope, developing competencies and strengthening family relationships. In other words, the information may be used by clinical practitioners to facilitate interventions with families.

Secondly, the information obtained from this study could be used to normalise the experiences of the family members. According to Walsh (2012), a key process of family resilience is the process of making meaning of adversity. By reducing the tendency to blame, shame and pathologise by viewing their situation as being normal, the family may be better equipped to make meaning of their experience. According to Walsh (2012), "normal" refers to the family's view of their experience to be expectable among families with the same challenges they are facing. In other words, these families may be able to normalise their experience when they identify that other families also experience similar feelings and reactions after and during a crisis.

Lastly, support groups can use this information and help families to use several resources, such as support from other families (Walsh, 2003a). According to Walsh (2003a), social support is an important contributor to building resilience. Walsh (2003a) explains that resilience can be facilitated through contact with other families who deal with similar issues and challenges, and through learning from each other. The families will be able to identify with other families (Walsh, 2003a) and also identify other resources that they can use in order to adapt after a family member has been diagnosed with schizophrenia.

In conclusion, strengths and qualities that are identified within families who have adapted after a member has been diagnosed with schizophrenia could be used to guide clinical practices and interventions with families who are living with a member with schizophrenia, or another chronic psychiatric illness. 


\subsection{Aims of the study}

The primary aim of this study was to identify strengths and qualities within families that they use to adapt after a member has been diagnosed with schizophrenia. The research question of this study is: "What resources do families use to adjust and adapt after a family member has been diagnosed with schizophrenia?" A secondary aim of this study was to determine whether there are differences between groups with regard to biographical variables (i.e. relationship to the ill member, language groups, racial groups, family structure and annual household income) and potential resilience variables, as measured with the different measuring instruments.

\subsection{Outline of the thesis}

In Chapter 2 the resilience constructs will be discussed, along with two family resilience frameworks that will be utilised in this study.

Chapter 3 covers the review of the literature that is related to the current study. The literature review will include a brief discussion of the burden felt by families in which a member has been diagnosed with schizophrenia. This will be followed by a discussion of international studies on resilience in families in which a member has been diagnosed with schizophrenia and other mental illnesses, as well as a review of South African studies of resilience in families in which a member has been diagnosed with schizophrenia and other mental illnesses, and families facing other adversities.

The methodology used in this study is discussed in Chapter 4. First, the research design is described, followed by a discussion of the participants, as well as of the qualitative and quantitative measures used. The chapter also includes the procedures of the study, the analysis of the qualitative and quantitative data, and the ethical considerations.

Chapter 5 provides the results of this study, whereas Chapter 6 provides a discussion of these results, followed by a summary and conclusion to this thesis.

\subsection{Conclusion}

Chapter 1 has provided an introduction to this study. It is clear that families worldwide are affected by schizophrenia. A reference to the diagnostic criteria and a brief discussion of the symptoms of schizophrenia were given in order to better understand how this diagnosis can cause a crisis within the family. In addition, the concept of expressed emotion and the 
contribution thereof to the relapse of a person with schizophrenia were discussed in order to contribute to the understanding of the crisis these families are faced with. Some needs of and suggested resources for these families have been identified. Families in which a member has been diagnosed with schizophrenia could struggle to adapt to their situation, although some families are able to adjust and adapt to their circumstances. Therefore, it is important to investigate the resilience of these families in order to help other families strengthen their coping mechanisms. The motivation for this study and the possible use of the results were also discussed. The following chapter provides the theoretical framework utilised in this study. 


\section{CHAPTER 2}

\section{THEORETICAL FRAMEWORK}

\subsection{Introduction}

Two theories were used to conceptualise this study. The primary theory is the Resiliency Model of Family Stress, Adjustment and Adaptation (McCubbin \& McCubbin, 1996a), and the secondary theory is the Family Resilience Framework described by Walsh (2012). Before discussing these theories, resilience and family resilience are defined, and the history and concept of resilience are discussed.

\subsection{The history of resilience}

The historical use of and focus on individual resilience has shifted towards family resilience. (Walsh, 2003a, 2012). The individual was seen to "survive" the dysfunctional family due to his or her individual resilience (Walsh, 2012). By focusing on individual resilience, researchers overlooked the possibility of family resilience (Walsh, 2003a). The focus was on the strengths of the individual and the individual's ability to overcome adversity (Walsh, 2003a). These strengths were identified as personality traits and coping strategies that the individual used to overcome a crisis. Very few researchers focused on the family's ability to contribute to resilience. Furthermore, most research focused on individual resilience within dysfunctional families, or those where psychiatric illnesses were present. Most researchers looked for resilience factors outside of the family (Walsh, 2003a). Families were seen as a factor that contributes to risk, rather than as a source of strength or as contributing to resilience (Walsh, 2003b, 2012). Rather than focusing on the deficits of the family, there has been a shift towards focusing on the family's strengths (Hawley \& DeHaan, 1996; Walsh, 2012).

This focus on the strengths, rather than on the deficits or pathology, has been described and named by Antonovsky as 'salutogenesis' (Antonovsky, 1979). 'Salutogenesis' means the origin of strength or health, with genesis literally meaning 'origin' and 'saluto' meaning 'health'. Rather than focusing on what caused or contributed to pathology, the focus is on identifying resources that can contribute to the resilience of the family. A salutogenetic approach or model will try to establish how a person or family manage to stay healthy. It argues that we are constantly on a continuum between two polar extremes, namely health and 
illness. When using a salutogenetic approach to family resilience, family resilience is described as the family's inherent ability to stay healthy (Antonovsky, 1979).

\subsection{The concept of resilience}

The concept of resilience has been described and defined by many. Some of these will be discussed in this section. McCubbin and McCubbin (1996a, p. 5) define resilience as

... the positive behavioural patterns and functional competence individuals and the family unit demonstrate under stressful or adverse circumstances, which determine the family's ability to recover by maintaining its integrity as a unit while insuring, and where necessary restoring, the well-being of family members and the family unit as a whole.

According to Walsh (2012), resilience refers to the process during which an individual or family adapts after a crisis. Walsh (2012, p. 399) defines family resilience as the ability to "withstand and rebound from disruptive life challenges". Hawley and DeHaan (1996) explain that the concept of family resilience is used to describe how families are able to adapt and 'bounce back' after crises. They identified several comparisons between definitions of family resilience (Hawley \& DeHaan, 1996). Firstly, the family experiences a crisis and is able to return to their baseline functioning after such a stressful event. Secondly, resilience includes the process of 'bouncing back'. Lastly, the focus of resilience is on strengths rather than deficits or pathology (Hawley \& DeHaan, 1996).

Therefore, it seems that we can confidently refer to the concept of 'family resilience' as the ability or attempt of a family to restore the balance within their family after a crisis or crises by making use of several resources that help them in this process. In addition to giving a description of resilience and definitions of resilience, for the purpose of this study it is important to have a good understanding of what is meant by a 'resilient family', as this study investigates the resilience of families.

\subsection{A resilient family}

Patterson (2002) describes two central aspects of family functioning that he refers to as protective factors, namely family cohesiveness, and flexibility in the family as a system. Both these processes have the same purpose, which is to achieve balance in the family. In addition 
to the family functioning processes (to enhance cohesiveness and flexibility) that create supportive relationships, communication is also a protective factor that families may use to make meaning. According to Patterson (2002), families are continuously trying to balance family demands and capabilities in order to adapt. A crisis can cause major changes in the structure and/or patterns of functioning in the family, and these patterns can either improve or not. Resilience is often related to this process of change (Patterson, 2002).

There are several resources that families use to overcome stress and decrease their risk for maladaptation. Cohesiveness, flexibility, communication and making meaning are some examples of protective factors that can facilitate family resilience (Patterson, 2002). The family's ability to be resilient is not only related to their internal qualities, but also to the risks and opportunities in their social systems within their ecological context (Patterson, 2002). These constructs are also described by Walsh (2012) in the family resilience framework, as well as by McCubbin and McCubbin (1996a) in the Resiliency Model of Family Stress, Adjustment and Adaptation.

\subsection{Walsh's family resilience framework}

The family resilience framework focuses on the strengths of the family, rather than focusing on their deficits. Instead of focusing on how the family have failed in the past, the focus shifts towards focusing on how the family can succeed in the present and prepare themselves for future challenges (Walsh, 2012). A basic view of this framework is that, when adversity strikes or the family experiences a crisis, the whole family are affected by such an event. Instead of isolating the individual member of the family, the focus when using this framework is on the family as a whole. The purpose is then to find the strengths of the family, enhance the family's best qualities and thereby reduce dysfunction. As a result, key family processes (as explained by Walsh) may help the family as a unit, as well as each member individually, to adapt after a stressful event (Walsh, 2012). By identifying resources and ways to adapt, Walsh (2012) explains that the family may be enabled to meet future challenges more successfully.

Walsh's theory developed from research done on the qualities that enhance individual resilience, as well as the well-being of the family unit. Walsh's framework identifies key family processes that can decrease stress and vulnerability in high-risk families, facilitate 
growth and healing within the family unit, and empower the family to move forward from adversity. These key processes are divided into three categories, namely the family's belief system, organisational patterns and communication patterns (Walsh, 2003b, 2012). These three categories will now be discussed briefly.

\subsubsection{Belief systems}

Belief systems refer to the process of making meaning of adversity, and having a positive attitude as well as transcendence and spirituality (Walsh, 2003b, 2012).

\section{Making meaning of adversity}

Making meaning of adversity means that the family approach crises as a shared challenge and have similar views of their strengths. This contributes to continuous growth and change (Walsh, 2012). By normalising the stress they experience, the family can have a different perspective that may enable them to better understand their actions and struggles, i.e. to make meaning of their experiences. By gaining a sense of coherence, they may better struggle with their experiences. This involves clarifying their problems and identifying their resources. Family members will often try to make sense of adversities by searching for a cause or something that can explain their crises (Walsh, 2012).

\section{Positive outlook}

The most important aspect of a having a positive outlook is to have hope (Walsh, 2012). A more optimistic view of life has been seen in families with a high level of functioning. Having a positive outlook is also based on the view that, if optimism can be learned, then helplessness can be 'unlearned'. To sustain a positive outlook, the family's view should be strengthened by successful adaptation processes, and support from their community. Identifying family strengths in difficult times may help the family to decrease their sense of helplessness. Another important aspect of a positive outlook is to have perseverance and initiative within the family as a unit (Walsh, 2012).

\section{Transcendence and spirituality}

Transcendence and spirituality provide meaning and purpose to families and are believed to come from beyond our own abilities (Walsh, 2012). An adversity may facilitate growth, 
change and learning. An adversity and the process of transcendence and spirituality can also make the members aware of each other (Walsh, 2012).

Although Walsh (2012) identified these belief systems, namely making meaning of adversity, having a positive outlook, and transcendence and spirituality, as helping the family move forward from adversity, she also identified a second set of key family processes, namely family organisation patterns.

\subsubsection{Family organisation patterns}

Organisational patterns consist of the family's ability to be flexible and connected, as well as focus on their social and economic resources (Walsh, 2012).

\section{Flexibility}

Flexibility also refers to the family's ability to 'bounce back', i.e. the ability of the family to continue despite a crisis or a traumatic event (Walsh, 2012). If the family are flexible, they are able to return to the level of functioning at which they were before the crisis. More often than not, however, families are not able to return to a previous level of functioning after a crisis. Walsh (2012) refers to resilience as "bouncing forward" - in other words the family change to adapt to a new way of living and incorporating the experience into their life. Families need to reorganise, and most often families need help to do so. Walsh (2012) argues that a firm, but flexible, authoritative figure is necessary for family functioning and for maintaining the well-being of the child during and after a stressful event. Walsh (2012) also argues that it is important for the parent and other caregivers to be nurturing, and to provide safety and assistance in crises. Vulnerable individuals, and especially children, need security, a sense of predictability, and assurance of continuity throughout such an event (Walsh, 2012).

\section{Connectedness}

Connectedness is an important aspect in the functioning of the family (Walsh, 2012). The family can be disrupted by a crisis and this crisis can cause a disruption in the connectedness between family members if they are not able to depend on each other. According to Walsh (2003b), resilience is strengthened by family members who support each other equally and who are committed to overcoming difficult situations together. Although they work together, it is also important for family members to respect and acknowledge each other's 
individualism. Every family member may react differently to the same event and attach different meanings to the experience (Becvar \& Becvar, 2003; Walsh, 2003b).

\section{Social and economic resources}

Social support and networks are very important during times of crisis (Walsh, 2012). These support systems may offer great practical and emotional support. It has also been recorded that role models and mentors are important in strengthening resilience in younger children (Walsh, 2012). Other aspects that strengthen resilience are involvement in community groups and faith gatherings. Those families that tend to be more isolated can be encouraged to be involved in such practices. Involvement in the community and receiving support from neighbours may strengthen resilience within the community as well as within the family and individual. Financial security is also an important aspect when considering the family as resilient. The economic situation of the family can be greatly influenced by crises. Financial risk has been documented to be one of the most common risk factors in single-parent families (Walsh, 2012). The concept of family resilience should not be used to blame families who are unable to be more resilient. They should rather be supported by institutions and the community (Walsh, 2012).

\subsubsection{Communication/problem-solving processes}

Communication patterns or problem-solving processes include clarity, open emotional expression, and collaborative problem solving (Walsh, 2012). Communication can increase the resilience of a family by making clear to family members what is happening and helping each other to understand what they are experiencing as a family unit. Through communication the family members can be encouraged to support one another emotionally. Communication can also help the family to find solutions to problems as a group - making each other feel important and making every member feel that they are making a contribution to the family's problem-solving process. It should be noted that this way of communication might not be accepted in some cultures, as certain cultures are more sensitive to expressing emotions and details of events or situations (Walsh, 2012). The importance of clarity in communication patterns will be discussed first.

\section{Clarity}

Clarity is seen to facilitate family functioning (Walsh, 2012). By working together, the family may gain a more comprehensive picture and understanding of what has happened. By sharing 
their experiences and meaning-making processes, closeness within the family can be facilitated. Secrecy and ambiguity may inhibit the family from making meaning, finding clarity and engaging in the healing process. The healing process can be facilitated by acknowledging the event and sharing their experiences with each other (Walsh, 2012). Although clarity has been described to facilitate the healing process, the importance of emotional expression was also identified by Walsh (2012).

\section{Emotional expression}

Emotional expression is facilitated by creating an environment in which the members feel safe and encouraged to share their feelings honestly and without feeling judged (Walsh, 2012). The family may not always move forward together. Some members may need more time to process their experiences. When a family are overwhelmed by the presence of a feeling of tension, they tend to experience conflict. When the family members feel helpless and out of control they tend to try to control each other. Pathologies are more likely to arise when emotions cannot be shared with loved ones and the people closest to them (Walsh, 2012). Emotional expression has been identified as an important factor in communication patterns within families, as well as in the technique of collaborative problem solving (Walsh, 2012).

\section{Collaborative problem solving}

Collaborative problem solving and conflict handling are important aspects that contribute to resilience (Walsh, 2012). The family as a unit should be able to share ideas to find ways to overcome adversity. Through this collaborative approach, healing and growth can be facilitated. When the family discuss solutions to problems together, they may gain an understanding of each other and become more protective of each other. The family also need to set goals and prioritise their needs in order to "bounce forward". By actively working together, the family are less likely to become passive, and more likely to overcome the adversity. Each family will have different resources and strengths that they may use in different ways to achieve successful adaptation after a crisis (Walsh, 2012).

Walsh's family resilience framework is based on three key family processes that can help families overcome adversity, namely beliefs, family organisation patterns, and communication or problem-solving processes (Walsh, 2003b, 2012). In the following section, the resiliency model of stress, adjustment and adaptation is discussed. 


\subsection{The Resiliency Model of Family Stress, Adjustment and Adaptation}

The Resiliency Model of Family Stress, Adjustment and Adaptation (further on referred to as the Resiliency Model) was developed by McCubbin and McCubbin (1996a) in an attempt to demonstrate and describe how some families may adjust and adapt after a crisis or crises, while others do not. This model evolved from earlier models of family resilience (McCubbin \& McCubbin, 1996a).

The Resiliency Model developed mainly from the ABCX model developed by Hill in 1949. A refers to the stressor, $\mathrm{B}$ to the resources, $\mathrm{C}$ to the definition of the stressor and $\mathrm{X}$ to factors that prevent the family from deteriorating in a crisis. After this model, the Double ABCX model was developed, which focused more specifically on coping skills and support from families, friends and community. The Family Adjustment and Adaptation Response (FAAR) model was developed next and elaborated on the Double ABCX model. This model focused especially on the family's ability to balance their resources and demands. In this model, the adjustment phase is described as the family's attempt to resist change, whereas the adaptation phase describes the processes families use to change and restructure in an attempt to overcome a crisis. The FAAR model was followed by the Typology Model of Family Adjustment and Adaptation, which focused on the existing processes of family functioning. This model focused more specifically on the family's appraisal processes and their functioning patterns that have already been established (McCubbin \& McCubbin, 1996a).

The Resiliency Model developed in reaction to these models and emphasises the four most important aspects of family functioning, namely (1) interpersonal relationships, (2) structure and function, (3) development, well-being and spirituality, and (4) relationships with the community. These four domains are affected when the family are faced with an adversity. The family should try to achieve a sense of balance and harmony in all four of these areas (McCubbin \& McCubbin, 1996a). This model explains that family resilience involves two processes, namely adjustment and adaptation. The function of the adjustment phase is to restore balance and harmony in the abovementioned areas of family functioning. The adaptation phase refers to processes that may enable the family to make changes in order to adapt after a crisis. The adjustment phase of the Resiliency Model will be discussed first. 


\subsubsection{The adjustment phase}

The adjustment phase of the Resiliency Model (see Figure 2.6.1) describes a sequence of family processes after experiencing a stressor. The outcome of this phase will lie on a continuum between a state of bonadjustment and maladjustment. The family reach a state of bonadjustment if they achieve a state of harmony and balance. If the family are still in a crisis situation and have not adjusted adequately, they will be in a state of maladjustment.

\section{Time}

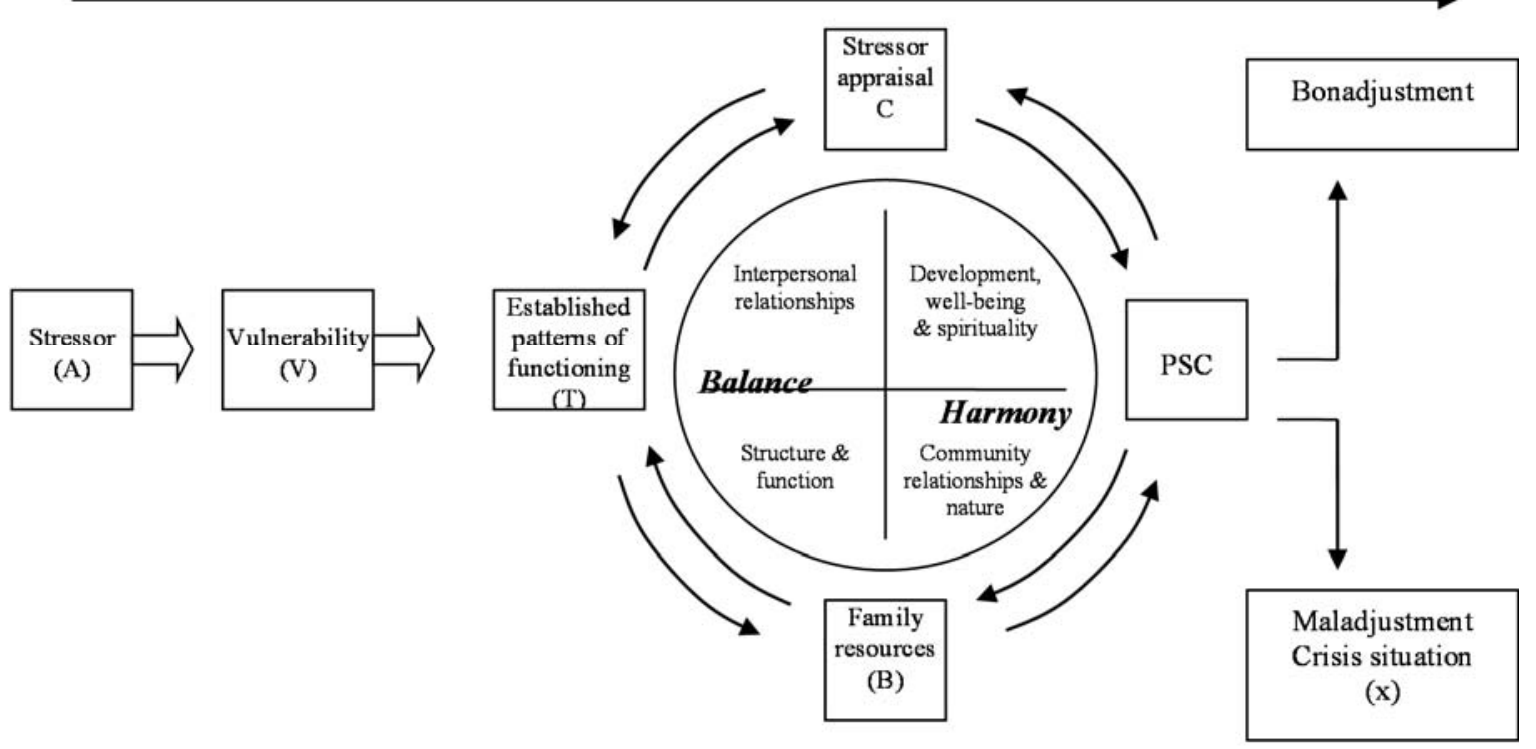

Figure 2.6.1. The adjustment phase of the Resiliency Model of Family Stress, Adjustment and Adaptation (adapted from McCubbin \& McCubbin, 1996a).

As can be seen from Figure 2.6.1, the family experience a stressor (A) of a certain severity, which interacts with the vulnerability (V) of the family. This vulnerability refers to all stresses within the family to this point, any changes that have occurred, or other stress experienced by family during the same period as the current stressor (A). This vulnerability interacts with the patterns of functioning established by the family $(T)$, which then interacts with the family's resources, which offer resistance (B). This interacts with the family's appraisal of the stressor (C). The family's appraisal of the stressor refers to how the family as a unit conceptualise the stressor or problem, i.e. how intense the stressor is felt by the family and how the family define this intensity, e.g. as a minor stressor, or as something as extreme as a catastrophe. The family's appraisal of the stressor interacts with the family's problemsolving and coping strategies (PSC). The problem-solving and coping strategies can refer to the communication patterns within the family during crisis, which are either affirming or 
incendiary, and if they seek help or support from the community or friends to solve the problem. Together, all these components interact with each other to create a level of adjustment within the family (McCubbin \& McCubbin, 1996a).

The outcome of the adjustment process will lie on a continuum from bonadjustment to maladjustment. Bonadjustment refers to a state of harmony and balance after resolving the problem. When the family reach bonadjustment, they will have overcome their crisis relatively comfortably. Only very small changes may have occurred during this process, and the family achieve a state of balance and harmony. If the family reach maladjustment, more serious changes may have to occur within the family to return to a state of balance, otherwise disharmony will be the result. When a family reach maladjustment, they are still in a crisis state and will continue to the adaptation phase (McCubbin \& McCubbin, 1996a).

\subsubsection{The adaptation phase}

The family will still be in a crisis state and enter the adaptation phase of the Resiliency Model (see Figure 2.6.2) if they did not adequately adjust to the stressor in the adjustment phase. Several factors have an effect on and influence the level of adaptation achieved by a family after experiencing a crisis. The level of adaptation achieved by the family is determined by several processes interacting with each other, as described in the next section. Figure 2.6.2 illustrates the adaptation phase of the Resiliency Model. 


\section{Time}

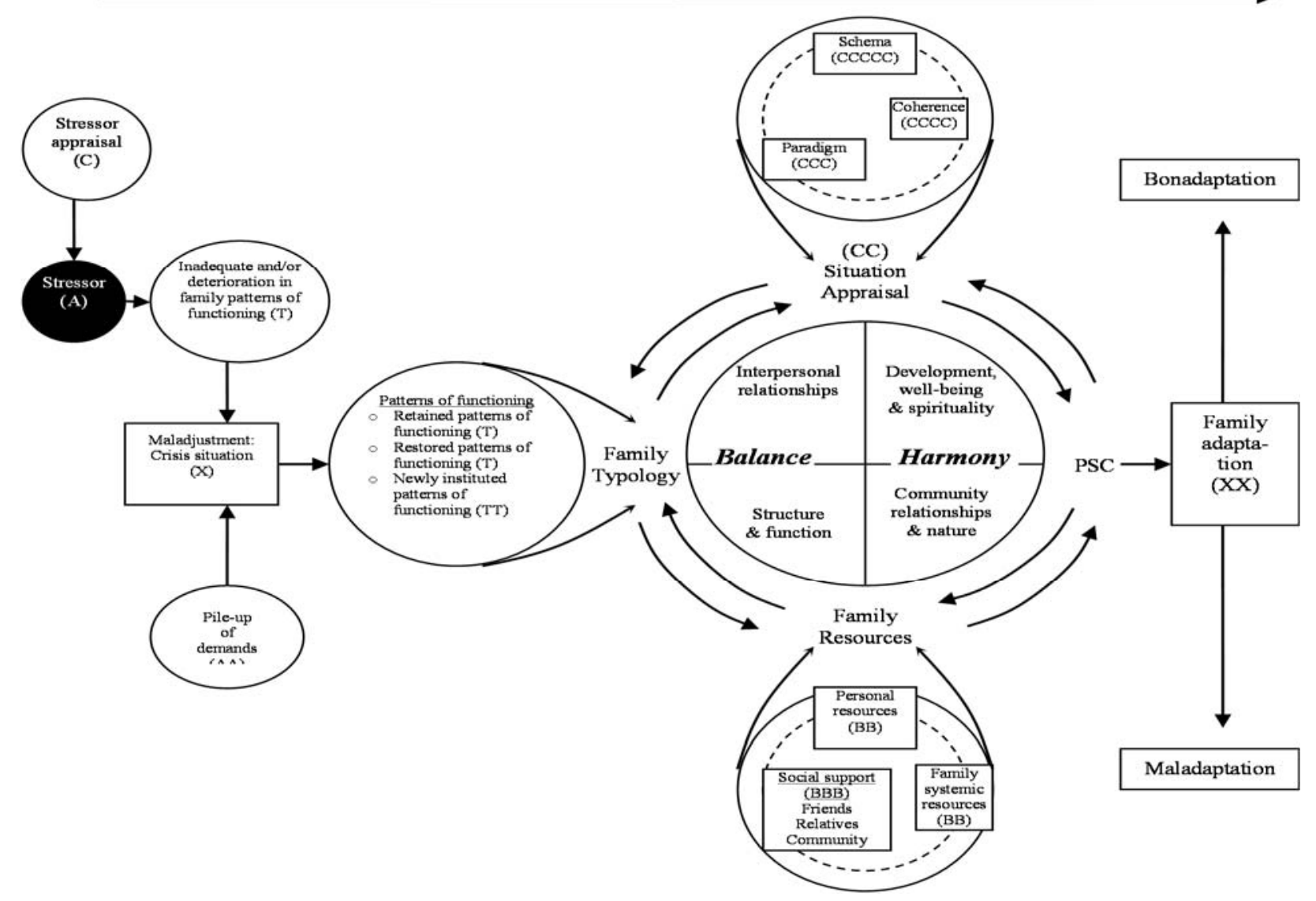

Figure 2.6.2. The adaptation phase of the Resiliency Model of Family Stress, Adjustment and Adaptation (adapted from McCubbin \& McCubbin, 1996a).

If the family enter the adaptation phase, this means that the established patterns of functioning (T) are problematic and are not helping the family to adjust. This situation also gets worse when more stressors emerge and contribute to the crisis, i.e. a pile-up of stressors (AA) occurs. The family attempt to achieve balance and harmony by making changes to adapt and overcome the crisis. The goal of the adjustment phase is to restore balance and harmony within all four of the family's most important areas of functioning, namely interpersonal relationships, structure and function, development, well-being and spirituality, and relationships with the community. Successful adaptation is referred to as bonadaptation and unsuccessful adaptation is called maladapataion. Bonadaptation and maladaptation are viewed on a continuum, and therefore the family's outcome of adaptation is referred to as a level of adaptation (XXX). Bonadaptation is influenced by several factors, namely the new patterns of functioning established by the family (TT), the changes or maintenance of already established patterns of functioning (T), the family's personal resources and capabilities (BB), the family's social support system (BBB), as well as the family's appraisal of the situation. 
Five levels of appraisal are defined by McCubbin and McCubbin (1996a), namely stressor appraisal (C), situational appraisal (CC), paradigms (CCC), coherence (CCCC), and schema (CCCCC). Three of these, namely paradigms (e.g. expectations shared within the family), coherence (e.g. the position of the family's sense of order, trust, predictability and manageability in relation to each other), and schema (e.g. family values and beliefs) impact on the situational appraisal of the family, as well as their definition of the stressor (C). Situational appraisal refers to the relationship between the family's view of the stressor and the capabilities that they believe they have to overcome the crisis. The already established patterns of functioning within the family, as well as the family's resources and family appraisal processes, have an impact on the type of problem solving and coping abilities (PSC) with which the family engage. PSC includes conflict management and problem solving within the family, as well as certain coping mechanisms. Over time, the family engage in a dynamic process, with the goal to restore harmony and balance in the four most important areas of functioning. If the family fail to adapt successfully, they achieve a level of maladaptation (XX). This outcome results in a crisis in the family and causes the family to engage in a cyclical process, which returns them to a place of unbalance and disharmony. The process then starts again at making changes in their established patterns of functioning, and they have to go through the processes discussed above again, i.e. the family processes of adaptation. If the family achieves bonadaptation, the family have successfully adapted and the established patterns of functioning usually are largely maintained.

\subsection{Advantages of a family resilience approach}

A resilience approach is strengths based, which means that the focus is on the strengths of the family instead of on their deficits (Walsh, 2012). By focusing on their strengths, the family are empowered. A resilience approach focuses more on the processes in families over time, and how changes are made within the family to overcome crises (Walsh, 2012). When using this approach, all families, regardless of the stresses and crises experienced, are viewed to have the potential to become resilient and overcome hardships. Such an approach can also be used in collaboration with other strength-focused approaches to give the family an opportunity to evaluate their own systems and focus on the strengths that may help them to overcome crises (Walsh, 2012). 


\subsection{Conclusion}

In this chapter, the theories that were utilised in this study were discussed. Two frameworks were given that provide processes in which families engage when faced with adversity. Walsh's resilience framework focuses on the strengths of the family, rather than focusing on their deficits, and provides three key family processes that help families to overcome a crisis (Walsh, 2012). In congruence with her framework, the primary theory used within this study, namely the Resiliency Model of Family Stress, Adjustment and Adaptation (McCubbin \& McCubbin, 1996a), describes how some families may adjust and adapt after a crisis or crises, while others do not. McCubbin and McCubbin (1996a) explain that two phases, namely adjustment and adaptation, contribute to the resilience (bonadjustment/bonadaptation) or maladjustment/maladaptation of the family.

This study aims to identify resources that families use to adjust and adapt after a family member has been diagnosed with schizophrenia. The next chapter (Chapter 3) gives a review of the literature regarding resilience in families. 


\section{CHAPTER 3}

\section{LITERATURE REVIEW}

\subsection{Introduction}

The aim of this study was to identify resources that families use to adapt after a member has been diagnosed with schizophrenia. This literature review includes a brief discussion of the burden experienced by families in which a member has been diagnosed with a mental disorder, and more specifically with schizophrenia. This will be followed by a discussion of international studies of resilience in families in which a member has been diagnosed with a mental disorder, and specifically schizophrenia, as well as a review of South African studies of resilience in families in which a member has been diagnosed with schizophrenia, those in which a member has been diagnosed with a mental illness, and lastly in families facing other adversities.

\subsection{Burden of schizophrenia on the family}

Researchers have suggested that families contribute to mental illness such as schizophrenia (Hatfield \& Lefley, 1987). Families contributing to schizophrenia have been labelled as "dysfunctional", or the mothers as "schizophrenogenic". Furthermore, the families have been seen to contribute to the relapse in a person with schizophrenia through negative expressed emotion (EE) (Hatfield \& Lefley, 1987).

The majority of the literature has focused on the burden that mental illness (Fujino \& Okamura, 2009; Maurin \& Boyd, 1990; Potasznik \& Nelson, 1984; Solomon \& Draine, 1996; Tsang et al., 2003), and specifically schizophrenia (Awad \& Voruganti, 2008; Chan, 2011; Glanville \& Dixon, 2005; Lefley, 1989; Rammohan et al., 2002a), causes for families. Factors that may contribute to the burden experienced by families include economic, physical, emotional and psychological stresses (Anuradha, 2004; Potasznik \& Nelson, 1984). Regarding emotional and psychological stress, the family may experience feelings of guilt (Anuradha, 2004; Potasznik \& Nelson, 1984) and anxiety (Anuradha, 2004; Potasznik \& Nelson, 1984; Tsang et al., 2003); helplessness (Anuradha, 2004; Tsang et al., 2003); delayed grief reactions (Anuradha, 2004); worry; disturbances in sleeping patterns (Potasznik \& Nelson, 1984); and a sense of frustration (Tsang et al., 2003). Tsang et al. (2003) also noted that a lack of mental health resources may contribute to the family's sense of burden. According to Abelenda and Helfrich (2003), although caring for the family member may be viewed as a burden, many also see caregiving as providing satisfaction in their lives. 
Except for the burden experienced by these families, many are confronted with stigmatisation and discrimination (Lefley, 1989; Tsang et al., 2003), especially families in which an individual is diagnosed with schizophrenia (González-Torres et al., 2007). Some authors have found that the diagnosis of a mental illness can symbolise loss to the family, and the family then need to adjust to this sense of loss (Jones, 2004; Maurin \& Boyd, 1990). They may perceive the illness as 'taking away' a 'normal' life from the diagnosed individual (Maurin \& Boyd, 1990).

Although much research has focused on the burden placed on families when caring for a family member with a mental illness, this study focuses on how families adjust and adapt after a diagnosis of schizophrenia has been made. Consequently, in the literature review that follows, the focus will rather be on positive aspects of families and the resources that helped these families to adapt. Firstly, international studies of resilience in families in which a member has been diagnosed with a mental illness are discussed.

\subsection{International studies of resilience in families}

Several international studies have identified resources that contribute to the resilience of a family in which a member has been diagnosed with a mental illness, and specifically schizophrenia. The identified resources are hardiness (Anarudha, 2004; Bigbee, 1992; Greeff, Vansteenwegen \& Ide, 2006; Zauszniewski, Bekhet \& Suresky, 2010); activities and routines of the family (Abelenda \& Helfrich, 2003; Anuradha, 2004); community support (Anuradha, 2004; Doornmos, 1996; Enns, Reddon \& McDonald, 1999; Greeff et al., 2006; Marsh et al., 1996; Rammohan, Rao \& Subbakrishna., 2002b; Saunders, 1999; Spaniol, 1987); passive appraisal (Anuradha, 2004; Doornbos, 1996; Greeff et al., 2006); positive or affirming communication patterns (Anuradha, 2004; Enns et al., 1999); and support from family and friends during the crisis (Anuradha, 2004; Doornbos, 1996; Enns et al., 1999; Greeff et al., 2006; Marsh et al., 1996; Namyslowska, 1986; Spaniol, 1987).

\subsubsection{Family hardiness}

In this study, the concept of family hardiness is defined as a stress-resistant and adaptation resource that refers to the commitment of the family to work together, the internal strengths of the family as a unit, as well as the durability of the family (McCubbin, Thompson \& McCubbin, 1996). Furthermore, family hardiness includes the family's ability to challenge the belief that change is an inevitable part of life, being able to reframe a situation and having the ability to learn. Lastly, family hardiness includes the family's sense of an internal locus of 
control (McCubbin et al., 1996). Family hardiness has been found as a resource in families in which a member has been diagnosed with a mental illness (Anarudha, 2004; Doornbos, 1996; Greeff et al., 2006; Han et al., 2007).

According to Anuradha (2004) and Doornbos (1996), among the problem-solving and coping strategies that they found in families in which a member had been diagnosed with a mental illness was the family's ability to reframe their situation in a more positive way. In this way the families are better able to adapt to their crisis (Anuradha, 2004, Doornbos, 1996). Furthermore, Greeff et al. (2006) collected data in Belgium from 30 families in which a member had been diagnosed with a mental disorder. Most of these members were diagnosed with schizophrenia, psychosis, a mood disorder or an anxiety disorder. Of the potential resilience factors measured by Greeff et al. (2006), family hardiness had the strongest positive correlation with family adaptation, indicated by both the parents and the children who took part in the study. In essence, for families in which a member has been diagnosed with a mental illness, family hardiness is an important factor that helps the family to adjust and adapt after the diagnosis (Greeff et al., 2006). In addition, Han et al. (2007) studied 365 Korean families who were providing care for a mentally ill family member. They also found a significant correlation between family hardiness and family adaptation (Han et al., 2007).

Although hardiness has been identified as a resilience factor, the activities and routines of the family have also been shown to contribute to resilience in families living with a member with a mental illness.

\subsubsection{Activities and routines}

The different activities and routines used and maintained by a family (and the meaning they attach to them) include parent-child togetherness, couple togetherness, child routines, meals together, family time together, family chores routines, relatives' connection routines, and family management routines (McCubbin et al., 1996). Regarding the activities and routines of a family, the normal patterns of family functioning may not be adequate after a crisis and therefore may need to change (Abelenda \& Helfrich, 2003; Anuradha, 2004). Anuradha (2004) found that the participation of the family in activities and the togetherness of the family are very important in the family's ability to be resilient. Abelenda and Helfrich (2003) explain that the family may experience some disruption after a diagnosis has been made, and that this may initiate change within the family. The family may realise that their usual patterns are not adequate to adjust to their 'new life', and therefore they might have to make 
several changes (Abelenda \& Helfrich, 2003). Although activities and routines within a family can contribute to the resilience of the family, support from their community can also contribute to adaptation when living with a member diagnosed with schizophrenia.

\subsubsection{Support from community}

The degree to which a family seek support from their community can be seen as an important factor contributing to the resilience of families (Anuradha, 2004; Doornmos, 1996; Marsh et al., 1996; McCubbin et al., 1996; Spaniol, 1987). Community support can include acquiring knowledge (Anuradha, 2004; Spaniol, 1987), making use of professional assistance (Marsh et al., 1996) and support groups (Anarudha, 2004; Marsh et al., 1996; Spaniol, 1987), as well as spiritual support (Anuradha, 2004; Doornbos, 1996; Enns et al., 1999; Marsh et al., 1996; Rammohan et al., 2002b; Saunders, 1999).

According to Anuradha (2004), among the problem-solving and coping strategies that they found in families in which a member had been diagnosed with a mental illness was the family's use of community resources. Anuradha (2004) adds that these families may have several needs, including a need for knowledge about the illness, support, as well as advice regarding related issues.

Marsh et al. (1996) collected qualitative data from 131 members of families with a member with a psychiatric illness in the United States of America (USA) through the National Alliance for the Mentally Ill (NAMI). These members included parents, siblings, children and members of the extended family. The majority of the diagnosed individuals were diagnosed with schizophrenia (70.5\%), followed by schizoaffective disorders (18.1\%). According to Marsh et al. (1996), most of the families attributed their ability to change to their own personal abilities, their relatives, their own family, support from and membership of NAMI, professional assistance, and support from their community (relatives, neighbours, work colleagues and other resources such as religion). They concluded that professionals should work with the family, and also attend to the needs of each family member (Marsh et al., 1996). In accordance with the findings of Marsh et al. (1996), Spaniol (1987) also found that support from the community can help the family to adapt to such a crisis.

Spaniol (1987) argued that several strategies may help family members to adapt to having a member with a mental illness, such as being involved in support groups for family members, and also groups from which they can acquire knowledge. Doornbos (1996) studied 85 
families from a mid-western state in the USA and found that support from the community may contribute to the resilience of a family. This study used several scales, which included a measure of specific problem-solving and behaviour strategies used during a crisis (Family Crisis Oriented Personal Evaluation Scale [F-COPES]). The question Doornbos (1996) asked was "What are the characteristics of the families of the mentally ill relative to the variables of family stressors, family coping, and family health?" The study compared families with mentally ill members to those without (normative families). The results from the F-COPES indicated that the families in the sample relied more on specific problem-solving and behavioural strategies than the normative families. The sample families experienced significantly less cohesion than normative families, but had a significantly higher degree of adaptability. The study identified several strengths within families with a member with a mental illness. Among these were that the families used specific problem-solving and behavioural strategies. Specific coping strategies included seeking spiritual support and using community resources (these families also used these strategies more than the normative families). Doornbos (1996) argued that, although previous researchers had documented the use of some of these resources, their research showed increased use of these resources by families with a mentally ill member when compared with normative families. Overall, the adaptability of the sample families was greater than that of the normative families. In other words, the sampled families were more flexible and better able to change when faced with adversity. The ability to manage conflict was better in the sample families than in the normative families, and the study also found that lower conflict was present in the sample families than in the normative families. This research provides supportive evidence of the resilience and strengths in families who face adversity, such as a chronic mental illness (Doornbos, 1996).

In addition to these findings relating to community support, which includes acquiring knowledge, making use of professional assistance and support groups, spiritual support has also been indicated as a factor contributing to the resilience of families with a member with a mental illness. Several researchers have found that seeking spiritual support (Anuradha, 2004; Doornbos, 1996) and religion contribute to the adaptation process within families caring for a mentally ill member (Anuradha, 2004; Doornbos, 1996; Enns et al., 1999; Marsh et al., 1996; Rammohan et al., 2002b; Saunders, 1999). 
Enns et al. (1999) collected quantitative data from 210 families who have a member with a psychiatric illness. They administered four instruments, namely Family Inventory of Life Events (FILE), Family Inventory of Resources for Management (FIRM), Family Crisis Oriented Personal Evaluation Scales (F-COPES), and Family Assessment Measure III (FAM III). FILE was used to measure the pile-up of life stressors, explained by McCubbin and McCubbin's (1996a) model of family resilience. FIRM was used in an attempt to identify support from extended family, the financial stance of the family, and two types of strengths within the family. These two strengths included the health and mastery of the family, as well as communication and esteem. F-COPES measures problem-solving skills during crises, and FAM-III identifies communication patterns, affective expression, roles within the family, accomplishment of tasks, and control. Enns et al. (1999) found that families who have a member with a psychiatric illness were less likely (in comparison to the general population) to seek support from their extended family members. Results from F-COPES, which measures coping styles of a family, showed that significantly more women than men indicated that their families would seek spiritual support during times of crisis. In comparison to the general population, both males and females indicated that their families are significanlt less likely to seek spiritual support in times of crisis. Also, significantly more participants (in the sample) indicated that their families would depend on social support in comparison to the general population. These families were also more likely to make use of support from their immediate family, rather than their extended family, when compared to the general population. According to the general scale of FAM-III, more families in the study than families from the general population were concerned about affective expression, communication, and control. In accordance with these findings, Rammohan et al. (2002b) also found spirituality to help families adapt to having a member diagnosed with schizophrenia.

Rammohan et al. (2002b) assessed 60 family members (carers) and patients in India in relation to the possible contribution of religion as a coping strategy by those caring for a family member with schizophrenia. These members had to be from a Hindu religion, to have been living with the patient for more than one year, and to be involved in the caring of the diagnosed individual. Exclusion criteria were being ill themselves, and having received previous therapy or counselling where they could have obtained coping skills. Where there was more than one carer, the one closest to the diagnosed individual was included in the study. They found that religious beliefs, rather than religious practices, significantly 
contributed to the dealing with stresses related to caring for a family member with schizophrenia (Rammohan et al., 2002b).

In addition to the use of resources within the community as a resiliency factor for families living with a member diagnosed with a mental illness, the family's ability to accept their situation has also been indicated as a family resilience resource in several studies.

\subsubsection{Passive appraisal}

Passive appraisal has been identified as a specific behavioural strategy for families to adjust and adapt to living with a member with a mental illness (Anuradha, 2004; Doornbos, 1996; Greeff et al., 2006, McCubbin et al., 1996). McCubbin et al. (1996) discuss specific problemsolving and behavioural strategies used by families in a crisis, which include passive appraisal. Anuradha (2004) and Doornbos (1996) both found that families with a member with a mental illness used specific behavioural and problem-solving strategies compared to families where no mental illness is present. Specific coping strategies used by these families also included passive appraisal (Anaradha, 2004; Doornbos, 1996). Within Greeff et al.'s (2006) study of resilience in families in which a member had been diagnosed with a mental illness, the parents reported that coping by passively appraising a crisis contributed to the adaptation process.

In contrast to accepting the illness, other authors have found that, for some families, denial of the illness and distancing themselves from it has helped the family to adapt (Namyslowska, 1986; Spaniol, 1987). Namyslowska (1986) concluded that when a family are confronted with serious illnesses, such as cancer or schizophrenia, the family may rather use their defence mechanism of denial to better enable them to adapt to the situation. They based this comment on the finding that knowledge about the illness negatively correlated with the family's adaptation process. Spaniol (1987) argued that several strategies may help the family members, including distancing themselves.

Although a contradiction exists within the literature about accepting the illness and their situation (Namyslowska, 1986; Spaniol, 1987), more recent literature has revealed that passive appraisal is a resilience factor for families in which a member is diagnosed with a mental illness (Anuradha, 2004; Doornbos, 1996; Greeff et al., 2006, McCubbin et al., 1996). In addition to the family's ability to accept their situation, positive communication patterns 
have also been indicated to contribute to the ability of the family to adapt to living with a member diagnosed with schizophrenia.

\subsubsection{Positive communication patterns}

Positive communication patterns within the family can be an important contributor to resilience within the family (McCubbin et al., 1996; Anuradha, 2004; Enns et al., 1999). Enns et al. (1999) compared their participants with the general population and found that a bigger proportion of participating families than families from the general population were concerned with affective expression and communication.

Although studies support the findings that hardiness, activities and routines of the family, community support, passive appraisal, and positive or affirming communication patterns can contribute to the family's ability to adapt, support from family and friends during crises have also been identified as contributing to the adaptation of families.

\subsubsection{Support from family and friends}

Support from family and friends during a crisis seem to contribute to a family's coping style during times of crisis, and to their ability to adapt (Anuradha, 2004; Enns et al., 1999; Marsh et al., 1996; Namyslowska, 1986; Spaniol, 1987). According to both Anuradha (2004) and Doornbos (1996), one of the specific coping strategies of these families was the ability to seek social support. Anuradha (2004) explains that the family as a social support system is very important and an important resource to call upon in times of crisis.

Enns et al. (1999) reported in their study that families in which a member is diagnosed with a mental illness were less likely to seek support from the extended family in comparison to the general population, and more likely to depend on support from their immediate family. Enns et al. (1999) also found that significantly more participants depended on social support compared to the general population. Saunders (1999) found that families who care for individuals with schizophrenia make use of social support. Greeff et al. (2006) found a significant correlation in the children's data between their families' experience of social support and family adaptation. In accordance with these findings, Namyslowksa (1986) also found social support as a contributing factor to the family's ability to cope with stresses.

Namyslowska (1986) studied 152 Polish families in which a spouse had been diagnosed with schizophrenia and compared these families with 1832 urban Polish families. The aim of the study was to find out how these families coped with stresses related to having a spouse with a 
serious mental illness. Namyslowska (1986) found that the family structure and the family's ability to function as a unit were important when coping with stresses. Namyslowska (1986) argued that research focused mostly on the negative factors of the family and how the family contributed to mental illness, rather than on how the family needed to cope with stresses related to living with a family member with a serious mental illness, such as schizophrenia.

It can be concluded that the family as a support system are very important when faced with a crisis or crises (Anuradha, 2004; Enns et al., 1999; Marsh et al., 1996; Namyslowska, 1986; Spaniol et al., 1999). As indicated, several international studies have identified hardiness, activities and routines of the family, community support, passive appraisal, positive or affirming communication patterns, and support from family and friends as resources during crises. There also are some studies on family resilience that were done in South Africa.

\subsection{South African studies of family resilience}

In this section, the literature found in the South African context on families in which a member had been diagnosed with schizophrenia, families living with a member diagnosed with a mental disorder, and resilience in families facing different adversities is discussed.

\subsubsection{Families in which a member has been diagnosed with schizophrenia}

A South African study that is most relevant to the current study aimed to identify factors that helped families to adjust and adapt after a crisis, which in this case was the diagnosis of schizophrenia in one of the family members (Haddad, 2008). Haddad (2008) included 18 families in a mixed-method study that aimed to identify factors that contribute to family adaptation after a member has been diagnosed with schizophrenia. Family representatives completed a biographical questionnaire; an open-ended qualitative question; as well as seven self-report questionnaires, namely the Family Attachment and Changeability Index 8 (FACI8), The Family Hardiness Index (FHI), Family Time and Routines Index (FTRI), the Social Support Index (SSI), the Family Crisis Oriented Personal Evaluation Scales (FCOPES), Family Problem Solving Communication (FPSC), and the Relative and Friend Support Index (RFS). It was found that spirituality and religion, understanding the illness, positive communication and family hardiness, social support, the family as a support system, and adherence to medication were the most important factors that helped families to cope. Haddad (2008) recommended that more families should be used in future studies. The current study used the same measures, with the same family adversity, namely the diagnosis of a family member with schizophrenia. However, more families participated in this study and the 
data from three different groups of family representatives (fathers, mothers, and siblings) were analysed and compared.

Another South African study evaluated the needs of families living with a member with schizophrenia (Sellmeyer, 2003). The aim of this qualitative study was to help mental healthcare professionals better attend to the needs of families in which a member had been diagnosed with schizophrenia. Open-ended and closed questions were asked to the 11 participants during interviews. All the participants were parents of a person diagnosed with schizophrenia, and the majority were mothers. The needs of these families were categorised into three themes, namely support, education, and practical assistance. Many families felt guilty about the illness, which caused the family to feel disempowered. Sellmeyer (2003) found that most of the families wanted to be informed about the illness, while others wanted more support from their community and understanding from health-care professionals, such as nurses and doctors. Many also wanted social support for their ill family member, as this illness causes isolation for the diagnosed member and it seemed difficult for the family to accept this social isolation as part of the disease. The families wanted consistent medication for their ill member, as well as knowledge about the illness. They also needed support and knowledge about the disorder immediately after the diagnosis was made. In the current study, both quantitative and qualitative data were collected and analysed to identify factors that help families to adapt after a member has been diagnosed with schizophrenia. In addition, the views of mothers, fathers and siblings are compared.

In addition to the South African literature on resilience in families in which a member has been diagnosed with schizophrenia, another study was found on family resilience in which a member has been diagnosed with a mental disorder.

\subsubsection{Families in which a member has been diagnosed with a mental disorder}

A third South African study focused on resilience in families in which a member had been diagnosed with a mental disorder (Jonker \& Greeff, 2009). Qualitative data were collected from the participants through an open-ended question and analysed using content analysis. Three broad categories were identified, namely internal factors (within the household), external resources (outside of the household) and characteristics related specifically to the diagnosed individual. According to the qualitative data, spirituality and religion, individual characteristics and social support were the most common factors that contributed to 
resilience. Quantitative data were collected using seven self-report questionnaires, namely The Family Hardiness Index (FHI), the Family Time and Routines Index (FTRI), the Social Support Index (SSI), the Family Crisis Oriented Personal Evaluation Scales (F-COPES), Family Problem Solving Communication (FPSC), and the Relative and Friend Support Index (RFS), to measure independent variables and the Family Attachment and Changeability Index 8 (FACI8) was used to measure the dependent variable. Spearman correlations and a bestsubset regression analysis were done on the quantitative data. The quantitative results revealed no significant correlation between spirituality and religion as a coping mechanism within the family. It was found that communication within the family as a unit contributed most to the adaptation process (Jonker \& Greeff, 2009). Significant positive correlations were found between the following independent variables and the dependent variable: the style of communication during the crisis (FPSC Total score), positive and supportive communication during the crisis (FPSC Affirming communication), family hardiness (FHI Total score), working together as a family (FHI Commitment), positive reframing and the family's ability to learn (FHI Challenge), the extent to which the family engaged in activities and routines (FTRI Total score), and routines to promote communication between the couple (FTRI Couple togetherness). Significant negative correlations were found between family adaptation (FACI8) and the following independent variables: negative communication patterns during the crisis (FPSC Incendiary communication), and passive acceptance of problematic issues (F-COPES Passive appraisal).

In addition to studies regarding resilience in families living with a member diagnosed with a mental disorder, and specifically schizophrenia, several studies have been conducted in the South African context, and specifically in the Western Cape, regarding the resilience of families facing other adversities.

\subsubsection{Resilience in families facing different adversities}

Several studies in South Africa, specifically in the Western Cape, have focused on resilience in families facing other adversities, such as poverty in single-parent families (Greeff \& Fillis, 2009), a remarriage in families (Greeff \& Du Toit, 2009), families who have experienced a heart-related trauma (Greeff \& Wentworth, 2009), families who have lost a home due to a shack fire (Greeff \& Lawrence, 2011), families in which a child has been diagnosed with autism (Greeff \& Van der Walt, 2010), and families of which the husband was diagnosed with prostate cancer (Greeff \& Thiel, 2012). The following resources were found to 
contribute to adaptation in the families: family hardiness (Greeff \& Du Toit, 2009; Greeff \& Lawrence, 2011; Greeff \& Thiel, 2012; Greeff \& Van der Walt, 2010; Greeff \& Wentworth, 2009; Greeff et al., 2006); passive appraisal (Greeff \& Van der Walt, 2010); seeking support from the community (Greeff \& Du Toit, 2009; Greeff \& Thiel, 2012; Greeff \& Wentworth, 2009;); passive appraisal (Greeff \& Van der Walt, 2010); affirming communication patterns within the family (Greeff \& Du Toit, 2009; Greeff \& Thiel, 2012; Greeff \& Van der Walt, 2010; Greeff \& Wentworth, 2009); and support from family and friends (Greeff \& Wentworth, 2009). These findings support the results of the international studies that were discussed earlier.

Several researchers in the South African context have found family hardiness to correlate significantly with family adaptation (Greeff \& Du Toit, 2009; Greeff \& Lawrence, 2011; Greeff \& Thiel, 2012; Greeff \& Van der Walt, 2010; Greeff \& Wentworth, 2009). Greeff and Thiel (2012) found that only the data from their female participants revealed significant positive correlations with famiy adaptation. These independent variables that positively correlted with famiy adaptation were as follows: commitment, challenge, and reframing of a situation.. Greeff and Lawrence (2011) found commitment, and both Greeff and Du Toit (2009) and Greeff and Lawrence (2011) found the ability to have a sense of control over outcomes in life, to contribute significantly to family adaptation. In addition, Greeff and Wentworth (2009) found the family's ability to redefine their crisis experience to be helpful in the adaptation process. In addition to hardiness, different activities and routines have also been identified as resilience factors in families facing adversities.

Different resources utilised by families and reported in studies included increased family time spent together (Greeff \& Du Toit, 2009); family activities and routines (Greeff \& Van der Walt, 2010; Greeff \& Wentworth, 2009); routines that promoted communication between the parents and their children; and routines that promoted responsibility in teens and children (Greeff \& Wentworth, 2009).

The degree to which a family sought support from their community has been reported to contribute to family adaptation (Greeff \& Du Toit, 2009; Greeff \& Thiel, 2012; Greeff \& Wentworth, 2009). Social support from the community and the family's integration into the community is believed to form an important part of family resilience (Greeff \& Du Toit, 2009; McCubbin et al., 1996). Greeff and Thiel (2012) found within their qualitative data that more men than women attributed their family's ability to adapt to the diagnosis of prostate 
cancer to professional support and knowledge. Greeff and Du Toit (2009) and Greeff and Thiel (2012) found in their qualitative data that spirituality and religion contributed to resilience in times of crisis.

In addition to the support from the community as a contributing factor to adaptation to a crisis, passive appraisal as a problem-solving and behavioural strategy used by families in a crisis has been found to correlate positively with family adaptation (Greeff \& Van der Walt, 2010).

The two dominant communication patterns used by families in crisis are either positive (supportive) or negative (incendiary) communication (McCubbin et al., 1996). Positive or affirming communication (Greeff \& Du Toit, 2009; Greeff \& Thiel, 2012; Greeff \& Van der Walt, 2010; Greeff \& Wentworth, 2009; Haddad, 2008), which conveys care and support, as well as open communication (Greeff \& Van der Walt, 2010) in the family, has been identified to correlate positively with the family's ability to adapt. Conversely, incendiary communication has been found to be negatively correlated with the family's ability to adapt to crises (Greeff \& Lawrence, 2011; Greeff \& Van der Walt, 2010; Greeff \& Wentworth, 2009). Incendiary communication is a pattern of negative communication that increases stress during a stressful event (McCubbin et al., 1996). In addition, support from family and friends have also been identified as a resilience factor in families facing a crisis (Greeff \& Wentworth, 2009).

In summary, the following resources have been identified in South African as well as international studies to contribute to the resilience of a family in which a member has been diagnosed with schizophrenia or a mental disorder: family hardiness (Anarudha, 2004; Greeff, et al., 2006; Haddad, 2008; Han et al., 2007); activities and routines of the family (Abelenda \& Helfrich, 2003; Anuradha, 2004; Haddad, 2008); community support (Anuradha, 2004; Doornbos, 1996; Enns et al., 1999; Greeff et al., 2006; Haddad, 2008; Jonker \& Greeff, 2009; Marsh et al., 1996; Rammohan et al., 2002b; Saunders, 1999; Sellmeyer, 2003; Spaniol, 1987); passive appraisal (Anuradha, 2004; Doornbos, 1996; Greeff et al., 2006); positive or affirming communication patterns (Anuradha, 2004; Enns et al., 1999); and support from family and friends during crises (Anuradha, 2004; Doornbos, 1996; Enns et al., 1999; Greeff et al., 2006; Haddad, 2008; Jonker \& Greeff, 2009; Marsh et al., 1996; Namyslowska, 1986; Spaniol, 1987). South African studies of resilience in families facing other adversities confirm these findings. 


\subsection{Conclusion}

It is evident that several factors may contribute to a family's ability to adjust and adapt to a crisis. These resources help the family to restore a balance in their life after they have been faced with adversity. McCubbin and McCubbin (1996a), as well as Walsh (2003b), identified several resilience resources that were confirmed in different ways by the studies that were reported in this chapter. These resources help families to adapt and therefore can be considered as contributing to the resilience of these families.

The scales that will be used in this study measure family hardiness, different activities and routines used and maintained by a family, seeking support from the community, specific problem-solving and behavioural strategies, which include passive appraisal, communication patterns within the family, and support from family and friends during a crisis. Family adaptation is the dependent variable in this study. In Chapter 4 the methodology for this study is discussed, including a discussion of all the measures implemented to identify resources and characteristics that may be associated with family adaptation. 


\section{CHAPTER 4}

\section{METHOD}

\subsection{Introduction}

Qualitative and quantitative data were collected and analysed in order to answer the following research question: "What resources do families use to adjust and adapt after a family member has been diagnosed with schizophrenia?” In this chapter, the research design will be discussed, followed by a description of the participants. Furthermore, an explanation of the qualitative and quantitative measures used in this study will be given, followed by the procedures of data collection, the methods used for data analyses, and ethical considerations.

\subsection{Research design}

This study utilised a cross-sectional mixed-method research design. In other words, both qualitative and quantitative data were collected only once from the participants. Qualitative data were collected by means of an open-ended question, which asked the participant to write in his/her own words what helped the family as a unit to adapt after the family member was diagnosed with schizophrenia. Quantitative data were collected using seven self-report questionnaires. According to Becvar and Becvar (2003), a single description of a family may not necessarily give an accurate representation of a family. To obtain a more comprehensive and rich description of the functioning and inner workings of the family, this study aimed to include two members from each family: a sibling and a parent, or both parents.

\subsection{Participants}

The participants for the study were recruited from three support groups in the Western Cape. These groups aim to support family members or carers of someone diagnosed with schizophrenia. In other words, the diagnosed family member was not part of the support group. For each support group, I first made contact with the primary leader or chairperson of the group. After permission was obtained to continue with the research, the families were approached and informed about the research. This process will be explained in more detail in the 'procedures' section. 
For a family to take part in this study it had to meet the following criteria:

- A single, young adult (over the age of 18) in the family had been diagnosed with schizophrenia. This person should live with the family, or receive care from the family.

- This family member should have been diagnosed by a psychiatrist prior to this research project.

- The first possible participant, the parent, should also be the diagnosed family member's caregiver.

- The second possible participant could be a parent or a sibling. If it was a parent, this person should also be the diagnosed family member's caregiver. If the second possible participant was a sibling of the diagnosed family member, he/she should be over the age of 18 years.

- The participant should be fluent in either English or Afrikaans.

In total, I approached 102 possible participants from all three support groups. Of the 102 group members, 75 indicated that they would be interested in participating in the project, while the other 27 did not want to participate. Of the 75 interested group members, 24 were excluded from the project due to the following reasons: four incomplete questionnaire sets were received back from participants, seven did not meet the inclusion criteria, and thirteen participants did not send their documents back to me. Therefore, of the 75 members who initially indicated that they were interested in participating in the project, 51 were included as participants in the study. The 51 participants represented 42 families. Nine families were represented by two family members and 33 families were represented by only one family member.

A total of 51 data sets were included in the present study. The majority of the parents $(n=39)$ who completed the questionnaires were female $(n=27)$. Of the siblings $(n=12)$ who completed the questionnaires, only one was male (i.e. a brother). Of the final group of participants $(\mathrm{N}=51), 37 \%(\mathrm{n}=19)$ were English speaking and $63 \%(\mathrm{n}=32)$ were Afrikaans speaking. With regard to gender, $75 \%(n=38)$ were female and $25 \%(n=13)$ were male, with a mean age of 55 years and a range of 21 to 84 years. With regard to race, the majority of participants were coloured $(55 \%, n=28)$, while $37 \%(n=19)$ were white and $8 \%(n=4)$ were black. The majority $(82 \%, \mathrm{n}=42)$ of the participants were of the Christian faith, while the rest were either Jewish $(6 \%, n=3)$, Muslim $(2 \%, n=1)$, or another religion $(2 \%, n=1)$, 
and $8 \%(n=4)$ had no religious affiliation. With regard to education, 18 participants had attained an education level of more or equal to 12 years (i.e. 12 = grade 12), 12 participants had an educational level of less than 12 years, and 21 participants' educational level was unknown.

Of the 42 families represented, 18 (43\%) described themselves as nuclear families, 14 (33\%) as extended, and $10(24 \%)$ were single-mother families. The majority of the families $(33 \%$, $\mathrm{n}=14$ ) earned a low income (i.e. less than R40 000 per year), while nine families $(21 \%)$ earned between R40 000 and R90 000 per year, seven families (17\%) earned between R90 000 and R150 000 per year, and 29\% $(n=12)$ of the families' income was more than R150 000 per year. In other words, $55 \%(n=23)$ of the households had an income of less than R90 000 per year, and 45\% $(n=19)$ earned an annual income of more than R90 000 . The mean age of the diagnosed family member was 31.8 years, with a range of 19 to 59 years. Most $(78.6 \%, n=33)$ were male, and $21.4 \%(n=9)$ were female.

The nine families from which two members independently completed the quantitative questionnaires were represented as follows: six families were represented by both parents, two families were represented by a mother and a sister, and one family was represented by two sisters of the diagnosed family member.

\subsection{Measures}

Quantitative data were collected using seven self-report questionnaires, which collectively give an indication of possible family resilience qualities within the family. Biographical information was collected using a self-report questionnaire (completed by one representative of the family), which collected information about the family with regard to structure of the household, age, gender, race, religion, language, annual income, education and information regarding the diagnosed family member (when the person was diagnosed, age and gender). Qualitative data were obtained through an open-ended question, included at the back of the biographical questionnaire, in which the participant was asked to indicate the strengths and the resources used by the family as a unit to adapt after the member had been diagnosed with schizophrenia (see Appendix B for the biographical questionnaire and the open-ended question). 
The quantitative data were collected independently from each participant. The following seven questionnaires were used: Family Attachment and Changeability Index 8 (FACI8), Family Hardiness Index (FHI), Family Time and Routines Index (FTRI), Social Support Index (SSI), Family Crisis Oriented Personal Evaluation Scales (F-COPES), Family Problem Solving Communication (FPSC), and the Relative and Friend Support Index (RFS). All questionnaires were available in both English and Afrikaans.

The Family Attachment and Changeability Index 8 (FACI8) (McCubbin, Thompson \& Elver, 1996) was developed to measure family adaptation, and was later adapted (McCubbin et al., 1996). This scale was used as a measure of family adaptation, which served as the dependent variable in this study. The FACI8 consists of 16 items and uses a six-point Likert-type scale that involves answers ranging from never to always. The FACI8 is divided into two subscales, namely attachment and changeability. The attachment subscale measures the strength of the bond between family members, whereas the changeability subscale measures the flexibility of the family members' relationships with each other. The internal reliability (Cronbach's alpha) of the attachment subscale is .73 , and the internal reliability of the changeability subscale is .80 (McCubbin et al., 1996). In the present study, the internal reliability (Cronbach's alpha) of the attachment subscale was .61 and the internal reliability of the changeability subscale was .77. The total score of the FACI8 was used as a measure of family adaptation.

The following scales were used to measure possible resilience factors within the family. All these variables served as independent variables in this study.

The Family Hardiness Index (FHI) (McCubbin, McCubbin \& Thompson, 1996b) was developed to measure hardiness as a stress-resistant and adaptation resource within the family (McCubbin et al., 1996). The concept of family hardiness refers to the internal strengths of the family as a unit, as well as the durability of the family unit (McCubbin \& McCubbin, 1996b). The scale consists of three subscales, namely commitment, challenge and control. Commitment refers to the family's interest in life, and the subscale aims to measure the family's ability to work together as a unit and their sense of internal strengths. Challenge involves the belief that change is an inevitably part of life and that it may present an opportunity for stimulation and growth, rather than a threat to security. This subscale measures the family's ability to be active, to learn and to be open to experience new things. 
The control subscale aims to measure the family's sense of being controlled externally or internally; in other words, whether they believe they have an internal sense of control over situations. The FHI consists of 20 items and requires the participant to respond to questions on a five-point Likert-type scale. For each item, the respondent has to rate the extent to which it applies to his/her family situation, with $0=$ not applicable, $1=$ false, $2=$ mostly false, $3=$ mostly true and $4=$ true. The overall internal reliability (Cronbach's alpha) of the FHI is .82 and the validity coefficients range from .20 to .23 , with criterion indices of family flexibility, satisfaction, and time and routines (McCubbin et al., 1996). In the present study, the reliability coefficients for the three subscales were: commitment $=.59$, challenge $=.37$, and control $=.71$.

The Family Time and Routines Index (FTRI) (McCubbin, McCubbin \& Thompson, 1996a) was developed to assess the different activities and routines used and maintained by families, as well as the value that they attach to them (McCubbin et al., 1996). The FTRI was designed to measure the family's routines in all stages of the family life cycle. These routines contribute to stability and continuity within the family. Depending on the family's life stage, their emphasis on certain routines can be different. Therefore, emphasis on routines can change over time as the family enters different stages in their family life cycle. The scale consists of 30 items with eight subscales, namely parent-child togetherness; couple togetherness; child routines; meals together; family time together; family chores routines; relatives connection routines; and family management routines. The parent-child togetherness subscale measures time spent together and communication between parents and children and adolescents. The couple togetherness subscale measures routines within the family that promote communication between the couple. The child routines subscale measures the importance that fixed routines for children that promote autonomy in the children has for a family. Family togetherness refers to routines that increase time spent together by the family, including special events. The family chores routines subscale includes items that measure the routines established in the family that promote responsibilities for the children and adolescents in the household. Meals together refer to the family's routines to promote togetherness through having fixed times for meals, whereas the relatives connection subscale refers to fixed routines with relatives. The family management subscale measures the family's emphasis on having predictable and fixed routines within the family that promote order within the household. The participant is required to choose an answer at each item that relates most to the experience of his/her family. The options to choose from in this four-point 
Likert-type scale are false, mostly false, mostly true, and true. The overall internal reliability (Cronbach's alpha) of the FTRI is .88, and the validity coefficients range from .19 to .34 with criterion indices of family functioning (McCubbin et al., 1996). In the present study, the FTRI showed an internal reliability of .88 for family (total score), and .95 for the importance of routines to the family (total score).

The Social Support Index (SSI) (McCubbin, Patterson \& Glynn, 1996) was developed to measure the degree to which a family seeks support from the community (McCubbin et al., 1996). Social support from the community is believed to form an important part of family resilience. The aim of the SSI is to gain an indication of whether the family views the community as supportive and also to assess their sense of connectedness with their community. The SSI consists of 17 items and uses a four-point Likert-type scale. The participant must choose from answers that range from strongly disagree to strongly agree. The overall internal reliability (Cronbach's alpha) of this scale is .82 , and it has a validity coefficient of .99 (McCubbin et al., 1996). In the present study, the SSI showed an internal reliability (Cronbach's alpha) of .73 for the full scale.

The Family Crisis Oriented Personal Evaluation Scales (F-COPES) (McCubbin, Olson \& Larsen, 1996) was developed to identify problem-solving and behavioural strategies used by families in a crisis (McCubbin et al., 1996). The F-COPES consists of 30 items that require the participant to respond to questions on a five-point Likert-type scale. The answers range from strongly disagree to strongly agree. These items focus on two levels of interaction, namely interaction between an individual and his/her family system, and interaction between the family and their social environment. The scale involves the following five subscales: acquiring social support; seeking spiritual support; reframing; mobilising social support; and passive appraisal. Acquiring social support involves seeking support from family, friends and neighbours, which is different to seeking spiritual support. The internal reliability (Cronbach's alpha) of this subscale is .83 (McCubbin et al., 1996). In the present study, the internal reliability was found to be .86 . Seeking spiritual support refers to the family's ability to acquire support from religious resources. In the original version of this subscale, an internal reliability (Cronbach's alpha) of .80 was established (McCubbin et al., 1996). In this study, an internal reliability of .89 was found. Reframing involves the ability of the family to redefine a crisis in order to make the stressful event more manageable. This subscale has an internal reliability (Cronbach's alpha) of .82 in the original version (McCubbin et al., 1996), 
and an internal reliability of .70 was established in this study. Mobilising social support involves the family's ability to seek and accept support from their community. The internal reliability of this subscale is .71 (McCubbin et al., 1996). In this study, this subscale showed an internal reliability of .66. Passive appraisal refers to the family's ability to accept problematic issues, thereby decreasing re-activity. The internal reliability (Cronbach's alpha) of this subscale is .63 (McCubbin et al., 1996). In the present study, the internal reliability was .57. The subscale scores were used in this study, instead of the total F-COPES score, because they give an indication of the different and more specific behaviours used by the family to cope with a crisis. These specific coping behaviours were correlated with the dependent variable, family adaptation (measured with FACI8).

Family Problem Solving Communication (FPSC) (McCubbin, McCubbin \& Thompson, 1996c) was developed to evaluate two dominant patterns (positive and negative) of family communication (McCubbin et al., 1996). These patterns are believed to play an important role in family coping strategies. The FPSC consists of 10 items and uses a four-point Likerttype scale (ranging from true to false) from which the participant much choose an answer he/she feels most accurately describes the family's behaviour during conflict. The scale is divided into two five-item subscales, namely incendiary communication and affirming communication. Incendiary communication is a pattern of negative communication that increases stress during a stressful event, whereas affirming communication creates a more calming environment through supportive and caring behaviour. Both these types of communication refer to how the family react in times of crisis. The aim of this scale is to establish whether the family use positive communication (affirming) towards each other, e.g. supporting and showing respect, or whether they use more negative communication (incendiary) patterns, e.g. blaming or criticising, during stressful situations. The overall internal reliability of this scale is .89 . Incendiary communication has an internal reliability of .78, whereas affirming communication has an internal reliability of .86 (McCubbin et al., 1996). In the present study, the internal reliability (Cronbach's alpha) of the affirming communication was .68 , and that of the incendiary communication subscale was .48. The FPSC total score reliability (Cronbach's alpha) was .65.

The Relative and Friend Support Index (RFS) was developed by McCubbin, Larsen and Olson (1996) to measure the degree to which families make use of support from family and friends during crisis situations (McCubbin et al., 1996). The RFS consists of eight items and 
uses a five-point Likert-type scale. The answers from which the participant must choose range from strongly disagree to strongly agree. The internal reliability (Cronbach's alpha) of the scale is .82 and it has a validity coefficient of .99 (McCubbin et al., 1996). In the present study, the internal reliability (Cronbach's alpha) for the RFS was found to be .83 .

\subsection{Procedure}

Ethical clearance for this study was obtained from the Research Ethics Committee: Human Research (Non-health) of Stellenbosch University (National Health Research Ethics Committee number: REC-050411-032, protocol number: HS856/2012). Permission was obtained from each chairperson or facilitator of the three support groups to attend their monthly meetings or to approach the group members. I attended one support group's monthly meetings three times, the second group's monthly meetings twice, and the third group's members were approached only once. The same procedure was followed for the first two groups. For the last group the information and procedures described below were given to the participants individually. During each visit I presented the research project to the group. After the group members had been informed about the project, they were able to willingly and voluntarily choose to become part of the research. They were given the opportunity to raise uncertainties and ask questions. The families were assured of anonymity and confidentiality. Informed consent was obtained from the participants (see Appendix C). I also made it clear to the group that the diagnosed family member would not take part in the study. The families who agreed to participate in the study were given the questionnaires to take home, or they could fill out the questionnaires in the presence of the researcher. Some participants chose to complete the questionnaires in the presence of the researcher and others chose to complete the questionnaires without the direct assistance of the researcher. The participants could contact me at any time, should they have questions. Those who took the questionnaires home received a self-addressed stamped envelope and were given the option to post the questionnaires back to me. The researcher made it clear to the participants that they should complete the questionnaires independently. One page with instructions to the participant was included in the envelope, with the aim of making the completion of the questionnaires easier for the participant (see Appendix D).

After completion of the questionnaire, the participants returned it to me via post, e-mail or fax, or brought it to the next support group meeting. The same procedures were followed 
during the second and third meetings. Incomplete questionnaires were excluded from the study.

There were minor differences in the procedures followed in the third group. The group's members were approached individually. I first gained permission from the chairperson to approach the group members individually, and she provided me with the group members' contact details. I presented the research to each member. After informing the group member of the research project, he/she was able to willingly and voluntarily choose to be part of the research. The members were given the opportunity to raise uncertainties and ask questions. The group members were assured of anonymity and confidentiality, and informed consent was obtained from each participant (see Appendix C). I also made it clear to each group member that the diagnosed family member would not take part in the study. All the members who agreed to participate agreed that I should read the questions to them and fill in their answers for them.

Where families were represented by two members, only one member had to complete the biographical questionnaire. In families which were represented by both a parent and a sibling, the parent completed the biographical questionnaire. Where two parents represented the family, the couple could choose who should complete the biographical questionnaire. After I received the questionnaires, the data were coded and analysed.

\subsection{Data analysis}

Several analyses were done with the quantitative data, namely a mixed model repeated measures analysis of variance $(\mathrm{N}=51)$, an analysis of variance (ANOVA), Pearson's product-moment correlations, and a best-subset regression analysis $(\mathrm{n}=42)$. The mixed model repeated measures ANOVA included all data sets $(\mathrm{N}=51)$. For the ANOVA, Pearson's product-moment correlations and best-subset regression analysis, only one data set per family was used for the calculations $(n=42)$. For the nine families who were represented by two family members, the following criteria were used to select the one data set: where both parents completed the questionnaires, the mothers' data sets were used; where the family were represented by a mother and a sibling, the mother's data set was also used. In the one family where two sisters represented the family, an average score was calculated and used in the analyses. Most of the participants were mothers, and therefore their data sets were used in preference to the fathers' or siblings', thereby contributing to a more homogenous group. 
The qualitative data analyses included all written answers to the qualitative question and were done through a process of thematic analysis. Of the 51 participants, five participants did not answer the qualitative question. Of these five, three were fathers from families represented by a mother and a father, and one was a sister from a family that was represented by a mother and a sister. Only one participant who was the only representative of a family did not complete the qualitative question. Therefore, 46 participants completed the qualitative question, representing 41 different families - qualitative responses were received from five families represented by two family members. In the following section the quantitative and qualitative data analysis techniques are discussed.

\subsubsection{Quantitative data analysis}

The quantitative data were analysed using the Statistica software program (Statsoft Incorporated, 2011) with the assistance of a senior statistician, Prof. Martin Kidd of the Centre for Statistical Consultation at Stellenbosch University.

First, a mixed model repeated measures ANOVA (variance estimation, precision and comparison) was used to compare the mothers, fathers and siblings with regard to scores obtained with the different scales to establish if any significant differences existed between these groups. For this analysis, all data sets were used $(\mathrm{N}=51)$. Secondly, an analysis of variance (ANOVA) was done for the different biographical variables and the other measured variables in terms of race, language, family structure and income $(n=42)$ to establish if any significant differences existed within these categories (race, language, family structure and income). Thirdly, Pearson's product-moment correlations were calculated between certain demographical variables (patient age, patient time since diagnosis, and income) $(n=42)$ and family adaptation (dependent variable), as well as between the dependent variable (family adaptation) and potential resilience variables (independent variables as measured with the FHI, FTRI, SSI, F-COPES, FPSC and RFS). Finally, a best-subset regression analysis was done to identify which combination of independent variables provided the best prediction of the dependent variable. To further justify the best subset, the 'best' 20 models were chosen and scrutinised to identify which independent variables were identified the most by this model. It was found that a combination of five independent variables best predicted the dependent variable. This will be reported in the 'results' chapter of this thesis. 


\subsubsection{Qualitative data analysis}

Resilience qualities were identified in the qualitative data through a process of thematic analysis (Braun \& Clarke, 2006). Thematic analysis is similar to the method used by grounded theorists (Strauss \& Corbin, 1990). A benefit of thematic analysis is its flexibility, which means that themes may be identified in several ways and still provide rich data (Braun \& Clarke, 2006). This approach allowed me to identify themes using my own judgement. A theme can be recognised when certain categories are identified repeatedly throughout the data. In other words, I examined the qualitative data to find information that continuously appeared in the data. This information that was repetitively seen within the data were categorised in terms of different themes. In order to recognise a theme, it is important to understand that a theme provides information that attempts to answer the research question (Braun \& Clarke, 2006). In this study, themes refer to identified resources described by the families that helped them to adapt after a family member had been diagnosed with schizophrenia.

An inductive approach was used to identify themes from the perspective of an essentialist/realist thematic analysis. An inductive approach allows the researcher to identify themes using her own judgement, and these categories do not have to fit into a pre-existing framework (Braun \& Clarke, 2006). An essentialist/realist perspective allows the researcher to assume a relationship between meaning, experience and language (Braun \& Clarke, 2006). Therefore, the meanings, motivations and experiences identified in the data can be theorised in a simplistic manner (Braun \& Clarke, 2006). In other words, the themes identified through the language used by the participants may reflect the meanings that the participants have attached to their experiences.

The data were analysed by applying the following six phases of thematic analysis to the data: (1) I first familiarised myself with the data, (2) then I generated initial codes for the data, (3) thereafter I searched for themes within the data, (4) followed by reviewing these themes, (5) then I defined and named the themes, (6) and lastly I produced these themes and results from the qualitative data (Braun \& Clarke, 2006).

\section{Phase 1: Familiarising myself with the data}

In some of the cases, I personally collected the data from the participants and therefore already had formed some ideas about the data. To familiarise myself with the content of the 
data, I repeatedly and actively read the written responses of the participants, searching for meanings and patterns within the data. During this phase, I already started to make notes that were used in the subsequent phases. When I had familiarised myself with the data, I moved on to the next phase, namely generating initial codes (Braun \& Clarke, 2006).

\section{Phase 2: Generate initial codes}

By this stage I had already generated some initial ideas about the results. This phase involves producing initial codes for the data that I have already identified as interesting and relevant to the research question. Coding involves organising or categorising the data into meaningful groups. I worked systematically through the entire data set and identified information relevant to the research question and interesting aspects of the data by writing notes next to and highlighting them. After codes had been identified in the entire data set, they were matched and I then searched for the repetition of these codes (Braun \& Clarke, 2006).

\section{Phase 3: Search for themes}

Phase three started after I had initially coded, examined and compared the data. During this stage I focused on organising the data on a broader level by categorising the codes that were connected, into different themes.During this phase, potential themes and subthemes were created (Braun \& Clarke, 2006).

\section{Phase 4: Review themes}

During this phase I refined the already categorised themes. I established whether the subthemes under a theme cohered meaningfully and whether there were clear and distinct differences between themes. During this phase, two levels of reviewing were followed. Level one involved reviewing the coded data extracts, which means that I read all the codes that had been examined and compared previously for each theme, and establish whether they were coherent. If the pattern between and within themes were coherent, I continued to the second level of the review process. During level two, the validity of themes in relation to the entire data set was considered.. The entire data set were re-read during this phase to establish whether the themes were coherent and accurately reflected the meanings that were present in the entire data set. The second reason for re-reading the entire data set were to consider whether any new codes emerged within themes that may have been overlooked during the initial stage of coding. At the end of this phase, I had a clear idea of the different themes, how they connected with each other and how they represented and were coherent with the overall data. Because I accepted the themes, the next phase was entered, namely defining and naming the themes (Braun \& Clarke, 2006). 


\section{Phase 5: Define and name themes}

During this phase I defined and further refined the themes. The themes were also further analysed by me. In other words, I was able to clearly identify and accurately describe the themes. It was clear to me what were themes and what were subthemes, and why certain subthemes went together and others did not. At the end of this phase I was able to clearly describe what a theme entailed, and I could clearly distinguish between themes (Braun \& Clarke, 2006).

\section{Phase 6: Produce and write up the results}

When I had worked out all the themes, phase 6 was entered. This phase involved the final analysis and write-up of the results. During this phase the whole story of the data were described and discussed. The validity of the data was made clear and the reader should be convinced about its validity. It is important that, by the end of this phase, all the analysis were clear, logical, and made sense within and across the data. I hope it is clear why I discuss the themes and how these themes contribute to answering the research question (Braun \& Clarke, 2006).

\subsubsection{Trustworthiness of qualitative data}

Several authors describe the validity (Creswell \& Miller, 2000; Johnson, 1997; Maxwell, 1992; Morse, Barrett, Mayan, Olson \& Spiers, 2002) and trustworthiness (Guba \& Lincoln, 1985; Shento, 2004) of qualitative data. The validity of research refers to the accuracy of the data and the reported results (Creswell \& Miller, 2000). Guba and Lincoln (1985) suggest that the validity of data can be evaluated by the following criteria: its credibility, transferability, dependability and confirmability. These criteria are described by Guba and Lincoln (1985) as the trustworthiness of data in their model of trustworthiness.

Credibility refers to evaluating the data in order to establish if it is a true representation of the sample's answers (Guba \& Lincoln, 1985). I tried my best to report the data as accurately as possible and through this express the 'voices' of the participants in the themes derived from the qualitative data. The transferability of the data refers to whether the data can be generalised and are applicable to other areas of interest and contexts (Guba \& Lincoln, 1985). I initially tried to recruit a large number of people in the hope that the results could be generalised and transferred to other groups. Although the three support groups were from different regions in the Western Cape and displayed different demographical details, the total 
group was not really representative and therefore the findings cannot be generalised to the wider population. This is also recognised as a limitation of this study. Dependability of the data refer to the consistency thereof and whether the study can be duplicated (Guba \& Lincoln, 1985). To ensure the dependability of the study and duplication thereof, I provided a detailed description of the research design, the measures used, the procedures followed for data collection, as well as the methods used for the data analyses. Confirmability refers to the researcher's awareness of research bias, and that the researcher should make sure that the results are a true representation of the realities of the participants (Guba \& Lincoln, 1985). Johnson (1997) also recognised research bias as a threat to validity. In order to reduce research bias, Johnson (1997) suggests the researcher should become more self-aware through a process of self-reflexivity and also by reporting data that disconfirm the researcher's initial expectations. Through self-reflexivity I was aware of my own values and initial ideas about the research that could have influenced the process of data analysis. By being aware of myself, I was able to decrease bias. I also comprehensively reported all significant data, both data that confirmed my expectations and data that did not.

Johnson (1997) distinguished between three types of validity, namely descriptive validity, interpretive validity and theoretical validity. Descriptive validity refers to the accuracy of the reported data as representatives of the true story told by the participants. Johnson (1997) explains that the researcher can achieve interpretive validity when she accurately reports the stories of the participants and also understands the data gathered from the participants. Descriptive and interpretive validity can be compared with Guba and Lincoln's (1985) concepts of credible and confirmable validity. An additional validity, not discussed by Guba and Lincoln (1985) in their model of trustworthiness, is Johnson's (1997) concept of theoretical validity. Theoretical validity refers to the theoretical basis that offers an explanation of the data. Therefore the data gathered should be confirmed and supported by theory (Johnson, 1997). As far as was possible I provided literature to support or contradict the findings of the study. The two theories used to conceptualise this study, and which were described in Chapter Two, are the Resiliency Model of Family Stress, Adjustment and Adaptation (McCubbin \& McCubbin, 1996a), and the Family Resilience Framework of Walsh (2012).

After analysing the quantitative and qualitative data, comparisons between the data were made. The goal of this process was to establish whether the quantitative and qualitative data 
complemented each other and whether the qualitative data gave more information about the families' adaptation processes. It was hoped that the qualitative data would provide rich descriptions of the lived experiences of these families and that it would reflect and support the quantitative data. These findings will be discussed in the 'results' chapter of this thesis.

In addition to discussing the research design, details of participants, measures used, procedures followed and methods of data analyses, several ethical procedures were followed in order to conduct the research.

\subsection{Ethical considerations}

Ethical clearance was obtained from the Research Ethics Committee: Human Research (Nonhealth) of Stellenbosch University. After ethical clearance was obtained, I attended monthly support group meetings of three different support groups in the Western Cape for families with a member who had been diagnosed with schizophrenia, with the permission of the chairperson or facilitator of each group. To protect the anonymity of these groups and their members, the names of the groups are not mentioned in this thesis. The number of meetings I attended depended on how many participants were recruited at the first meeting. All members of each group were not present each month, therefore new or other members were present at following meetings. In other words, other members could be approached during the subsequent meetings. During such a meeting, the members were informed about the research project. They then had the opportunity to willingly and voluntarily agree to participate in the research project. Once members chose to participate, they were not obliged to continue or complete any questionnaire if they were not able to, or did not want to do so. In other words, although they initially may have agreed to participate, they could refuse to proceed. Every participant was informed about the confidentiality and anonymity of any information obtained from them. The completed questionnaires were stored in a safe place in the supervisor's office in the Department of Psychology at Stellenbosch University for the duration of the study, and will be stored for the duration of five years after the completion of the study. These documents were only available to me and my supervisor.

To ensure confidentiality and anonymity, a code was assigned to each data set after a telephone number had been collected from some of the participants. This was to ensure that 
all the questionnaires were received after completion and also to keep track of all the data sets. Only I knew which contact information corresponded with which code.

There were no physical risks involved in the research process, but I was aware that some of the items in the questionnaires may have caused some emotional discomfort. The participants were informed about the availability of professional assistance should they experience any discomfort. No discomfort was reported by any of the participants. Giving the participants the opportunity to identify resources and strengths within their family may help them to adapt to having a member diagnosed with schizophrenia. Through the research process, the participants were encouraged to think about positive aspects of their family that may have given them a sense of control over their lives and therefore could have helped them to feel empowered. This process may also have been therapeutic for the participants, because they may have recognised strengths within their family that could help prepare them for future crises. In fact, some participants reported to me after completing their questionnaires that, during the process of participating in the research, they had thought differently about their family. They reported that they had recognised strengths within their family and felt relieved to have had the opportunity to express their needs and their roles within their family. All ethical considerations were discussed with the participants during the process of obtaining informed consent (see Appendix C).

\subsection{Conclusion}

The aim of this study was to identify resilience factors in families in which a member has been diagnosed with schizophrenia. Both qualitative and quantitative data were collected and analysed in order to answer the following research question: "What resources do families use to adjust and adapt after a family member has been diagnosed with schizophrenia?" In this chapter, both the qualitative measure used, and the quantitative measures, were explained. Qualitative data were collected using an open-ended question, while quantitative data were collected using seven self-report questionnaires. The analysis techniques, procedures followed, participant information and ethical consideration have also been discussed in this chapter. The results of the data analyses are reported in the next chapter (Chapter 5: Results). 


\section{CHAPTER 5}

\section{RESULTS}

\subsection{Introduction}

In this chapter, the quantitative results are reported, followed by the qualitative results. First, a mixed model repeated measures analyses of variance (variance estimation, precision and comparison) was used to compare the mothers, fathers and siblings with regard to scores obtained on the different scales to establish whether significant differences existed between these groups. For this analysis, all data sets were used $(\mathrm{N}=51)$. Secondly, analyses of variance (ANOVA) were done for the different biographical variables and the other measurements in terms of race, language, family structure and income $(n=42)$. Thirdly, Pearson's product-moment correlations were calculated between certain biographical variables (patient age, patient time since diagnosis, and income) $(\mathrm{n}=42)$ and family adaptation (dependent variable), as well as between the dependent variable (family adaptation) and potential resilience variables (independent variables as measured with the FHI, FTRI, SSI, F-COPES, FPSC and RFS). These results are reported in this chapter, followed by a discussion of the outcome of a best-subset multiple regression analysis, which was done to identify which combination of independent variables provides the best prediction of the dependent variable.

Lastly, the results obtained from the qualitative data analyses are reported and compared with the results of the quantitative analyses. The qualitative data analyses included all written responses $(n=46)$ to the open-ended question.

\subsection{Quantitative data analyses}

Several analyses were done, namely a mixed model repeated measures analysis of variance $(\mathrm{N}=51)$, an analysis of variance (ANOVA), Pearson's product-moment correlations, and a best-subset regression analysis $(n=42)$. For the ANOVA, Pearson's product-moment correlations and best-subset regression analysis, only one family representative's data set was used for the calculations. For the nine families who were represented by two family members, the following criteria were used to select only one data set: where both parents completed the questionnaires, the mother's data set was used; where the family was represented by a mother and a sibling, the mother's data set was also used; and in the one family represented by two 
sisters, an average score was calculated and used in the analyses. The results of the mixed model repeated measures ANOVA are reported first.

\subsubsection{Mixed model repeated measures analysis of variance}

A mixed model repeated measures ANOVA (variance estimation, precision and comparison results) was done to compare the responses of the mothers $(n=27)$, fathers $(n=12)$ and siblings $(n=12)$ for possible significant differences between groups. If a significant difference was found between groups, the Fisher's least significant difference (LSD) post-hoc test was done to further evaluate this significant result. All results are shown in Table 5.2.1. Following Table 5.2.1, the results of the post-hoc testing (LSD) are reported briefly.

Table 5.2.1

Results of the mixed model repeated measures ANOVA $(N=51)$

\begin{tabular}{|c|c|c|}
\hline \multirow[b]{2}{*}{ Variable } & \multicolumn{2}{|c|}{$\begin{array}{c}\text { Relationship with } \\
\text { diagnosed individual } \\
\text { (mother, father or sibling) }\end{array}$} \\
\hline & F-values & p-values \\
\hline $\begin{array}{l}\text { Problem solving and behaviour during crisis (Family Crisis Oriented } \\
\text { Personal Evaluation Scale [F-COPES] total score) }\end{array}$ & 1.44 & 0.30 \\
\hline Actively seeking social support (F-COPES Social support) & 1.74 & 0.24 \\
\hline Redefining crisis in a more positive way (F-COPES Reframing) & 1.68 & 0.25 \\
\hline Seeking spiritual support (F-COPES Spiritual support) & 0.69 & 0.53 \\
\hline $\begin{array}{l}\text { Seeking out community resources and accepting help from the } \\
\text { community (F-COPES Family mobilisation) }\end{array}$ & 4.34 & $0.06^{* *}$ \\
\hline $\begin{array}{l}\text { Passive acceptance of problematic issues to minimise re-activity } \\
\text { (F-COPES Passive appraisal) }\end{array}$ & 2.57 & 0.15 \\
\hline $\begin{array}{l}\text { Degree to which the family finds support in their community (Social } \\
\text { Support Index [SSI] total score) }\end{array}$ & 0.25 & 0.79 \\
\hline $\begin{array}{l}\text { Extent to which the family engages in activities and routines } \\
\text { (Family Time and Routines Index [FTRI]: Family, total score) }\end{array}$ & 2.23 & 0.19 \\
\hline $\begin{array}{l}\text { The importance and value the family attach to family time and } \\
\text { routines (FTRI Importance, total score) }\end{array}$ & 0.40 & 0.96 \\
\hline $\begin{array}{l}\text { Routines to promote autonomy and order in children and teens (FTRI } \\
\text { Childhood routines) }\end{array}$ & 1.3 & 0.37 \\
\hline $\begin{array}{l}\text { Routines to promote communication between couples (FTRI Couple } \\
\text { togetherness) }\end{array}$ & 5.9 & $0.03 *$ \\
\hline & (Table & \\
\hline
\end{tabular}




\begin{tabular}{|c|c|c|}
\hline \multirow[b]{2}{*}{ Variable } & \multicolumn{2}{|c|}{$\begin{array}{c}\text { Relationship with } \\
\text { diagnosed individual } \\
\text { (mother, father or sibling) }\end{array}$} \\
\hline & F-values & p-values \\
\hline $\begin{array}{l}\text { Routines to promote togetherness through family mealtimes (FTRI } \\
\text { Meals together) }\end{array}$ & 5.18 & $0.05 *$ \\
\hline $\begin{array}{l}\text { Routines to promote communication between parents and children } \\
\quad \text { (FTRI Parent-child togetherness) }\end{array}$ & 8.31 & $0.03 *$ \\
\hline Special events and family time (FTRI Family togetherness) & 3.6 & 0.08 \\
\hline $\begin{array}{l}\text { Routines to promote meaningful connection with relatives (FTRI } \\
\text { Relatives connectedness) }\end{array}$ & 0.23 & 0.80 \\
\hline $\begin{array}{l}\text { Routines to promote teen and child responsibilities in the home } \\
\quad \text { (FTRI Family chores) }\end{array}$ & 1.72 & 0.26 \\
\hline Routines to maintain order in the home (FTRI Family management) & 5.10 & $0.06^{* *}$ \\
\hline $\begin{array}{l}\text { Family's use of friends and relatives as a coping mechanism during } \\
\text { crisis (Relative and Friend Support Index [RFS]) }\end{array}$ & 1.94 & 0.21 \\
\hline $\begin{array}{l}\text { Style of family communication during crisis (Family Problem } \\
\text { Solving Communication Index [FPSC] Total score) }\end{array}$ & 0.35 & 0.71 \\
\hline Positive, supportive communication during crisis (FPSC Affirming) & 0.61 & 0.57 \\
\hline $\begin{array}{l}\text { Negative, inflammatory communication patterns during crisis (FPSC } \\
\text { Incendiary) }\end{array}$ & 0.12 & 0.89 \\
\hline $\begin{array}{l}\text { Family hardiness: the internal strengths and durability of the } \\
\text { family (Family Hardiness Index (FHI) Total score) }\end{array}$ & 0.84 & 0.48 \\
\hline Ability to work together and internal strengths (FHI Commitment) & 0.16 & 0.85 \\
\hline Positive reframing, ability to learn (FHI Challenge) & 0.75 & 0.51 \\
\hline Internal locus of control (FHI Control) & 0.68 & 0.54 \\
\hline Family Adaptation (FACI8 Total score) & 0.11 & 0.90 \\
\hline Strength of the bond between family members (FACI8 Attachment) & 0.17 & 0.85 \\
\hline $\begin{array}{l}\text { Flexibility of the family members' relationships with each other } \\
\text { (FACI8 Changeability) }\end{array}$ & 0.07 & 0.93 \\
\hline
\end{tabular}

$* p<0.05 * * p<0.10$

Significant differences were found between groups - based on who represented the family (mother, father or sibling) - for scores obtained with the F-COPES subscale: family 
mobilisation $(p<0.10)$, and for four of the Family Time and Routines Index (FTRI) subscales, namely couple togetherness $(p<0.10)$, meals together, parent-child togetherness, and family management. LSD post-hoc testing was done to determine between which groups these significant differences were. For Family coping: Mobilising social support (see Table 5.2.1), the post-hoc testing revealed that a significant difference was present between the responses of the mothers and the siblings $(\mathrm{p}=0.02, \mathrm{p}<0.05)$, with the mothers having significant higher scores on this scale than the siblings (see Appendix E, Figure 5a).

With regard to the Family time and routine measures, the post-hoc LSD testing revealed a significant difference between the responses of the fathers and the siblings $(p=0.01)$, with the fathers having higher scores on the couple togetherness subscale than the siblings (see Appendix E, Figure 5b.1). A significant difference was established between the scores of the mothers and the siblings $(\mathrm{p}=0.03)$, as well as between the scores of the fathers and the siblings $(\mathrm{p}=0.02)$ on the meals together subscale. The fathers' responses were the highest, followed by the mothers and then the siblings (see Appendix E, Figure 5b.2). With regard to the parent-child togetherness measures, the fathers scored significantly higher than the mothers $(\mathrm{p}<0.01)$ (see Appendix E, Figure 5b.3). Lastly, with regard to the family management scores, the fathers scored significantly higher than the siblings $(p=0.04)$, as well as significantly higher than the mothers $(\mathrm{p}<0.05)$ (see Appendix E, Figure 5b.4).

\subsubsection{Analyses of variance (ANOVA)}

Analyses of variance were done to test for differences within the biographical variables race (white and coloured), language (Afrikaans and English), family structure (single mother, nuclear family, extended family) and income (< R90 000 per year, and $>$ R90 000 per year) for scores obtained with the self-report questionnaires (see Table 5.2.2). LSD post-hoc testing was only administered if a significant difference was found between groups for a specific biographical variable (family structure), because more than two independent variables were present within this variable, namely single-mother family, extended family, and nuclear family. This was done to establish exactly where the significant differences were (singlemother household, extended family household, or nuclear family). The results are shown in Table 5.2.2 and will be discussed more extensively in the next chapter of this thesis. 
Table 5.2.2

Results of ANOVAs for differences between groups within biographical variables $(n=41)$

\begin{tabular}{|c|c|c|c|c|c|c|c|c|}
\hline \multirow[t]{2}{*}{ Variable } & \multicolumn{2}{|c|}{ Race } & \multicolumn{2}{|c|}{ Language } & \multicolumn{2}{|c|}{ Family structure } & \multicolumn{2}{|c|}{ Income } \\
\hline & $\mathrm{F}$ & $\mathrm{p}$ & $\mathrm{F}$ & $\mathrm{p}$ & $\mathrm{F}$ & $\mathrm{p}$ & $\mathrm{F}$ & $\mathrm{p}$ \\
\hline $\begin{array}{l}\text { Problem solving and behaviour during crisis (Family Crisis } \\
\text { Oriented Personal Evaluation Scale [F-COPES] total score) }\end{array}$ & 1.72 & 0.20 & 0.90 & 0.35 & 0.03 & 0.97 & 0.95 & 0.33 \\
\hline Actively seeking social support (F-COPES Social support) & 6.5 & $0.02 *$ & 2.33 & 0.13 & 0.42 & 0.66 & 3.87 & 0.06 \\
\hline Redefining crisis in a more positive way (F-COPES Reframing) & 1.19 & 0.28 & 7.12 & $0.01 * *$ & 1.08 & 0.35 & 0.04 & 0.84 \\
\hline Seeking spiritual support (F-COPES Spiritual support) & 11.86 & $<0.01 * *$ & 9.96 & $<0.01 * *$ & 3.47 & $0.04 *$ & 10.95 & $<0.01 * *$ \\
\hline $\begin{array}{l}\text { Seeking out community resources and accepting help from the } \\
\text { community (F-COPES Family mobilisation) }\end{array}$ & 0.00 & 0.97 & 4.58 & $0.04 *$ & 2.95 & 0.06 & 0.05 & 0.83 \\
\hline $\begin{array}{l}\text { Passively accepting problematic issues to minimise re-activity ( } F \text { - } \\
\text { COPES Passive appraisal) }\end{array}$ & 20.84 & $<0.01 * *$ & 35.59 & $<0.01 * *$ & 2.82 & 0.07 & 5.69 & $0.02 *$ \\
\hline $\begin{array}{l}\text { Degree to which the family finds support in their community } \\
\text { (Social Support Index [SSI] total score) }\end{array}$ & 0.92 & 0.34 & 0.06 & 0.81 & 0.24 & 0.79 & 3.34 & 0.08 \\
\hline $\begin{array}{l}\text { Extent to which the family engages in activities and routines } \\
\text { (Family Time and Routines Index [FTRI]: Family, total score) }\end{array}$ & 0.01 & 0.93 & 0.15 & 0.70 & 0.34 & 0.71 & 0.17 & 0.68 \\
\hline $\begin{array}{l}\text { The importance and value the family attached to family time } \\
\text { and routines (FTRI Importance, total score) }\end{array}$ & 0.07 & 0.80 & 3.05 & 0.09 & 10.12 & $<0.01 * *$ & 0.065 & 0.80 \\
\hline $\begin{array}{l}\text { Routines to promote autonomy and order in children and teens } \\
\text { (FTRI Childhood routines) }\end{array}$ & 1.19 & 0.29 & 2.82 & 0.10 & 0.04 & 0.96 & 0.64 & 0.43 \\
\hline $\begin{array}{l}\text { Routines to promote communication between couples (FTRI } \\
\text { Couple togetherness) }\end{array}$ & 0.00 & 0.97 & 0.06 & 0.81 & 0.80 & 0.46 & 0.12 & 0.75 \\
\hline $\begin{array}{l}\text { Routines to promote togetherness through family mealtimes } \\
\text { (FTRI Meals together) }\end{array}$ & 0.45 & 0.83 & 0.75 & 0.39 & 0.89 & 0.42 & 0.45 & 0.51 \\
\hline $\begin{array}{l}\text { Routines to promote communication between parents and } \\
\text { children (FTRI Parent-child togetherness) }\end{array}$ & 0.16 & 0.69 & 0.10 & 0.76 & 1.62 & 0.21 & 0.07 & 0.80 \\
\hline
\end{tabular}


Table 5.2.2 (continued)

\begin{tabular}{|c|c|c|c|c|c|c|c|c|}
\hline \multirow[t]{2}{*}{ Variable } & \multicolumn{2}{|c|}{ Race } & \multicolumn{2}{|c|}{ Language } & \multicolumn{2}{|c|}{ Family structure } & \multicolumn{2}{|c|}{ Income } \\
\hline & $\mathrm{F}$ & $\mathrm{p}$ & $\mathrm{F}$ & $\mathrm{p}$ & $\mathrm{F}$ & $\mathrm{p}$ & $\mathrm{F}$ & $\mathrm{P}$ \\
\hline Special events and family time (FTRI Family togetherness) & 1.73 & 0.20 & 2.86 & 0.10 & 0.02 & 0.98 & 0.14 & 0.71 \\
\hline $\begin{array}{l}\text { Routines to promote meaningful connection with relatives (FTRI } \\
\text { Relatives connectedness) }\end{array}$ & 2.57 & 0.12 & 1.47 & 0.23 & 2.35 & 0.11 & 0.50 & 0.48 \\
\hline $\begin{array}{l}\text { Routines to promote teen and child responsibilities in the home } \\
\text { (FTRI Family chores) }\end{array}$ & 0.44 & 0.51 & 0.00 & 0.99 & 0.88 & 0.43 & 3.32 & 0.08 \\
\hline $\begin{array}{l}\text { Routines to maintain order in the home (FTRI Family } \\
\text { management) }\end{array}$ & 0.60 & 0.45 & 0.51 & 0.48 & 1.21 & 0.31 & 0.01 & 0.94 \\
\hline $\begin{array}{l}\text { Family's use of friends and relatives as a coping mechanism } \\
\text { during crisis (Relative and Friend Support Index [RFS]) }\end{array}$ & 2.45 & 0.13 & 1.07 & 0.31 & 0.53 & 0.59 & 3.49 & 0.07 \\
\hline $\begin{array}{l}\text { Style of family communication during crisis (Family Problem } \\
\text { Solving Communication Index [FPSC] Total score) }\end{array}$ & 0.00 & 0.95 & 1.47 & 0.23 & 1.48 & 0.24 & 0.32 & 0.57 \\
\hline Positive, supportive communication during crisis (FPSC Affirming) & 1.01 & 0.32 & 0.04 & 0.84 & 0.41 & 0.67 & 0.08 & 0.78 \\
\hline $\begin{array}{l}\text { Negative, inflammatory communication patterns during crisis } \\
\text { (FPSC Incendiary) }\end{array}$ & 1.01 & 0.32 & 5.37 & $0.03 *$ & 2.44 & 0.10 & 1.5 & 0.23 \\
\hline $\begin{array}{l}\text { Family hardiness: the internal strengths and durability of the } \\
\text { family (Family Hardiness Index (FHI) Total score) }\end{array}$ & 0.09 & 0.77 & 2.16 & 0.15 & 1.61 & 0.22 & 3.3 & 0.08 \\
\hline Ability to work together and internal strengths (FHI Commitment) & 0.04 & 0.84 & 1.29 & 0.26 & 0.16 & 0.85 & 0.99 & 0.33 \\
\hline Positive reframing, ability to learn (FHI Challenge) & 1.43 & 0.24 & 0.11 & 0.74 & 0.78 & 0.47 & 0.13 & 0.72 \\
\hline Internal locus of control (FHI Control) & 2.79 & 0.10 & 11.73 & $<0.01 * *$ & 4.82 & $0.01 * *$ & 5.03 & $0.03 *$ \\
\hline Family adaptation (FACI-8 Total score) & 0.66 & 0.42 & 0.47 & 0.50 & 1.5 & 0.25 & 5.59 & $0.02 *$ \\
\hline Strength of the bond between family members (FACI- 8 & 3.63 & 0.06 & 5.4 & $0.02 *$ & 3.2 & $0.05 *$ & 9.19 & $<0.01 * *$ \\
\hline Attachment) & & & & & & & & \\
\hline $\begin{array}{l}\text { Flexibility of the family members' relationships with each other } \\
\text { (FACI-8 Changeability) }\end{array}$ & 0.08 & 0.77 & 0.51 & 0.48 & 0.20 & 0.82 & 1.30 & 0.26 \\
\hline
\end{tabular}
$* p<0.05, * * p<0.01$ 
According to Table 5.2.2 significant differences in the following variables were found between groups: the use of coping strategies (F-COPES), the importance and value the family attach to family time and routines (FTRI Importance, total score), negative communication patterns during a crisis (FPSC Incendiary), a sense of an internal locus of control within the family (FHI Control), overall family adaptation (FACI8 Total score), and the strength of the bond between family members (FACI8 Attachment subscale).

\section{Differences in the use of coping strategies (F-COPES scores)}

Significantly different scores between groups were found for five of the subscales of FCOPES, namely seeking social support, reframing, seeking spiritual support, family mobilisation, and passive appraisal.

A significant difference $(p=0.02)$ was found between white and coloured households in terms of actively seeking social support (F-COPES Social support), with the white households seeking more social support in times of crisis than the coloured households (see Appendix E, Figure 1.1).

A significant difference $(\mathrm{p}=0.01)$ was found between the two language groups in redefining their crisis in a more positive way (F-COPES Reframing). The results reveal that the Afrikaans-speaking families make significantly more use of redefining their crisis in a more positive way than the English-speaking families (see Appendix E, Figure 1.2).

Significant differences were found between groups with regard to race, language, family structure and income for seeking spiritual support (F-COPES Spiritual support). A significant difference was found between white and coloured $(\mathrm{p}<0.01)$ households, with the coloured households seeking more spiritual support in times of crisis than the white households (see Appendix E, Figure 1.3.1). With regard to home language, the Afrikaans-speaking households sought spiritual support more in times of crisis than the English-speaking households (F-COPES Spiritual support) $(\mathrm{p}<0.01)$ (see Appendix E, Figure 1.3.2). A significant difference was found between the different family structures $(\mathrm{p}=0.04)$ in seeking spiritual support (F-COPES Spiritual support subscale). Due to the significance at the 5\% level, which indicates that significant difference(s) existed between the family structures, LSD post-hoc testing was done to find out between which family structures these differences were. In other words, LSD post-hoc testing determined whether significant differences existed between the single-mother and extended households, the extended and the nuclear 
families, or the nuclear and the single-mother households. The LSD post-hoc testing revealed a significant difference $(\mathrm{p}=0.01)$ between the single-mother households and the extended family households, with the extended family households seeking significantly more spiritual support when in crisis than the single-mother households (see Appendix E, Figure 1.3.3). A significant difference $(\mathrm{p}<0.01)$ in seeking spiritual support was also found between the households with an income of less than R90 000 and those with an income of more than R90 000 per year). The lower-income households sought significantly more spiritual support than the higher-income group (see Appendix E, Figure 1.3.4).

A significant difference was found between the Afrikaans- and English-speaking families in seeking out community resources and accept help from the community (F-COPES Family mobilisation, $p=0.04)$. The English-speaking families relied more on seeking out community resources and accepting help from the community than the Afrikaans-speaking families (see Appendix E, Figure 1.4).

Significant differences were found within groups (race, language and income) for the variable passive acceptance of problematic issues (FC passive appraisal). A significant difference was found between the two races $(\mathrm{p}<0.01)$, with the white households making significantly more use of passive acceptance of problematic issues as a coping style than the coloured households (see Figure 1.5.1). A significant difference also was found between Afrikaans- and English-speaking households' passive acceptance of problematic issues $(\mathrm{p}<0.01)$, with the latter making significantly more use of passive acceptance of issues than the Afrikaans-speaking households (see Appendix E, Figure 1.5.2). A significant difference was found between the two income groups with regard to the passive acceptance of problematic issues $(\mathrm{p}=0.02)$. The higher-income group made significantly more use of passively accepting problematic issues than the lower-income households (see Appendix E, Figure 1.5.3).

\section{Differences between groups with regard to the importance and value families attach to family time and routines (FTRI Importance, total score)}

A significant difference $(\mathrm{p}<0.01)$ was found between groups (different family structures) for the variable 'importance and value families attach to family time and routines'. LSD post-hoc testing revealed significant differences between the single-mother and nuclear family households $(\mathrm{p}<0.01)$, with the nuclear families attaching significantly more importance and 
value to family time and routines than the single-mother households. Another significant difference revealed by the post-hoc testing was between the single-mother and extended family household structures $(\mathrm{p}<0.001)$, with the extended families attaching significantly more importance and value to family time and routines than the single-mother households (see Appendix E, Figure 2).

\section{Differences between groups with regard to negative, inflammatory communication patterns during a crisis (FPSC Incendiary)}

A significant difference $(p=0.03)$ was found between the two language groups with regard to negative communication patterns during times of crisis. The Afrikaans-speaking households showed significantly higher scores on this scale, which means that these households used more negative communication patterns during times of crisis than the English households (see Appendix E, Figure 3).

\section{Differences between groups with regard to the families having an internal locus of control (FHI Control scores)}

A significant difference $(\mathrm{p}<0.01)$ was found between the English- and Afrikaans-speaking households with regard to having a sense of an internal locus of control. The Englishspeaking households had higher scores, which suggests that these households had a stronger sense of an internal locus of control than the Afrikaans-speaking households (see Appendix E, Figure 4.1).

A significant difference $(\mathrm{p}=0.01)$ was found between family structures with regard to having a sense of an internal locus of control. The LSD post-hoc testing revealed significant differences between the extended family and single-mother households ( $p=0.01$ ), as well as between the extended family structure and nuclear family households $(p=0.01)$. In both instances, the extended family households indicated a significantly lower internal locus of control (as a coping style) than the other two family structures (see Appendix E, Figure 4.2).

A significant difference was found between the families from the two income groups ( $<$ R90 000 and $>$ R90 000 annual household income) with regard to having a sense of an internal locus of control $(\mathrm{p}=0.03)$, with the families from the higher-income group indicating a significantly higher internal locus of control than the families from the lowerincome group (see Appendix E, Figure 4.3). 


\section{Differences between groups with regard to family adaptation (FACI8 Total score)}

A significant difference between the two income groups ( $<$ R90 000 and $>$ R90 000 per year) was found with regard to the overall adaptability of these families (FACI8 Total score, $\mathrm{p}=$ 0.02). The higher-income group showed significantly more family adaptation than the lowerincome group (see Appendix E, Figure 5.2).

\section{Differences between groups with regard to family attachment (FACI8 Attachment subscale)}

Significant differences were found within the language, family structure and income subgroups with regard to the strength of the bond between family members (FACI8 Attachment scores). A significant difference was found between the two language groups $(p=0.02)$, with the English-speaking households having a significantly stronger sense of a bond between their family members than the Afrikaans-speaking households (see Appendix E, Figure 5.1.1). A significant difference was found $(p=0.05)$ between the different family structures with regard to the strength of the bond between family members (FACI8 Attachment subscale). To further evaluate the significant differences, LSD post-hoc testing was administered, which revealed a significant difference between the nuclear households and the extended family households $(\mathrm{p}=0.05)$, with the nuclear households having a stronger sense of a bond between family members than the extended family households (see Appendix E, Figure 5.1.2.). With regard to the two income groups (< R90 000 and $>$ R90 000 per year), the higher-income households revealed a significantly stronger bond between family members than the lower-income households $(p<0.01)$ (see Appendix E, Figure 5.1.3).

\subsubsection{Correlations between the dependent and independent variables}

Pearson's product-moment correlations were calculated between measures of certain demographical variables (patient age, time since diagnosis of patient, and family income) and measures of family adaptation (FACI8 Total score), as well as between all measures of the independent variables (measured with scales and their subscales) and family adaptation (FACI8 Total score). In order to draw conclusions from the correlation coefficients calculated, it is important to understand the meaning of these values. The correlation coefficient is an indication of the strength of the relationship between variables (Howell, 2008). This value is a point on the scale between -1.00 and +1.00 . The closer this value is to either of these limits, the stronger the relationship between the two variables (Howell, 2008). 
Only one data set per family was used for the calculations $(n=42)$. The results are shown in Table 5.2.3.

Table 5.2.3

Pearson's product-moment correlations between demographic variables, independent variables and family adaptation (FACI8 Total score) $(n=42)$

Variable

Patient age

Time since diagnosis of patient

Family income

Problem solving and behaviour during crisis (Family Crisis Oriented Personal

Evaluation Scale [F-COPES] total score)

Actively seeking social support (F-COPES Social support)

Redefining a crisis in a more positive way (F-COPES Reframing)

Seeking spiritual support (F-COPES Spiritual support)

Seeking out community resources and accepting help from the community ( $F$ COPES Family mobilisation)

Passive acceptance of problematic issues to minimise re-activity (F-COPES Passive appraisal)

Degree to which the family finds support in their community (Social Support Index [SSI] total score)

Extent to which the family engages in activities and routines (Family Time and Routines Index [FTRI]: Family total score)

The importance and value the family attached to family time and routines (FTRI

Importance, total score)

Routines to promote autonomy and order in children and teens (FTRI Childhood routines)

Routines to promote communication between couples (FTRI Couple togetherness)

Routines to promote togetherness through family mealtimes (FTRI Meals together)

Routines to promote communication between parents and children (FTRI Parentchild togetherness)

Special events and family time (FTRI Family togetherness)

Routines to promote meaningful connection with relatives (FTRI Relatives connectedness)

Routines to promote teen and child responsibilities in the home (FTRI Family chores)

Routines to maintain order in the home (FTRI Family management)

Family's use of friends and relatives as a coping mechanism during crisis (Relative \& Friend Support Index [RFS]) $\mathrm{p}$

$-0.07$

0.64

$0.13 \quad 0.41$

$0.33 \quad 0.04^{*}$

$-0.10$

0.53

$-0.13$

0.40

$\begin{array}{ll}0.03 & 0.87\end{array}$

$-0.30 \quad 0.06$

$-0.01 \quad 0.96$

$0.32 \quad 0.04$

$0.41<0.01 * *$

$0.22 \quad 0.24$

$0.11 \quad 0.47$

$0.02 \quad 0.90$

$0.03 \quad 0.87$

$0.04 \quad 0.79$

$\begin{array}{ll}0.19 & 0.29\end{array}$

$0.44<0.01 * *$

$0.28 \quad 0.11$

$0.10 \quad 0.61$

$0.03 \quad 0.87$

$-0.21 \quad 0.19$

(Table continues) 
Table 5.2.3 (continued)

\begin{tabular}{lcc}
\hline Variable & $\mathrm{r}$ & $\mathrm{p}$ \\
\hline $\begin{array}{l}\text { Style of family communication during crisis (Family Problem Solving } \\
\quad \text { Communication Index [FPSC] Total score) }\end{array}$ & 0.65 & $<0.01^{* *}$ \\
$\quad$ Positive, supportive communication during crisis (FPSC Affirming) & 0.46 & $<0.01^{* *}$ \\
$\quad$ Negative, inflammatory communication patterns during crisis (FPSC Incendiary) & -0.66 & $<0.01^{* *}$ \\
Family hardiness: the internal strengths and durability of the family (Family & 0.69 & $<0.01^{* *}$ \\
$\quad$ Hardiness Index (FHI) Total score) & 0.55 & $<0.01^{* *}$ \\
Ability to work together and internal strengths (FHI Commitment) & 0.50 & $<0.01^{* *}$ \\
Positive reframing, ability to learn (FHI Challenge) & 0.35 & $<0.01^{* *}$ \\
Internal locus of control (FHI Control) & &
\end{tabular}

$* p<0.05, * * p<0.01$

As shown in Table 5.2.3, nine significant positive correlations were found between the measured independent variables and the dependent variable, family adaptation. One significant negative correlation $(\mathrm{r}=-0.66, \mathrm{p}<0.01)$ was found between family adaptation and incendiary family communication(FPSC Incendiary communication). These significant positive correlations are considered as resilience factors and will be discussed further in the next chapter.

\subsubsection{Best-subset regression analysis}

A best-subset regression analysis was utilised to identify which combination of independent variables best predicts the dependent variable. To further justify the best subset, the 'best' 20 models were chosen and scrutinised to confirm which independent variables were identified the most by this model (see Figure 5.2.4). It was found that a combination of five independent variables best predicted the dependent variable. The results are shown in Table 5.2 .4 . 
Table 5.2.4

Results of the best-subset multiple regression analysis $(\mathrm{n}=42)$

$$
\text { Variable }
$$

Beta-coefficient $\quad t(31) \quad p$-value

$(\beta)$

Seeking spiritual support (F-COPES Spiritual support)

$-0.21$

$-1.60$

0.12

Degree to which the family finds support in their

$2.00 \quad 0.05^{*}$

community (Social Support Index [SSI] total score)

The importance and value the family attach to family

1.70

0.10

time and routines (FTRI Importance, total score)

Family's use of friends and relatives as a coping

mechanism during crisis (Relative and Friend

Support Index [RFS])

Family hardiness: the internal strengths and durability

of the family (Family Hardiness Index (FHI) total

score)

$* p<0.05, * * p<0.01$

The combination of the following five independent variables best predicted changes in the dependent variable: the family seeking spiritual support (FC Spiritual), the degree to which the family find support in their community (SSI Total score), the importance and value the family attach to family time and routines (FTRI Importance, total score), the family's use of friends and relatives as a coping mechanism during crisis (RFS Total score), and the internal strengths and durability of the family (FHI Total score). This combination of independent variables explained $61 \%$ of the variance in the dependent variable $\left(\mathrm{R}^{2}=.61\right)$. Three independent variables within this group contributed significantly to the variance in the dependent variable, namely the degree to which the family finds support from their community (SSI Total score), the family's use of friends and relatives as a coping mechanism during crisis (RFS Total score), and the internal strengths and durability of the family (FHI Total score). Figure 5.2.4 shows how the independent variables featured in the best 20 models, according to the best-subset regression analysis. 


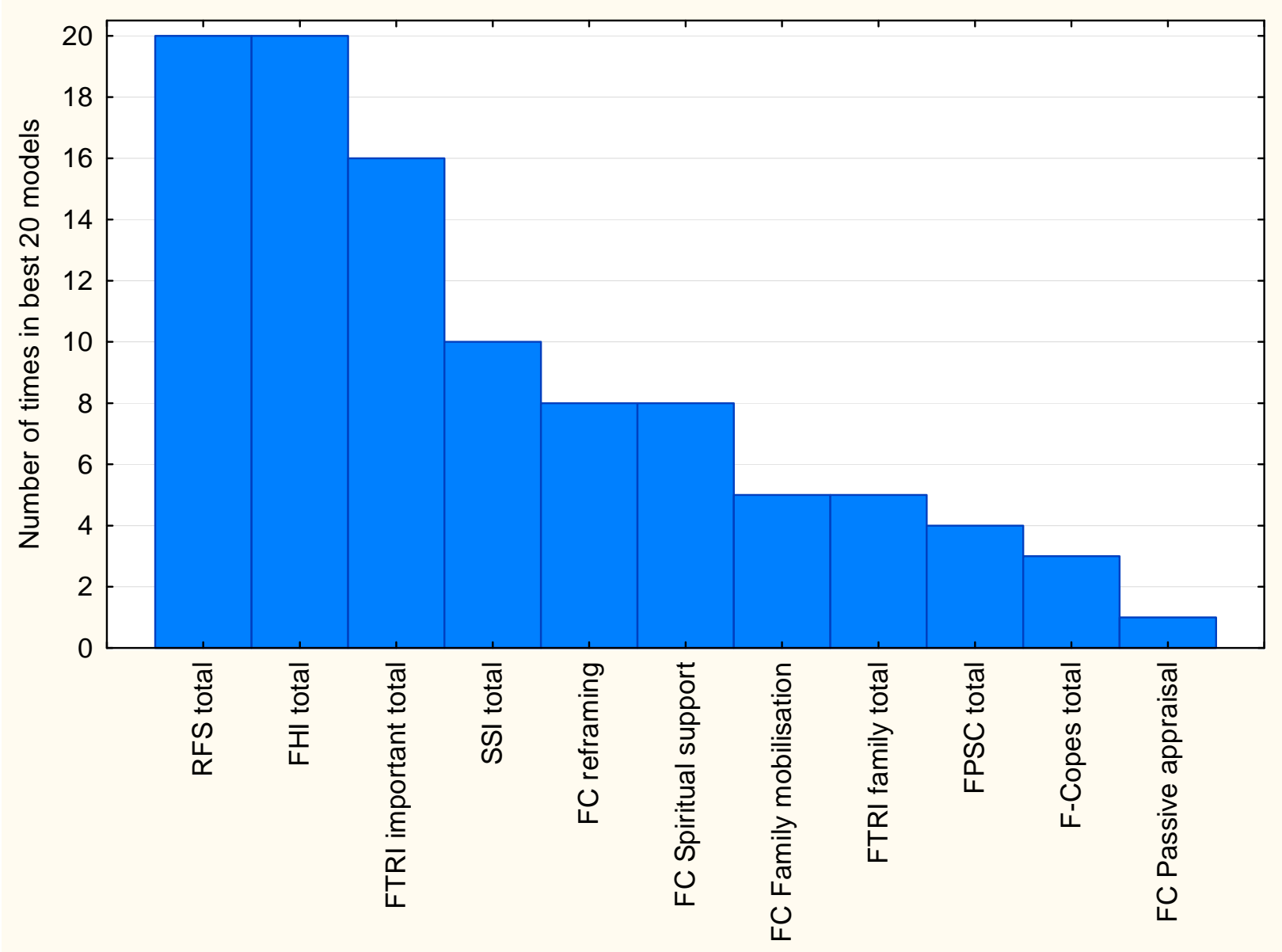

Figure 5.2.4 Histogram showing the presence of independent variables in the 20 best models.

As seen from Figure 5.2.4, two independent variables were represented in all 20 models, namely family hardiness - the internal strengths and durability of the family (FHI Total score) - and the family's use of friends and relatives as a coping mechanism during crisis (Relative and Friend Support Index [RFS]).

\subsection{Qualitative data analyses}

Family resilience qualities were identified from the qualitative data through a process of thematic analysis (Braun \& Clarke, 2006). This approach allowed me to first identify different codes within the data, and then categorise them into themes and subthemes. These themes and subthemes were used in an attempt to answer the following research question: "What resources do families use to adjust and adapt after a member has been diagnosed with schizophrenia?" The subthemes were categorised into three umbrella themes that emerged from the data, namely social support, characteristics and resources within the family, and 
factors specifically relating to the diagnosed family member. These themes, subthemes and categories within the subthemes are summarised in Table 5.3.

Table 5.3

Family resilience themes and subthemes that emerged from the qualitative data analyses $(n=$ 46)

\begin{tabular}{|c|c|c|}
\hline Themes & Subthemes & Categories within subthemes \\
\hline Social support & $\begin{array}{l}\text { - Support within the household } \\
\text { - Support from family, friends, } \\
\text { relatives and neighbours } \\
\text { - Support from the community }\end{array}$ & $\begin{array}{l}\text { Community support: support } \\
\text { groups, knowledge, } \\
\text { hospitals and professionals, } \\
\text { spiritual support, financial } \\
\text { support }\end{array}$ \\
\hline \multirow[t]{4}{*}{$\begin{array}{l}\text { Characteristics and resources } \\
\text { within the family }\end{array}$} & $\begin{array}{l}\text { Routines and time spent together } \\
\text { as a family }\end{array}$ & \\
\hline & Hardiness & $\begin{array}{l}\text { - Sense of control } \\
\text { - Beliefs } \\
\text { - Reframing }\end{array}$ \\
\hline & Passive appraisal & \\
\hline & $\begin{array}{l}\text { Communication within the } \\
\text { family }\end{array}$ & $\begin{array}{l}\text { - Honest communication, } \\
\text { - Affirming communication }\end{array}$ \\
\hline \multirow[t]{2}{*}{$\begin{array}{l}\text { Factors related to the } \\
\text { diagnosed family member }\end{array}$} & $\begin{array}{l}\text { Characteristics of the diagnosed } \\
\text { member }\end{array}$ & \\
\hline & Attitude towards the member & $\begin{array}{l}\text { - Encouragement } \\
\text { - Communication } \\
\text { - Routine } \\
\text { - Distance }\end{array}$ \\
\hline
\end{tabular}

Several resilience factors were identified that form part of the three main themes. These themes are as follows: social support (community support, support from family, neighbours, and friends, as well as spiritual support), characteristics and patterns of the family (family time and routines, hardiness, passive appraisal, communication patterns within the family), and factors relating to the diagnosed family member. Firstly, resilience factors related to social support will be discussed. 


\subsubsection{Social support}

The participants were asked to write down the resources and qualities that helped them as a family to adjust and adapt after a family member had been diagnosed with schizophrenia. Several families wrote answers that can be organised under the umbrella theme of social support. The social support identified and elicited from the qualitative data were categorised into three subthemes. These are support within the household; support from family (outside the household), friends and neighbours; and support from the community.

\section{Support within the household}

These families supported each other by each having responsibilities in the household and trying to understand each other by sharing their feelings. This was also referred to as the emotional support family members give to one another. In some families, the mothers tried to stabilise a crisis situation by trying to keep everyone calm and in this way support each other. It was also suggested that the parents should support each other by sharing their feelings and communicating with each other. Below are examples of a mother illustrating the importance of the couple supporting each other, and two sisters explaining how the family should help each other and share responsibilities in order to help them adapt to their crisis:

"As ons as ouers hartseer gevoel het, het ons mekaar beter laat voel deur daaroor te praat."

"Ek as middelste van vyf kinders het besluit om 'n familie byeenkoms te hou waar ek die bietjie kennis wat ek van die diagnose gehad het met almal te deel. Dit het geweldige druk van die persone in ons onmiddelike houshouding afgeneem."

"Ons vat maar almal beurte om na sy behoeftes om te sien en help waar ons kan met die medikasie."

Except for the support these family members showed each other, they also accepted support from family members outside the household, and from their friends and neighbours. This was identified as a resilience factor and will be discussed below.

\section{Support from family, friends, neighbours}

Some families referred to the support they received from their extended family, friends and neighbours and how this support helped them as a family to adapt to the crisis. By sharing their difficulties with their friends and neighbours, they increased their ability to be 
understood by others. Because their friends, families and neighbours did not always understand the illness and their crisis, it was important for the family to explain their situation. Through this their friends and neighbours were better equipped to support them as a family. These families explained that being able to share with others contributed to having a sense of belonging, feeling connected with others and not feeling alone. In this way the families explained that, through the social support they received from friends and neighbours, they were better able to adapt. A mother explained how she showed her friends to support them as a family:

"Friends - Told all close friends in order to stop gossiping about the person's strange behaviour, and to try to educate them so that they could support us."

Below are examples of a mother, sister and father illustrating the support they received, as well as the contribution of the support from family and friends helping them not to feel alone and isolated:

"Other members of the family rallied round and helped financially and emotionally."

"Daar is ook baie bystand vanaf die families en ander naasbestaandes."

"Ons steek niks weg nie en praat openlik met mense oor ons situasie. Die besprekings bring aan die lig van baie ander mense wat ook siek is en bring die besef dat ons nie in isolasie daarna moet kyk nie en ook nie in isolasie leef nie."

Although some families would communicate with their friends and extended family (outside the household) about their struggles, others were not able to communicate openly with their family and friends due to the stigma attached to mental illness. Below are examples of a sister stating that they would not share their problems with their neighbours, and a mother referring to the stigma and how it contributed to them struggling to find support within the community:

"Vra by bure vir geldjie en kos, maar nie met die probleem nie. Sal nie die probleem met hulle deel nie."

"Due to stigma of mental illness we really battled to find anyone willing to discuss their experiences with schizophrenia."

Not only did the support from families, friends and neighbours help most families to adapt to the crisis, the support they received from their community also helped. 


\section{Community resources and support}

Involvement in the community was important for most of these families. The support they received from the community is categorised and reported in the following order: support groups, searching and accepting knowledge about the diagnosis, help from hospitals and health-care professionals, as well as financial support. It was very important for most of these families to attend support group meetings. Through these meetings they were able to share information, which contributed to feeling connected to others who are experiencing or have experienced the same crisis. Making friends at the support group also helped some families. They were able to teach each other through sharing their experiences and knowledge. Below are responses from three mothers explaining how belonging to a support group helped:

"For me, my best support comes from the support group, which I stumbled upon through the community newspaper when I/we were attending Groote Schuur Hospital. The fact that I could contact a member who had or is experiencing the same problem. Knowing that you alone has a small measure of comfort."

"I joined the support group committee about three years ago and have gained insight from the extensive experience of the committee members."

"The informal sharing at groups and the variety of informed speakers have provided reassurance, reliable information and skills to cope ... other caregivers at the support groups become closer than family...”

Through sharing, and from the information made available by these support groups, the members were able to acquire knowledge about the illness. This helped them to know how to handle the diagnosed individual, and to understand what was happening. Although they acquired a lot of knowledge from their support groups, they also increased their knowledge by making use of other resources.

Knowledge was a very important resource mentioned by most of the families. Some families used several resources to gain information about the illness, such as searching on the internet. Acquiring knowledge of the illness made the families understand and be better equipped to handle their ill member. This information helped them to know what to do, and what to expect, which made the family feel empowered. Knowledge also helped the families to make sense of the illness, and this contributed to having a sense of control (subsequently referred to as hardiness). Being educated, and educating others, helped these families. This knowledge 
was mostly shared within the family and at support group meetings, and some families also shared their knowledge with friends and extended family. Knowledge was also gained through personal experiences with the diagnosed family member, and this was shared with other families. What follows are three mothers' and one father's response when asked what helped them as a family to adapt to having a member diagnosed with schizophrenia. They identified knowledge as a resource factor and some also explained how they acquired knowledge.

"Committee members with knowledge and information. Talks from professional speakers. Group discussions. Reading books on the subject."

"I started reading books from their library, which helped form the basis of my knowledge and the understanding of the illness."

"Inligting, via die internet of spesifieke inligtingstukke. Kennis is mag. Deur te weet waarteen jy veg kan jy weet hoe jy jou moet voorberei.”

"Die help ook baie om te lees in tydskrifte en die internet."

Although they searched for and acquired knowledge in different ways, many families identified hospitals and professionals in the field as having also helped them to adapt to their crisis.

Many of the families were helped by admitting their family member to the hospital, especially immediately after a psychotic episode. Professionals such as doctors, psychologists and social workers also helped these families to adapt after a diagnosis of schizophrenia had been made. A few families explained that counselling services, which were made available to them through professionals and in the hospitals, helped them to understand and adapt to having a member diagnosed with schizophrenia. Many families expressed the importance of medication and regular check-ups. Most families searched for help and treatment from hospitals and health-care professionals. Below are a mother and father explaining that help from hospitals and professionals were resources that helped them to adapt.

“My daughter's psychologist and psychiatrist made themselves available for our many questions regarding what to expect, dosages of medication, etc."

"Die ondersteuning wat ons gekry het by ... Hospitaal en die gemeenskapsklinieke" 
With the additional knowledge and support the families received from hospitals and professionals in their community, many identified spiritual support as a contributing factor to their ability to adapt and adjust to having a member diagnosed with schizophrenia. The importance of religion was expressed by many of these families as helping them adapt to their crisis. This included going to church, praying, and attending church activities. Other families also explained that their friends from church helped them. Below two fathers and one mother explain the importance of religion to their family's ability to adapt to having a member diagnosed with schizophrenia:

"As gesin sal ons op die Here vertrou om ons te lei."

"Godsdiens: Ons kragbron is die Here se beloftes dat Hy ons onderhou - In die Vader, die Seun en die Heilige Gees. Bywoning van kerkdienste, Bybel lees en gebed inspireer ons. Gebedsvriende - ons het 'n groot groep mense wat vir ons bid by die kerk, vriende en familie."

"Praying to God, members of the church they help me cope, so all the people next to me..."

Except for the community support received through the resources of support groups, knowledge, support from hospitals and professionals and spiritual support, financial support was also identified as a resource that helped families to adapt to having a family member diagnosed with schizophrenia.

Some families with a low annual household income (less than R90 000 per year) listed finances as a resource to their family's ability to adapt and adjust. This was only seen in the low-income group and not in the higher-income households (more than R90 000 per year). These families with a lower annual household income explained that financial support from the community and their friends helped them to adapt to their crisis. Below are how a mother and a sister responded when asked what helped the family as a unit to adapt to the diagnosis:

"Mense by die werk is 'n hulpbron - finansieel. Iets gekoop vir seun."

"Finansies."

Social support in the form of support within the household, support from family outside the household, and from friends and neighbours, and lastly support from the community, were 
identified as important resources for the adaptation process of these families. In the next section, the characteristics and resources within the family as a resilience factor are reported.

\subsubsection{Characteristics and resources within the family}

Although the families identified social support as a resilience factor, characteristics and resources within the family were also described. These characteristics and resources that helped them to adapt and adjust to having a member with schizophrenia will be reported as follows: routines and time spent together, hardiness, passive appraisal, and communication.

\section{Routines and time spent together}

The families mentioned that togetherness within the household was very important, as it contributed to feeling connected to each other. This togetherness and connectedness were established through several routines within the family and the time they spent together. The routines described by families were regularly going to church together, having prayer routines, and working together. Although it was important for many families to have routines and activities for the whole family, it also was important for them to have individual activities. One sister's had the following to say about being together as a family:

"I always try to include my brother, spend time with him ... sticking together as a family going on holidays, picnics, doing certain things that included and excluded my brother."

She described their different routines and time spent together, as well as how she ensured individual activities. A brother of a family member diagnosed with schizophrenia said that, in order to adapt to having a member with schizophrenia, the family should spend time together:

"Baie tyd saam spandeer as gesin."

Although it was important for these families to spend time together and have certain routines, the participants also expressed hardiness as a resource for their resilience.

\section{Hardiness}

Hardiness was mentioned several times by participants as having a sense of control within the family over external events and having certain beliefs. They also said that having hope, showing love, not giving up, and having a sense of humour in the family helped them to adapt to and accept the illness. It was explained by the participants that, as a family, they had 
a belief in the meaning of life, and that they could take control. Some explained that the medication contributed to a sense of control within the family. A sense of an internal locus of control was inferred from the data, namely that the family ("we") could overcome the crisis, which also contributed to the family's sense of togetherness. Staying motivated, trying to make sense of the situation and understanding the illness contributed to the adaptation process for these families. A father explained how having hope contributed to their family's adaptation:

"Hoop: Ons glo en vertrou dat die Here 'n doel het met alles en dat ons seun met behulp van medikasie en die genade van God heeltemal sal herstel."

A sister of one of the diagnosed family members said:

"Having a strong belief we (and my brother) would stabilise - we would survive."

Certain beliefs also helped these families, such as the belief that everything was going to be 'OK'. A belief in survival and coping was also elicited from the data of some of these families. Belief in God, praying and reading religious books helped some families. One of the fathers of a diagnosed family member said:

"Niks gebeur sonder 'n rede nie. Daarom het ons as gesin gebedsessies begin om ons geestelik te versterk."

A mother added:

"Die enigste manier wat ek moontlik glo die gesin tot sover oorleef het, is my geloof en gebede van groepe."

Hardiness as a resilience factor contributed to the families' ability to adapt to their crisis. In addition, the ability to accept their family member and the illness was also mentioned. Passive appraisal as a coping strategy will now be reported.

\section{Passive appraisal}

Passive appraisal was repeatedly evident in the responses of most of the families, i.e. the ability to accept the illness. The families said that it was important to accept the illness as part of their life and to approach every day on its own. A sister said that accepting the problem helped them to adapt as a family: 
"In some ways being able to embrace the problem, whilst not collapsing altogether."

Two mothers described their acceptance and its contribution to their family's ability to adapt:

"Ek het vrede gevind."

"Aanvaar haar met haar siekte en laat gesin deel van mekaar voel."

The family's ability to accept the illness helped them to adapt to the crisis. The role communication plays within the family will now be reported, as described by the families.

\section{Communication within the family}

Several families explained that honest and affirming communication within the household helped them to adapt and adjust to having a family member with schizophrenia.

\section{Honest and affirming communication}

It was important for some families to communicate about problems openly and honestly and to talk about the diagnosis within the household. It was also important for these families to discuss the illness openly and honestly with the diagnosed individual, as well as with the rest of the family. A father explained how communication helped them as a family:

“Ons as ouers gesels ook gereeld oor die onderwerp en bespreek ook baie die onderwerp met $\mathrm{Jan}^{1}$ self. Die feit dat ons oor die onderwerp gesels maak dit makliker vir ons as gsin om die siekte te verstaan."

Herewith a mother's response:

"It helped that the father and I discussed everything to do with our son, trying to see each other's point of view, trying to respect our differing opinions, etc."

Although honest communication was identified as a resilience factor, the contribution of affirming communication to the resilience of these families during times of crisis was also identified. It was important for many families to use affirming communication during conflict. They explained that, during times of crisis, it helped to stay calm and keep the peace. Many families explained that it also helped to show love and affection towards family members, and to express positive emotions towards each other. One mother said:

\footnotetext{
${ }^{1}$ This name was changed in order to protect the anonymity of the participant and the family member.
} 
"Hom te laat weet en glo dat ons hom lief het. Baie geduldige oor het met ander mense se probleme. Goeie humorsin. Ons hou van lag en is 'n baie grapperige familie. Deursettingsvermoë moet aan die orde van die dag wees. Wees nederig en sagmoedig sodat jy dit kan terugkry."

From the qualitative data, honest and affirming communication within the family during times of crisis was identified as helping the family adapt to having a member with schizophrenia. In addition to social support and characteristics and resources within the family, factors relating to the diagnosed family member were also identified as resilience factors and will be discussed in the next section.

\subsubsection{Factors relating to the diagnosed family member}

Within the written answers received from the participants to the question: "In your own words, please describe what helped (e.g. available resources, qualities of your family) your family as a unit to adapt after the family member was diagnosed with schizophrenia", specific characteristics of the diagnosed family member were identified. These characteristics of the member, as well as the family members' attitudes and ways of treating the member, helped the family to adapt to the diagnosis.

\section{Characteristics of the diagnosed member}

Certain characteristics of the diagnosed individual were identified as helping the family adapt to the diagnosis. These included the person's adherence to medication, being independent, having responsibilities, having certain routines and activities, being involved in the community, attending support groups for people with schizophrenia, and having a positive attitude. Examples of independence and community involvement will now be reported.

If the diagnosed family member was able to be more independent, such as having work, having certain responsibilities and making a personal effort to use the resources available to him/her to gain knowledge of his/her illness, it helped the family to adapt to the diagnosis. A mother explained how the ill member's independence contributed to relief within the family:

"She is self-supporting and for the time being is an enormous relief for us, and we are grateful." 
Some families felt that it helped the family if the diagnosed member was involved in voluntary work and working with people who have other illnesses. One family explained that it helped the family and the diagnosed member to see and work with people who experienced "worse" illnesses. It was also important for some families that the diagnosed member be involved in activities outside of the home. A mother explained how involvement in voluntary work had helped her daughter:

"My daughter did some voluntary work at a special needs school and found the children very loving and accepting, especially the Down's syndrome children. This had a positive impact on her."

Although certain characteristics of the diagnosed person helped the family adapt to their crisis, the importance of the attitude of the family members towards and the way they treated the ill member also helped them to adapt better to having a member diagnosed with schizophrenia.

\section{Attitude towards the diagnosed individual}

The ways in which the family treated and helped the diagnosed individual contributed to the family's ability to adapt to their crisis. These included encouraging the family member in several ways, communicating with the member, and helping the member to adhere to a routine. Some families also said that distancing themselves from the member helped them.

Many families believed that it was important to encourage the diagnosed member to be independent, to be involved in the community, and to attend support groups. It was also important to support, motivate and have patience with their family member. Some families explained that they tried to prevent symptoms by keeping the diagnosed member from situations that they believed were more likely to contribute to symptoms. It was also important to help the member to accept the illness. Some families explained that it helped to encourage the individual to be grateful and look at the 'bright' side, instead of focusing on his/her deficits. They also tried to make the member feel important. A sister and a mother explain below what helped them to adapt to their crisis:

"Tried to encourage him to accept the illness."

"Vital to be honest with my son. Vital to make him aware that he is loved no matter what, that he is not a failure or a disappointment to me. Giving quality time, gentleness, 
compassion and tolerance at all times is essential. Always build on patient's self-esteem and being a good citizen, a good, kind person to others. To be consistent in your own behaviour as a carer/parent. Making my son feel needed and loved and useful and appreciated is vital. Encourage him to think of less fortunate people to help others, not to assume he has nothing to offer. He must never feel a burden or useless or stupid."

Although it is important for the family to encourage the diagnosed family member in several ways, it is also important for the family to communicate with the family member with schizophrenia in order to improve their ability to adapt. As mentioned earlier, communication in the family is very important, but especially with the diagnosed individual. Communication with the diagnosed individual should be honest and open. The illness should be explained to the person in the hope that he/she gains insight into his/her own mental health, as well as an understanding thereof. Those families in which the diagnosed individual had some insight said that this helped them as a family to adapt. It is important that the diagnosed individual understand the role and importance of adherence to medication. This was very important and expressed by most participants. Below a mother explains the importance of communication with her son who has been diagnosed with schizophrenia and a sister identifies the importance of being aware of what you say to your ill family member:

"Informing my son about his illness. Educating my son about his illness, the essential taking of medication at correct times and ensuring he knows he is not responsible for having the illness."

"Hy vra ook baie vrae en mens moet nogal jou antwoorde mooi kies met so 'n persoon.”

In addition to communication with the diagnosed family member as a resource contributing to the resilience of these families, the importance of having a specific routine for the person diagnosed with schizophrenia and being consistent were also identified. Taking the diagnosed individual out of the home and allowing him/her to be involved in activities outside the family helped these families to adapt. A mother explains the importance of having a routine for the diagnosed member:

"To have a routine and importantly, non-negotiable boundaries, especially regarding cleanliness, bad behaviour, aggression and routine." 
A few families also identified distance as a resource for their ability to adapt to having a member diagnosed with schizophrenia. These families explained that distancing them from the situation and their family member at times helped them to deal with the situation. Through this they were able to view the situation from a different perspective. One mother pointed out:

"Only by distancing myself, or not engaging, I am able to deal with the situation."

To summarise, several subthemes were elicited from the qualitative data, and these were illustrated by quotes from the participants in this section. These subthemes were categorised into three overarching themes, namely social support, characteristics and resources within the family, and factors relating to the diagnosed family member. Although these resilience factors were identified within the qualitative data, many are supported by the quantitative data. The next section provides a short comparison of the findings.

\subsection{Quantitative results supported by the qualitative results}

A couple of themes from the qualitative data supported significant positive Pearson's product-moment correlations between the independent variables and the dependent variable (family adaptation). These independent variables are the degree to which the family find support in their community, family togetherness through family time and special events, family hardiness, the family's ability to work together and their internal strengths, having an internal locus of control, the ability to learn from life events, the style of communication during a crisis, and the use of positive supporting communication during a crisis. These variables found in the quantitative data are supported by the themes elicited from the qualitative data analyses. Another significant correlation found between one demographic variable (household income) and family adaptation was supported by data from the qualitative results. I refer here to the financial support mentioned in the qualitative data, where some families from low-income households reported finances as being helpful in their process to adapt to their crisis. This resilience factor was only identified in the low-income groups, which supports the statistically significant difference between the two household income groups (< R90 000/year and > R90 000/year) with regard to family adaptation (FACI8 Total score).

Themes or variables not measured or identified in the quantitative approach were revealed by the qualitative analyses and are discussed in the next chapter. 


\subsection{Conclusion}

The results of the qualitative and quantitative analyses were reported in this chapter. In relation to the quantitative data, a mixed model repeated measures ANOVA was administered to test for differences between the responses of the mothers, fathers and siblings. Several significant differences were found between these groups for some of the measured variables. Significant differences between groups (based on race, language, family structure and income) were found using analyses of variance (ANOVA) and were reported in this chapter. The results of the Pearson's product-moment correlations were also reported, as well as the results of the best-subset regression analysis. The results obtained from the quantitative data analyses supported by the themes elicited from the qualitative data were reported. A discussion of all the significant quantitative results as well as all qualitative results will follow in Chapter 6 (Discussion and Conclusion). 


\section{CHAPTER 6 \\ DISCUSSION AND CONCLUSION}

\subsection{Introduction}

The primary aim of this study was to identify family resilience qualities that families use to adjust and adapt after a member has been diagnosed with schizophrenia. The research question was: "What resources do families use to adjust and adapt after a family member has been diagnosed with schizophrenia?" A secondary aim of this study was to determine whether there are significant differences between groups with regard to biographical variables (i.e. relationship to the ill member, language groups, racial groups, family structure, and annual household income) and potential resilience variables.

As a framework to discuss the results, I will use the independent variables that correlated significantly positively with the dependent variable (family adaptation) and that consequently are considered family resilience qualities. These findings will be compared to the qualitative findings (where applicable), the literature and the theoretical frameworks utilised in this study. This will be followed by a discussion of additional findings from the best-subset regression analyses, and any other qualitative findings not measured quantitatively in this study, or that were not significant in the quantitative results. A discussion of the significant differences between groups, based on the quantitative data, will follow. Thereafter I will discuss the limitations of the study and make recommendations for future research. Lastly, a conclusion to this study is given.

\subsection{Significant correlations with family adaptation}

Ten statistically significant correlations were found between independent variables and family adaptation. Nine of these variables had a positive relationship with family adaptation, namely family income; the degree to which the family find support in their community; special events and family time; the style of communication during crises; positive communication patterns during crises; family hardiness; the ability of the family to work together and their internal strengths; positive reframing and the ability to learn; and the internal locus of control within families. Only one independent variable displayed a negative correlation with family adaptation, namely incendiary communication during times of crisis. First I will discuss family income as a family resilience quality. 


\subsubsection{Family income}

Family income as an independent variable correlated positively with the dependent variable (family adaptation). This indicates that the higher the income of the families, the better they were able to adapt when faced with a crisis. This can be due to the possibility that the higherincome group had more resources available that may have facilitated their adaptation process. According to Walsh (2003b), economic resources can be vital in times of crisis and can enable the family to obtain practical support. A chronic illness such as schizophrenia can have a substantial effect on the income of families, thereby contributing to stress and creating disharmony in the family. In the qualitative data, some families with a low annual income $(<$ R90 000/year) referred to financial support from their community as a resource that helped them to adapt to their crisis. This was not seen in the higher-income group. Greeff and Van der Walt (2010) also found in their study that families from a higher (upper and middle class) socioeconomic group reported better adaptation. In her family resilience framework, Walsh (2012) also refers to financial security as an important factor when considering the family as resilient.

\subsubsection{Degree to which the family find support in their community}

The degree to which the family find support in their community (Social Support Index [SSI]) correlated positively with family adaptation. This suggests that, if families get support from their community they are better able to adapt in times of crisis. This finding is supported by the results of the best-subset regression analysis (see Table 5.2.4). Within the qualitative data, support from the community includes that obtained from support groups, as well as the knowledge acquired from support group meetings. Other community resources indicated by the families include hospitals and professionals, as well as support from their church. Support from the community has been found by several researchers to contribute to the resilience of a family (Anuradha, 2004; Doornbos, 1996; Greeff \& Du Toit, 2009; Greeff \& Thiel, 2012; Greeff \& Wentworth, 2009; Haddad, 2008; Jonker \& Greeff, 2009; Marsh et al., 1996; McCubbin et al., 1996; Sellmeyer, 2003; Spaniol, 1987, Walsh, 2012). Knowledge, the use of support groups (Anuradha, 2004; Greeff \& Thiel, 2012; Haddad, 2008; Sellmeyer, 2003; Spaniol, 1987) and professional assistance (Marsh et al., 1996; Sellmeyer, 2003) as resources to adapt to adversities have been found in other studies. In addition, Sellmeyer (2003) found that families in which a member has been diagnosed with schizophrenia need more understanding from health-care professionals. 
Social support has been identified as a resilience factor in families in which a member has been diagnosed with schizophrenia (Saunders, 1999), and in families in which a member has been diagnosed with a mental illness (Anuradha, 2004; Doornbos, 1996; Enns et al., 1999; Greeff et al., 2006). The finding that social support contributes to the resilience of families is also supported by the two theoretical frameworks used in this study, namely the Resiliency Model (McCubbin \& McCubbin, 1996a), and the Family Resilience Framework (Walsh, 2012). Within the Resiliency Model, social support is indicated as a resource that helps families to adapt. Social support may decrease stress and help the family to function more effectively on a day-to-day basis.

\subsubsection{Special events and family time}

Within the quantitative results, special events and family time (FTRI Family togetherness) were found to correlate significantly positively with family adaptation. This was also found in a similar study by Haddad (2008). This finding indicates that, as the family spend more time together, their adaptation also increases. It seems important for these families to spend time together and engage in activities in which the whole family are present, as this significantly facilitates their adaptation to having a family member diagnosed with schizophrenia. The qualitative results revealed that the families attributed much of their ability to adapt to the importance of spending time together as a family and having certain routines within the family. When the family find time to spend together, they attend to each member's needs and prevent the ill member from receiving all the time of the family. This creates a balance in the family, enables the family to recognise and use their available resources, and allows the family members to rely on each other for mutual support. According to Walsh (2003b), this may also create a sense of connectedness in the family, facilitating family resilience.

Family times and routines have been found in other studies to contribute to the resilience in families in which a member has been diagnosed with schizophrenia (Haddad, 2008), those families in which a member has been diagnosed with a mental illness (Abelenda \& Helfrich, 2003; Anuradha, 2004), as well as families facing other adversities (Greeff \& Du Toit, 2009; Greeff \& Van der Walt, 2010; Greeff \& Wentworth, 2009). The finding that the activities and routines of the family contribute to the resilience of families is also supported by the two theoretical frameworks used in this study, namely the Resiliency Model (McCubbin \& McCubbin, 1996a) and the Family Resilience Framework (Walsh, 2012). 


\subsubsection{Style of communication during crisis}

The style of communication during times of crisis (Family Problem Solving Communication Index [FPSC] Total score) correlated positively with family adaptation. This suggests that, in essence, the style of communication is directly associated with the level of family adaptation. The quality of communication seems important in times of crisis. Effective communication may help the family solve problems and understand each other better. If the family are able to communicate effectively, they will better be able to resolve problems and work together, which may decrease stress and improve adaptability. According to Walsh (2003b), communication creates clarity and promotes emotional expression, which may facilitate problem solving. Also, sharing information may help the family better solve problems together (Walsh, 2003b). More important was the finding that the two types of communication, namely affirming and incendiary, also correlated significantly with family adaptation.

The importance of communication during crisis is supported by previous authors (Anuradha, 2004; Enns et al., 1999; Greeff \& Du Toit, 2009; Greeff \& Thiel, 2012; Greeff \& Van der Walt, 2010; Greeff \& Wentworth, 2009; Haddad, 2008; Jonker \& Greeff, 2009; McCubbin et al., 1996; Patterson, 2002; Walsh, 2012).

\subsubsection{Positive, supportive communication during crises}

A significant positive correlation was found between the use of supportive, affirming communication during times of crisis (FPSC Affirming) and family adaptation. This suggests that, as the family's ability to communicate in a calm and supportive way increases, the ability of the family to adapt to their crisis will also increase. Speaking calmly to each other may help the family to better understand each other and work together to solve problems. The family may function more satisfactory if they are able to support instead of criticise each other. Effective and clear communication may reduce disagreement and improve clarity, which may facilitate resilience. This is supported by the findings of the qualitative results, which revealed honest and affirming family communication to be an important contributor to the family's ability to adapt during times of crisis.

Many researchers have found that affirming communication (Anuradha, 2004; Enns et al., 1999; Greeff \& Du Toit, 2009; Greeff \& Thiel, 2012; Greeff \& Van der Walt, 2010; Greeff \& Wentworth, 2009; Haddad, 2008; Jonker \& Greeff, 2009; McCubbin et al., 1996; Walsh, 
2012), as well as open communication (Greeff \& Van der Walt, 2010; Walsh, 2012), contribute to family resilience.

\subsubsection{Negative, inflammatory communication patterns during crisis}

Only one significant negative correlation was found with family adaptation, namely negative, inflammatory communication patterns during crisis (FPSC Incendiary). This suggests that, if the family use negative communication, e.g. blaming and criticising each other in times of crisis, their adaptation will decrease and they most likely will continue to remain stuck in a crisis situation. Blaming and criticising each other may provoke disagreements and create stress within the family, which may not help the family but rather contribute to a crisis situation in the family. This suggests that negative communication that facilitates conflict is not a resilience resource and should not be used by families who need to adapt in times of crisis. Several studies support the finding that incendiary communication during crises negatively affects the family's ability to adapt and adjust to a crisis (Greeff \& Lawrence, 2011; Greeff \& Van der Walt, 2010; Greeff \& Wentworth, 2009; Haddad, 2008; Jonker \& Greeff, 2009, McCubbin et al., 1996).

\subsubsection{Family hardiness: The internal strengths and durability of the family}

The strongest positive correlation with family adaptation was the families' internal strengths and durability (Family Hardiness Index (FHI) Total score). This suggests that, if the family resist stress and endure their situation, their ability to adapt to a crisis will increase. Also, hardiness may decrease stress and facilitate the resilience of families. According to the bestsubset regression analysis (see Table 5.2.4), the family's internal strength and durability was one of the five independent variables that best predicted family adaptation and was also present in all 20 models (see Figure 5.2.4). This variable also contributed significantly to the variance in family adaptation.

Hardiness has been found in many studies to contribute to the family's ability to adapt and adjust to a crisis (Anarudha, 2004; Doornbos, 1996; Greeff \& Du Toit, 2009; Greeff \& Lawrence, 2011; Greeff \& Thiel, 2012; Greeff \& Van der Walt, 2010; Greeff \& Wentworth, 2009; Greeff et al., 2006; Haddad, 2008; Han et al., 2007; McCubbin \& McCubbin, 1996a; Walsh, 2012). A more specific finding was that Haddad (2008) found a significant positive correlation between the family's internal strength and durability (FHI Total score) and family adaptation (FACI8). 


\subsubsection{Ability to work together and internal strengths}

Quantitatively, a significant positive correlation was found between the family's ability to work together and their internal strengths (FHI Commitment) and family adaptation. The family need to remain interested in life and to work together to overcome a crisis. When the family work together they may decrease stress, solve problems together and create a trustworthy environment. According to McCubbin et al. (1996), when the family commit to working together, stress is reduced and family resilience is facilitated. The qualitative results revealed that there was a strong sense of "we' in some of these families that helped them to overcome their situation through their ability to work together.

\subsubsection{Positive reframing, ability to learn}

The family's ability to try to make sense of their situation and learn about the illness (FHI Challenge) helped them to adapt to their crisis. Having the belief that change is an inevitable part of life, and that change may present an opportunity for growth, enabled these families to better adapt to their crisis. When the family are able to reframe their crisis in a more positive way, hardiness will develop. Due to the chronic course of schizophrenia and the disabling symptoms, the family are challenged to think of and use new ideas to cope on a day-to-day basis, which allows the family to be resilient.

\subsubsection{Internal locus of control}

Quantitatively, a positive correlation was found between the family's sense of an internal locus of control (FHI Control) and family adaptation. This suggests that, if there is an increase in the family's belief that they are in control of their lives and their situation, their ability to adapt to their crisis will also increase. Qualitatively, hardiness was reflected as having a sense of control over external events. A sense of an internal locus of control was inferred from the data, namely that the family ("we") can overcome a crisis, which also contributed to the family's sense of togetherness. Furthermore, the families explained that their belief in the meaning of life and that they can take control of their lives contributed to the family's sense of having control over their situation.

In addition to the significant correlations between the independent variables and family adaption, contributors to family adaptation were also find within the best-subset regression analyses (see Table 5.2.4) that were not revealed in the correlation calculations (see Table 5.2.3). 


\subsection{Additional findings from the best-subset regression analyses}

In the best-subset regression analyses, three additional variables that were not significant in the correlation calculations were found to best predict family adaptation in combination with two other variables. These three variables were spiritual support; the importance and value the family attached to family time and routines; and relative and friend support.

\subsubsection{Seeking spiritual support}

Seeking spiritual support was found within the best-subset regression analyses to be one of the independent variables that best predicts family adaptation (see Table 5.2.4). Although this was not significant in the correlation analyses, this finding is supported by the qualitative results. This suggests that, when families seek spiritual support, they feel that they are better able to cope with their situation.

Spiritual support has also been found by many other researchers to contribute to family resilience (Anuradha, 2004; Doornbos, 1996; Enns et al., 1999; Haddad, 2008; Jonker \& Greeff, 2009; Marsh et al., 1996; McCubbin \& McCubbin, 1996a; Rammohan et al., 2002b; Saunders, 1999; Walsh, 2012). Haddad (2008) explains that the most important factors described by families to contribute to adaptation are spirituality and religion. The study by Jonker and Greeff (2009) also supports this finding, although spirituality and religion were found as a resilience factor in their qualitative data and were not supported by their quantitative data. Enns et al. (1999) found that more women than men depended on spiritual support and religion, whereas Greeff and Thiel (2012) found that more men than women described spirituality to help their families to adapt. Differences between gender groups were not significant in the current study.

\subsubsection{Relative and friend support}

According to the best-subset regression analysis, the family's use of friends and relatives as a coping mechanism during crisis (Relative \& Friend Support Index [RFS]) was one of the five independent variables that best predicted family adaptation; this aspect was present in all 20 models and contributed significantly to the variance in the dependent variable (see Table 5.2.4). This finding is supported by a subtheme (support from family, friends, relatives and neighbours) of one of the themes (social support) elicited from the qualitative data. This suggests that families who seek support from their relatives and their friends adapted better to having a member diagnosed with schizophrenia. The support families receive from relatives and friends may provide them with different or new ways of coping, in contrast to the support 
received from within the family. This kind of support also decreases stress within the family and facilitates resilience.

The role of support from family, friends, relatives and neighbours is supported by the findings of other studies of family resilience (Anuradha, 2004; Haddad, 2008; Enns et al., 1999; Greeff \& Wentworth, 2009; Marsh et al., 1996; McCubbin \& McCubbin, 1996a; Namyslowska, 1986; Spaniol et al., 1999; Walsh, 2012). Haddad (2008) found this category as a theme in his qualitative data, and it was supported in the quantitative data as a significant positive correlation between the family's use of friends and relatives as a coping mechanism during crisis (RFS) and family adaptation (FACI8).

In addition to these findings from the quantitative analyses, some themes elicited from the qualitative data were not supported by the quantitative results, or the variables were not measured by the scales used in the quantitative approach. These findings are discussed in the next section.

\subsection{Additional findings from the qualitative data}

An additional theme that is related to the diagnosed family member emerged from the qualitative data. In addition, the subtheme of passive appraisal (as a coping mechanism) was elicited from the qualitative data, but not found to be statistically significant for family adaptation in the quantitative analyses.

\subsubsection{Factors relating to the diagnosed family member}

Factors relating to the diagnosed family member include characteristics of the diagnosed member, as well as the attitude of the family towards the diagnosed family member. These characteristics of the diagnosed member refer to adherence to medication, being independent, having responsibilities, having certain routines and activities, being involved in the community, attending support groups for people with schizophrenia, and having a positive attitude. These factors helped the family to better adapt to their situation. Resilience factors relating to the diagnosed family member, such as the patient's adherence to medication (Haddad, 2008; Sellmeyer, 2003), and individual characteristics of the diagnosed member Haddad, 2008) are supported by previous research (Haddad, 2008; Jonker \& Greeff, 2009; Namyslowska, 1986; Sellmeyer, 2003; Spaniol, 1987).

Several categories emerged within the subtheme of the attitude of the family towards the diagnosed family member. These include encouraging the family member in several ways, 
open and honest communication with the member, and helping the member to adhere to a routine.

\subsubsection{Passive appraisal}

It was repeatedly mentioned in the qualitative data that it is important for families to accept their family member's diagnosis. When accepting the diagnosis, the families indicated that they were better able to adapt. When the family are able to accept the diagnosis and make meaning of their situation, stress will decrease and they will able to find different ways of adapting to their situation (Walsh, 2003b). Passive appraisal as a contributor to the family's ability to adjust and adapt after a member has been diagnosed with a mental illness, has been found in previous studies (Anuradha, 2004; Doornbos, 1996; Greeff et al., 2006).

In addition to the independent variables within the quantitative data, and the themes elicited from the qualitative analyses (viewed in this study as family resilience qualities), several differences with regard to the measured variables were found between groups.

\subsection{Differences between groups with regard to the measured variables}

The secondary aim of this study was to determine whether there were significant differences between groups with regard to biographical variables (i.e. relationship to the ill member, language groups, racial groups, family structure, and annual household income) and potential resilience variables. Differences were found between groups based on who represented the family (mother, father or sibling), racial groups (white or coloured), home language (Afrikaans or English), household structure (single mother, and nuclear or extended families), and income $(<$ R90 000 or $>$ R90 000/year).

\subsubsection{Differences in the use of coping strategies (F-COPES scores)}

Several differences were found between groups for the following coping strategies: seeking out community resources, actively seeking social support, redefining the crisis in a more positive way, seeking spiritual support, and passive acceptance of the problem.

Seeking out community resources and accept help from the community (F-COPES Family mobilisation)

The Afrikaans-speaking families more so than the English-speaking families, and the siblings more so than the mothers of the diagnosed person, perceived their families to seek out and accept support more readily in times of crisis (see Table 5.2.2). This suggests that these groups perceive their families to make more use of the access they have to resources in their 
community in times of crisis. These resources can include health-care facilities and the support groups for families in which a member has been diagnosed with schizophrenia.

\section{Actively seeking social support (F-COPES Social support)}

The white families perceived their families to actively seek out support from social resources in times of crisis more so than did the coloured families (see Table 5.2.2). According to McCubbin et al. (1996), social support decreases stress and promotes adaptability to crises. The white families viewed themselves as relying more on social support, which enabled them to adapt as a family to the changes that occur as a result of having a family member diagnosed with schizophrenia.

\section{Redefining the crisis in a more positive way (F-COPES Reframing)}

The Afrikaans-speaking families perceived themselves as making significantly more use of redefining the crisis in a more positive way as a coping style during times of crisis than the English-speaking families (see Table 5.2.2). For these families it was more important to think of the crisis in a more positive way to enable them to approach the crisis differently and in this way find new ways to adapt. When these families approached the crisis differently, they acquired a new perspective on the illness and found different ways of coping with the diagnosis of schizophrenia in their family.

\section{Seeking spiritual support (F-COPES Spiritual support)}

The coloured families more than the white families, the Afrikaans-speaking families more than the English-speaking families, the extended families more than the single-mother families, and the lower-income families more than the higher-income families (see Table 5.2.2) perceived their families to seek out and rely more on support from spiritual resources during times of crisis. According to McCubbin et al. (1996), spirituality is an important component within the resiliency framework that guides new/different ways of functioning in families in times of crisis. In these families, religion and the use of spiritual resources may provide the family with emotional and practical support to reduce stress and facilitate family resilience. As mentioned earlier, several researchers have found that spiritual support contributes to family resilience (Anuradha, 2004; Doornbos, 1996; Enns et al., 1999; Haddad, 2008; Jonker \& Greeff, 2009; Marsh et al., 1996; McCubbin \& McCubbin, 1996a; Rammohan et al., 2002b; Saunders, 1999; Walsh, 2012). 
Passive acceptance of problematic issues to minimise re-activity (F-COPES Passive appraisal)

The white families more than the coloured families, the English-speaking families more than the Afrikaans-speaking families, and the higher-income families more than the lower-income families (see Table 5.2.2) viewed their families as accepting a problematic situation during times of crisis and thereby also minimising the possibility that the problem re-occurs. When families are able to accept the crisis, they will be able to focus their attention on resources that may help them to adapt (Walsh, 2003b).

In addition to the differences found between groups with regard to the use of coping strategies, differences between groups were also found for family time together and family routines. These will be discussed in the next section.

\subsubsection{Differences with regard to family time and routines (FTRI scores)}

With regard to differences between groups in terms of the use of family time and routines, the following family time and routines are relevant: the importance and value the family attach to family routines, routines that promote communication between couples, family togetherness through mealtimes, parent-child communication, and routines that promote order in the home.

The importance and value families attach to family routines (FTRI Importance, total score)

In times of crisis, the nuclear and extended families, more so than the single-mother families (see Table 5.2.2), perceived their families as attaching more importance and value to their family routines. These routines probably contribute to order and predictability in the home, which may facilitate family resilience.

\section{Routines to promote communication between couples (FTRI Couple togetherness)}

The fathers, more so than the siblings, perceived communication between couples as a coping mechanism during times of crisis (see Table 5.2.2). The children are not involved in this routine, because it is communication between the couple, and therefore it may not seem as important to the children as the parents. This result suggests that the fathers view couple communication in their families as more relevant to adaptation in times of crisis.

\section{Routines to promote togetherness through family mealtimes (FTRI Meals together)}

The parents more so than the siblings of a person diagnosed with schizophrenia perceived their families to make more use of routines that promote togetherness in times of crisis (see Table 5.2.2). Having meals together possibly provides time for the family to communicate, 
share their concerns and feel more connected. The siblings may think that there are other ways to promote togetherness, but the parents seem to think that the family use these routines to promote resilience. Therefore, the parents perceive their family as making more use of spending time together through regular mealtimes to facilitate their adaptation.

\section{Routines to promote communication between parents and children (FTRI Parent- child togetherness)}

More fathers than mothers perceived their families as making use of routines that promote communication between parents and children in times of crisis (see Table 5.2.1). Although it was previously reported that fathers think that couple communication is important to adapt to their family situation, they also think that communication between the parents and children is of importance in their family when facing crises. This communication may facilitate clarity and bring the family together.

\section{Routines to promote order in the home (FTRI Family management)}

The fathers, more so than the mothers and siblings, perceived the family as making more use of routines that maintain order in the home in times of crisis (see Table 5.2.1). In addition to the fathers' perception of the family as using communication as a resilience factor in times of crisis, they also view their family as making use of order in the home to facilitate the family's adaptation. Clear and concise communication has the ability to create order in the home, because it enables every member to express and share emotions and vital information, which may facilitate problem solving.

\subsubsection{Negative, inflammatory communication patterns during times of crisis (FPSC Incendiary)}

Afrikaans-speaking families perceived their families as using significantly more negative communication during times of crisis than English-speaking families (see Table 5.2.2). According to the Afrikaans-speaking families, they are more likely to criticise and blame other members in the family when crises emerge. It is clear from a previous finding of this study, namely that negative, inflammatory communication correlates significantly negatively with family adaptation, that this kind of communication does not facilitate resilience but rather contributes to disharmony in the family.

\subsubsection{Internal locus of control (FHI Control)}

The English-speaking participants rather than the Afrikaans-speaking families, the singlemother and nuclear families rather than the extended families, and the higher-income families rather than the lower-income families (see Table 5.2.2), perceived their families as having a 
stronger sense of internal control over their situation. These participants had a stronger sense that their families could control situations internally and that they were not controlled by external events and situations. These families viewed themselves as having a stronger belief that they were able to overcome the crisis and that they could support each other as a family.

\subsubsection{Family attachment (FACI8 Attachment)}

The higher-income group rather than the lower-income group, the English-speaking families rather than the Afrikaans-speaking families, and the nuclear families rather than the extended families (see Table 5.2.2) viewed their families as having a stronger bond between members in times of crisis. These families viewed themselves as being close to each other when faced with a crisis. This connectedness probably helped them more, compared to the other families, to adapt in times of crisis. Feeling more connected indicates that these families were closer and may be better able to work together to solve problems.

\subsubsection{Family adaptation (FACI8 Total score)}

Overall, the higher-income families perceived their families to be better able to adapt in times of crisis compared to the lower-income group (see Table 5.2.2). It could be that families from the higher-income group had more resources available that may have facilitated their adaptation process. As discussed earlier, annual income had a positive correlation with family adaptation. The fact that the higher-income group were better able to adapt supports this finding.

Several resources that are associated with the resilience of families living with a member diagnosed with schizophrenia were identified in this study. Differences between groups were also discussed. The limitations of this study, as well as recommendations for future studies, are discussed in the next section.

\subsection{Limitations and recommendations}

Four limitations of this study are emphasised. Firstly, when considering the results of the study, it is important to take note of the reliability coefficients (Cronbach's alpha) of the scales. Care should be taken when interpreting the results from those scales with a reliability coefficient of less than .70 (F-COPES Passive appraisal, FACI8 Attachment, FHI Control, FHI Challenge, FPSC Total score, FPSC Incendiary, FPSC Affirming, F-COPES Mobilisation, F-COPES Passive appraisal). Secondly, the use of the 0.1 significance level in some cases increases the chance of making a Type 1 statistical error (rejecting the null hypothesis when it is correct). Thirdly, all participants were members of a support group which may have skewed the sample and they are therefore not representative of the South 
African population and the findings, therefore, cannot be generalised to all South African families with a member diagnosed with schizophrenia. Lastly, given that the majority of South Africans are black Africans, it is a limitation of this study that it focused only on coloured and white families.

There are five recommendations for future studies. Firstly, future studies should include black Africans in order to have a more representative sample of the diverse South African population. Secondly, future studies should use bigger samples in order to increase the generalisability of their findings. Thirdly, future studies should consider having a parent as the family member diagnosed with schizophrenia, rather than a child (as was the case in this study). Fourthly, it is recommended that future studies focus on a purely qualitative design in order to retrieve rich descriptions of the lives of these families. More themes could be elicited in this way. Fifthly, the data for this study were not collected over time. Walsh (2012) says the characteristic of resilience in families changes over time. Future studies should look at families over time in order to evaluate whether differences occur with regard to their coping and adaptation. Lastly, the findings of this study can be used for the development and implementation of interventions for families in which a member has been diagnosed with schizophrenia, as there seems to be a need for this type of research (Zauszniewski et al., 2010).

\subsection{Conclusion}

The aim of this study was to identify strengths and qualities within families that are used to adapt after a member has been diagnosed with schizophrenia. This mixed-method study revealed several factors that are associated with resilience in these families. Several significant correlations with family adaptation were found in the quantitative results, and these have been discussed. The quantitative results were compared with the qualitative themes, the literature and the two theoretical frameworks utilised in this study, namely the Resiliency Model (McCubbin \& McCubbin, 1996a) and the Family Resilience Framework (Walsh, 2012). Several differences were found between groups with regard to biographical variables (e.g. relationship to the ill member, language group, racial group, family structure and annual household income). Finally, the limitations of this study and recommendations for future studies that may contribute to research on family resilience and schizophrenia were presented. It is evident that several resources may help families in which a member has been diagnosed with schizophrenia to adapt. 


\section{REFERENCES}

Abelenda, J., \& Helfrich, C.A. (2003). Family resilience and mental illness: The role of occupational therapy. Occupational Therapy in Mental Health, 19(1), 25-39.

American Psychiatric Association. (2000). DSM-IV-TR: Diagnostic and statistical manual of mental disorders ( $4^{\text {th }}$ ed., text revision). Washington, DC: Author.

Andreasen, N.C., \& Carpenter, W.T.J. (1993). Diagnosis and classification of schizophrenia. Schizophrenia Bulletin, 19(2), 199-214.

Antonovsky, A. (1979). Health, stress and coping. San Francisco, CA: Jossey-Bass Inc.

Anuradha, K. (2004). Empowering families with mentally ill members: A strengths perspective. International Journal for the Advancement of Counselling, 26(4), 383-391.

Awad, A.G., \& Voruganti, L.N.P. (2008). The burden of schizophrenia on caregivers: A review. PharmacoEconomics, 26(2), 149-162.

Becvar, D.S., \& Becvar R.J. (2003). The historical perspective. In D.S. Becvar \& R.J. Becvar (Eds.), Family therapy: a systemic integration (5th ed., pp. 14-63). London: Guilford Press.

Bigbee, J.L. (1992). Family stress, hardiness, and illness: A pilot study. Family Relations, 41(2), 212-217.

Braun, V., \& Clarke, V. (2006). Using thematic analysis in psychology. Qualitative Research in Psychology, 3(2), 77-101. doi:10.1191/1478088706qp063oa

Chan, S. (2011). Global perspective of burden of family caregivers for persons with schizophrenia. Archives of Psychiatric Nursing, 25(5), 339-349. doi:10.1016/j.apnu.2011.03.008

Creswell, J.W., \& Miller, D.L. (2000). Determining validity in qualitative inquiry. Theory into Practice, 39(3), 124-130.

Doornbos, M.M. (1996). The strengths of families coping with serious mental illness. Archives of Psychiatric Nursing, 10(4), 214-220.

Enns, R.A., Reddon, J.R., \& McDonald, L. (1999). Indications of resilience among family members of people admitted to a psychiatric facility. Psychiatric Rehabilitation Journal, 23(2), 127-138.

Fujino, N., \& Okamura, H. (2009). Factors affecting the sense of burden felt by family members caring for patients with mental illness. Archives of Psychiatric Nursing, 23(2), 128-137. doi:10.1016/j.apnu.2008.05.006 
Gabbard, G.O. (2005). Psychodynamic psychiatry in clinical practice. Washington, DC: American Psychiatric Publication.

Glanville, D., \& Dixon, L. (2005). Caregiver burden, family treatment approaches and service use in families of patients with schizophrenia. The Israel Journal of Psychiatry and Related Sciences, 42(1), 15-22.

González-Torres, M.A., Oraa, R., Arístegui, M., Fernández-Rivas, A., \& Guimon, J. (2007). Stigma and discrimination towards people with schizophrenia and their family members. Social Psychiatry \& Psychiatric Epidemiology, 42(1), 14-23. doi:10.1007/s00127-0060126-3

Greeff, A.P., \& Du Toit, C. (2009). Resilience in remarried families. The American Journal of Family Therapy, 37(2), 114-126. doi:10.1080/01926180802151919

Greeff, A.P., \& Fillis, A.J.A. (2009). Resiliency in poor single parent families. Families in Society, 90(3), 279-285. doi:10.1606/1044-3894.3902

Greeff, A.P., \& Lawrence, J. (2011). Indications of resilience factors in families who have lost a home in a shack fire. Journal of Community \& Applied Social Psychology, 22(3), 210-224. doi:10.1002/casp.1108

Greeff, A.P., \& Thiel, C. (2012). Resilience in families of husbands with prostate cancer. Educational Gerontology, 38(3), 179-189.

Greeff, A.P., \& Van der Walt, K.-J. (2010). Resilience in families with an autistic child. Education and Training in Autism and Developmental Disabilities, 45(3), 347-355.

Greeff, A.P., \& Wentworth, A. (2009). Resilience in families that have experience heartrelated trauma. Current Psychology, 28(4), 302-314. doi:10.1007/s12144-009-9062-1

Greeff, A.P., Vansteenwegen, A., \& Ide, M. (2006). Resiliency in families with a member with a psychological disorder. The American Journal of Family Therapy, 34(4), 1-16. doi:10.1080/01926180600637465

Guba, E.G., \& Lincoln, Y.S. (1985). Fourth generation evaluation. Thousand Oaks, CA: Sage.

Haddad, J. (2008). Resilience in families where a member is living with schizophrenia. Unpublished dissertation, Nelson Mandela Metropolitan University, Port Elizabeth, South Africa.

Han, K., Lee, P., Park, E., Park, Y., Kim, J., \& Kang, H. (2007). Family functioning and mental illness: A Korean correlational study. Asian Journal of Nursing, 10(2), 129-136.

Hatfield, A., \& Lefley, H. (1987). Families of the mentally ill: Coping and adaptation. New York: The Guilford Press. 
Hawley, D.R., \& DeHaan, L. (1996). Towards a definition of family resilience: Integrating life span and family perspectives. Family Process, 35(3), 283-298.

Henry, J.D., Rendell, P.G., Green, M.J., McDonald, S., \& O’Donnell, M. (2008). Emotion regulation in schizophrenia: Affective, social, and clinical correlates of suppression and reappraisal. Journal of Abnormal Psychology, 117(2), 473-478.

Honkonen, T., Saarinen, S., \& Salokangas, R.K. (1999). Deinstitutionalization and schizophrenia in Finland II: Discharged patients and their psychosocial functioning. Schizophrenia Bulletin, 25, 543-551.

Howell, D.C. (2008). Fundamental statistics for the behavioural sciences ( $6^{\text {th }}$ ed.). Belmont, CA: Thomson/Wadsworth. Johnson, R.B. (1997). Examining the validity structure of qualitative research. Education, 118(2), 282-289.

Jones, D.W. (2004). Families and serious mental illness: Working with loss and ambivalence. British Journal of Social Work, 34(7), 961-979. doi:10.1093/bjsw/bch123

Jones, S., \& Hayward, P. (Eds.). (2004). Coping with schizophrenia: A guide for patients, families and caregivers. Oxford: Oneworld Pub.

Jonker L., \& Greeff, A.P. (2009). Resilience factors in families living with people with mental illnesses. Journal of Community Psychology, 37(7), 859-873.

Kritzinger, J., Swartz, L., Mall, S., \& Asmal, L. (2011). Family therapy for schizophrenia in the South African context: Challenges and pathways to implementation. South African Journal of Psychology, 41(2), 140-146.

Lefley, H.P. (1989). Family burden and family stigma in major mental illness. American Psychologist, 44(3), 556-560. doi:10.1037/0003-066X.44.3.556

Marsh, D.T., Lefley, H.P., Evans-Rhodes, D., Ansell, V.I., Doerzbacher, B.M., LaBarbera, L., \& Paluzzi, J.E. (1996). The family experience of mental illness: Evidence for resilience. Psychiatric Rehabilitation Journal, 20(2), 3-12.

Maurin, J., \& Boyd, C. (1990). Burden of mental illness on the family: A critical review. Archives of Psychiatric Nursing, 4(2), 99-107.

Maxwell, J.A. (1992). Understanding and validity in qualitative research. Harvard Educational Review, 62(3), 279-300.

McCubbin, H.I., Larsen, A., \& Olsen, D. (1996). The Relative and Friend Support index (RFS). In H.I. McCubbin, A.I. Thompson, \& M.A. McCubbin (Eds.), Family assessment: Resiliency, coping and adaptation - Inventories for research and practice (p. 825). Madison, WI: University of Wisconsin System. 
McCubbin, H.I., McCubbin, M.A., \& Thompson, A.I. (1996a). Family Time and Routines Index (FTRI). In H.I. McCubbin, A.I. Thompson \& M.A. McCubbin (Eds.), Family assessment: Resiliency, coping and adaptation - Inventories for research and practice (pp. 325-340). Madison: University of Wisconsin System.

McCubbin, H.I., Olson, D., \& Larsen, A. (1996). Family Crisis Oriented Personal Scales (FCOPES). In H.I. McCubbin, A.I. Thompson \& M.A. McCubbin (Eds.), Family assessment: Resiliency, coping and adaptation - Inventories for research and practice (pp. 455-507). Madison: University of Wisconsin Publishers.

McCubbin, H.I., Patterson, J.M., \& Glynn, T. (1996). SSI: Social Support Index. In H.I. McCubbin, A.I. Thompson \& M.A. McCubbin (Eds.), Family assessment: Resiliency, coping and adaptation - Inventories for research and practice (pp. 357-389). Madison: University of Wisconsin System.

McCubbin, H.I., Thompson, A.I., \& Elver, K.M. (1996). Family Attachment and Changeability Index 8 (FACI8). In H.I. McCubbin, A.I. Thompson \& M.A. McCubbin (Eds.), Family assessment: Resiliency, coping and adaptation - Inventories for research and practice (pp. 725-751). Madison: University of Wisconsin System.

McCubbin, H.I., Thompson, A.I., \& McCubbin, M.A. (1996). Family assessment: Resiliency, coping and adaptation - Inventories for research and practice. Madison: University of Wisconsin Publishers.

McCubbin, M.A., \& McCubbin, H.I. (1996a). Resiliency in families: A conceptual model of family adjustment and adaptation in response to stress and crisis. In H.I. McCubbin, A.I. Thompson \& M.A. McCubbin (Eds.), Family assessment: Resiliency, coping, and adaptation - Inventories for research and practice (pp. 1-64). Madison, WI: University of Wisconsin.

McCubbin, M.A., \& McCubbin, H.I. (1996b). Family resistance and resiliency resources: Typologies of patterns of functioning. In H.I. McCubbin, A.I. Thompson \& M.A. McCubbin (Eds.), Family assessment: Resiliency, coping, and adaptation - Inventories for research and practice (pp. 64-99). Madison, WI: University of Wisconsin System.

McCubbin, M.A., McCubbin, H.I., \& Thompson, A.I. (1996b). Family Hardiness Index (FHI). In H.I. McCubbin, A.I. Thompson \& M.A. McCubbin (Eds.), Family assessment: Resiliency, coping and adaptation - Inventories for research and practice (pp. 239-305). Madison: University of Wisconsin System. 
McCubbin, M.A., McCubbin, H.I., \& Thompson, A.I. (1996c). Family Problem Solving Communication (FPSC). In H.I. McCubbin, A.I. Thompson, \& M.A. McCubbin (Eds.), Family assessment: Resiliency, coping and adaptation - Inventories for research and practice (pp. 639-686). Madison: University of Wisconsin System.

Morse, J.M., Barrett, M., Mayan, M., Olson, K., \& Spiers, J. (2002). Verification strategies for establishing reliability and validity in qualitative research. International Journal of Qualitative Methods, 1(2), 1-19.

Namyslowska, I. (1986). Social and emotional adaptation of the families of schizophrenic patients. Family Systems Medicine, 4(4), 398-407. doi:10.1037/h0089693

Patterson, J.M. (2002). Understanding family resilience. Journal of Clinical Psychology, 58(3), 233-246.

Potasznik, H., \& Nelson, G. (1984). Stress and social support: the burden experienced by the family of a mentally ill person. American Journal of Community Psychology, 12(5), 589607.

Rammohan, A., Rao, K., \& Subbakrishna, D. (2002a). Burden and coping in caregivers of persons with schizophrenia. Indian Journal of Psychiatry, 44(3), 220-227.

Rammohan, A., Rao, K., \& Subbakrishna, D.K. (2002b). Religious coping and psychological wellbeing in carers of relatives with schizophrenia. Acta Psychiatrica Scandinavica, 105(5), 356-362. doi:10.1034/j.1600-0447.2002.1o149.

Rossler, W., Salize, H.J., Cucchiaro, G., Reinhard, I., \& Kernig, C. (1999). Does the place of treatment influence the quality of life of schizophrenics? Acta Psychiatrica Scandinavica, 100(2), 142-148.

Sadock, B.J., \& Sadock, V.A. (2007). Kaplan and Sadock's synopsis of psychiatry: Behavioural sciences, clinical psychiatry $\left(10^{\text {th }}\right.$ edition $)$. Philadelphia, PA: Lippencott Williams and Wilkins.

Saunders, J.C. (1999). Family functioning in families providing care for a family member with schizophrenia. Issues in Mental Health Nursing, 20(2), 95-113. doi:10.1080/016128499248691

Sawa, A., \& Snyder, S.H. (2002). Schizophrenia: Diverse approaches to a complex disease. Science, 296, 692-693.

Sellmeyer, P.A. (2003). An exploratory study on the needs of families with a relative with schizophrenia who are utilising services at Cape Mental Health Society. Unpublished dissertation, University of Cape Town, South Africa. 
Shento, A.K. (2004). Strategies for ensuring trustworthiness in qualitative research projects. Education for Information, 22(2), 63-75.

Solomon, P., \& Draine, J. (1996). Examination of grief among family members of individuals with serious and persistent mental illness. The Psychiatric Quarterly, 67(3), 221-234.

Spaniol, L. (1987). Coping strategies of family caregivers. In A. Hatfield \& H. Lefley (Eds.), Families of the mentally ill: coping and adaptation (pp. 208-222). New York: The Guilford Press.

Statsoft Incorporated. (2011). Statistica Version 10. Tulsa, Oklahoma.

Strauss, A., \& Corbin, J. (1990). Basics of qualitative research: Techniques and procedures for developing grounded theory. Newbury Park, CA: Sage.

Tsang, H., Tam, P., Chan, F., \& Chang, W. (2003). Sources of burdens on families of individuals with mental illness. International Journal of Rehabilitation Research, 26(2), 123-130.

Walsh, F. (2003a). The concept of family resilience: Crisis and challenge. Family Process, 35(3), 261-281.

Walsh, F. (2003b). Family resilience: A framework for clinical practice. Family Process, 42(1), 1-18.

Walsh, F. (2012). Family resilience: Strengths forged through adversity. In F. Walsh (Ed.), Normal family processes ( $4^{\text {th }}$ ed., pp. 399-423). London: The Guilford Press.

Ward, R. (Ed.). (2008). Coping skills for carers: A reference manual for families and carers of people with schizophrenia. Cape Town: Cape Support for Mental Health.

World Health Organization Assessment Instrument for Mental Health Systems [WHOAIMS]. (2007). WHO-AIMS report on mental health system in South Africa, Cape Town, South Africa. ISBN: World Health Organization 2007.

Zauszniewski, J., Bekhet, A., \& Suresky, M. (2010). Resilience in family members of persons with serious mental illness. Nursing Clinics of North America, 45(4), 613-631. doi:10.1016/j.cnur.2010.06.007 


\section{APPENDIX A}

\section{Diagnostic criteria of schizophrenia}

A. Characteristic symptoms: Two/more of the following, each present for a significant portion of time during a 1-month period (or less if successful treated):

1. Delusions ${ }^{1}$,

2. Hallucinations ${ }^{2}$,

3. Disorganized speech (e.g. frequent derailment ${ }^{3}$ or incoherence ${ }^{4}$ )

4. Grossly disorganised or catatonic behaviour ${ }^{5}$

5. Negative symptoms, i.e., affective flattening, alogia $^{6}$, or avolition ${ }^{7}$

Note: only one criterion A symptom is required if delusions are bizarre or hallucinations consist of a voice keeping up a running commentary on the person's behaviour or thoughts or two or more voices conversing with each other

B. Social/Occupational dysfunction: For a significant portion of the time since the onset of the disturbance, one or more major areas of functioning such as work, interpersonal relations, or self-care are markedly below the level achieved prior to the onset (or when the onset is in childhood or adolescence, failure to achieve expected level of interpersonal, academic, or occupational achievement).

C. Duration: Continuous signs of the disturbance persist for at least 6 months. This 6month period must include at least 1 month of symptoms (or less if successfully treated) that meet Criterion A (i.e., active-phase symptoms) and may include periods of prodromal or residual symptoms.

During these prodromal residual periods, the signs of the disturbance may be manifested by only negative symptoms or two or more symptoms listed in Criterion A present in an attenuated form (e.g. odd beliefs, unusual perceptual experiences).

D. Schizoaffective and mood disorder exclusion: Schizoaffective disorder and mood disorder with psychotic features have been ruled out because either (1) no major depressive, manic, or mixed episodes have occurred concurrently with the activephase symptoms, or (2) if mood episodes have occurred during active-phase symptoms, their total duration has been brief relative to the duration of the active and residual periods.

E. Substance/general medical condition exclusion: The disturbance is not due to the direct physiological effects of a substance (e.g. a drug of abuse, a medication) or a general medical condition 
F. Relationship to a pervasive developmental disorder: If there is a history of autistic disorder or another pervasive developmental disorder, the additional diagnosis of schizophrenia is made only if prominent delusions or hallucinations are also present for at least a month (or less if successfully treated).

Classification of longitudinal course (can be applied only after at least 1 year has elapsed since the initial onset of active-phase symptoms):

Episodic with interepisode residual symptoms (episodes are defined by the re-emergence of prominent psychotic symptoms); also specify if: with prominent negative symptoms Episodic with no interepisode residual symptoms

Continuous (prominent psychotic symptoms are present throughout the period of observation); also specify if: with prominent negative symptoms

Single episode in partial remission: also specify if: with prominent negative symptoms

\section{Single episode in full remission}

\section{Other or unspecified pattern}

\section{NOTE}

Please see the following clarifications (Sadock \& Sadock, 2007) of words and concepts used in the above diagnostic criteria of schizoprenia

${ }^{1}$ Delusion - False belief, based on incorrect inference about external rality, that is firmly held despite objective and obvious contradictory proof or evidence and despite the fact that other members of the culture do not share the same belief

${ }^{2}$ Hallucination - False sensory perception occurring in the absence of any relevant external stimulation of the sensory modality involved. Any of the five senses (auditory, visual, tactile, olfactory, or gustatory) may be affected by hallucinatory experiences in patients with schizophrenia. The most common hallucinations are auditory, which is the false perception of sound, usually voices, but also other noises, such as music. Visual hallucinations (which primarily involve the sense of sight) are common. Those primarily involving the sense of touch (tactile), smell (olfactory), and taste (gustatory) are not common.

${ }^{3}$ Derailment - Gradual or sudden deviation in train of thought without blocking; sometimes used synonymously with loosening of association

${ }^{4}$ Incoherence - Communication that is disconnected, disorganised, or incomprehensible.

${ }^{5}$ Catatonic behaviour - This can refer to catatonic excitement (excited, uncontrolled motor activity. Patients in catatonic state may suddenly erupt into an excited state and may be violent), catatonic 
posturing (voluntary assumption of an inappropriate or bizarre posture, generally maintained for long periods of time. May switch unexpectedly with catatonic excitement), catatonic rigidity (Fixed and sustained motoric position that is resistant to change), or catatonic stupor (Stupor in which patients ordinarily are well aware of their surroundings)

${ }^{6}$ Alogia - Inability to speak because of a mental deficiency or an episode of dementia

${ }^{7}$ Avolition - lack of drive or motivation 


\section{APPENDIX B}

\section{Biographical Questionnaire}

All information is strictly confidential

Please tick the box that applies to you or fill in the space(s)

\section{General}

Age:

Gender: $\square$ Male $\square$ Female

Race: $\square$ White $\square$ Coloured $\square$ Black $\square$ Other (please specify)

Religion: $\square$ Christian $\square$ Jewish $\square$ Muslim $\square$ No affiliation $\square$ Other (please specify)

Language: $\square$ English $\square$ Afrikaans $\square$ isiXhosa $\square$ Other (please specify)

Area where you live (or town):

Please answer the following with regard to the sibling completing the questionnaires:

Age:

Gender: $\square$ Male $\square$ Female

Please answer the following with regard to the diagnosed family member:

Your relationship with diagnosed family member: $\square$ Own child $\square$ Family member (please specify)

Age and gender of diagnosed family member:

Time since member was diagnosed:

(years) (months)

\section{Household/Family Structure}

Number of family members in your household: Adults: Children:

Any other permanent tenants? (if yes, please specify):

Please answer the following regarding each adult member in your household:

\begin{tabular}{|c|c|c|c|c|c|}
\hline Adult & $\begin{array}{c}\text { Male/ } \\
\text { Female }\end{array}$ & $\begin{array}{c}\text { Relationship to diagnosed } \\
\text { member (parent, sibling, cousin, } \\
\text { aunt, uncle, grandparent, other) }\end{array}$ & Age & $\begin{array}{c}\text { Level of education (primary } \\
\text { school, high school, diploma, } \\
\text { degree, other) }\end{array}$ & Employed \\
\hline 1 & $\mathrm{M} / \mathrm{F}$ & & & & Yes/No \\
\hline 2 & $\mathrm{M} / \mathrm{F}$ & & & & Yes/No \\
\hline 3 & $\mathrm{M} / \mathrm{F}$ & & & & Yes/No \\
\hline 4 & $\mathrm{M} / \mathrm{F}$ & & & & Yes/No \\
\hline 5 & $\mathrm{M} / \mathrm{F}$ & & & Yes/No \\
\hline
\end{tabular}

Please answer the following regarding each child in your household:

\begin{tabular}{|c|c|c|c|c|c|}
\hline Child & $\begin{array}{c}\text { Male/ } \\
\text { Female }\end{array}$ & $\begin{array}{c}\text { Relationship to diagnosed } \\
\text { member }\end{array}$ & Age & Level of education & Employed \\
\hline 1 & $\mathrm{M} / \mathrm{F}$ & & & & Yes/No \\
\hline 2 & $\mathrm{M} / \mathrm{F}$ & $\mathrm{M} / \mathrm{F}$ & & & Yes/No \\
\hline 3 & & & & Yes/No \\
\hline 4 & $\mathrm{M} / \mathrm{F}$ & & & Yes/No \\
\hline 5 & $\mathrm{M} / \mathrm{F}$ & & & Yes/No \\
\hline
\end{tabular}

Please indicate the family structure of your household:

$\square$ Single mother $\square$ Single father $\square$ Nuclear family $\square$ Extended family

$\square$ Other (please describe)

\section{Annual family income (in Rand):}

$\square$ less than $40000 \quad \square$ between 40000 to $90000 \quad \square$ between 90000 to $150000 \quad \square$ more than 150000 
In your own words, please describe what helped (e.g. available resources, qualities of your family) your family as a unit to adapt after the family member was diagnosed with schizophrenia:

(please do not hesitate to use more space if necessary) 


\section{Biografiese Inligting}

Alle inligting is streng vertroulik en sal anoniem verwerk word

Merk asb. die mees toepaslike blokkie met 'n kruis en/of vul die aangeduide spasies in

\section{Algemeen}

Ouderdom:

Geslag: $\square$ Manlik $\square$ Vroulik

Bevolkingsgroep: $\square$ Wit $\square$ Kleurling $\square$ Swart $\square$ Ander(spesifiseer):

Geloof: $\square$ Christen $\square$ Joods $\square$ Moslem $\square$ Geen $\square$ Ander (spesifiseer asb):

Huistaal: $\square$ Engels $\square$ Afrikaans $\square$ isiXhosa $\square$ Ander (Spesifiseer asb):

Area waar u bly (of stad/dorp):

Antwoord asb. die volgende m.b.t. die ander gesinslid wat die vraelyste gaan invul:

Ouderdom: Geslag: $\square$ Manlik $\square$ Vroulik

Antwoord asb. die volgende m.b.t die gediagnoseerde gesinslid:

U verhouding met gediagnoseerde lid: $\square$ Eie kind $\square$ Familielid (spesifiseer asb)

Ouderdom en geslag van gediagnoseerde lid:

Tyd sedert gesinslid gediagnoseer is: (jare) (maande)

\section{Huishouding/Familiestruktuur}

Aantal gesinslede: Volwassenes: Kinders:

Enige ander permanente inwoners in u huis (indien ja, spesifiseer asb):

Antwoord asb. die volgende m.b.t. elke volwassene in u huishouding

\begin{tabular}{|c|c|c|c|c|c|}
\hline Volwassene & $\begin{array}{c}\text { Manlik/ } \\
\text { Vroulik }\end{array}$ & $\begin{array}{c}\text { Verhouding tot gediagnoseerde } \\
\text { lid (ouer, broer/suster, } \\
\text { tannie/oom, grootouer) }\end{array}$ & Ouderdom & $\begin{array}{c}\text { Vlak van opvoeding } \\
\text { (laerskool, hoërskool, } \\
\text { diploma, graad, ander) }\end{array}$ & Werkend \\
\hline 1 & $\mathrm{M} / \mathrm{V}$ & & & & $\mathrm{Ja} / \mathrm{Nee}$ \\
\hline 2 & $\mathrm{M} / \mathrm{V}$ & & & & $\mathrm{Ja} / \mathrm{Nee}$ \\
\hline 3 & $\mathrm{M} / \mathrm{V}$ & & & & $\mathrm{Ja} / \mathrm{Nee}$ \\
\hline 4 & $\mathrm{M} / \mathrm{V}$ & & & & $\mathrm{Ja} / \mathrm{Nee}$ \\
\hline 5 & $\mathrm{M} / \mathrm{V}$ & & & & $\mathrm{Ja} / \mathrm{Nee}$ \\
\hline
\end{tabular}

Antwoord asb. die volgende m.b.t. elke kind in u huishouding

\begin{tabular}{|c|c|c|c|c|c|}
\hline Kind & $\begin{array}{c}\text { Manlik/ } \\
\text { Vroulik }\end{array}$ & $\begin{array}{c}\text { Verhouding tot gediagnoseerde } \\
\text { lid }\end{array}$ & Ouderdom & Vlak van opvoeding & Werkend \\
\hline 1 & $\mathrm{M} / \mathrm{V}$ & & & & $\mathrm{Ja} / \mathrm{Nee}$ \\
\hline 2 & $\mathrm{M} / \mathrm{V}$ & & & & $\mathrm{Ja} / \mathrm{Nee}$ \\
\hline 3 & $\mathrm{M} / \mathrm{V}$ & & & & $\mathrm{Ja} / \mathrm{Nee}$ \\
\hline 4 & $\mathrm{M} / \mathrm{V}$ & $\mathrm{Ja} / \mathrm{Nee}$ \\
\hline 5 & $\mathrm{M} / \mathrm{V}$ & & & & $\mathrm{Ja} / \mathrm{Nee}$ \\
\hline
\end{tabular}

Dui asb die familiestruktuur van u huishouding aan:

Enkel ma $\square$ Enkel pa $\square$ Kerngesin $\square$ Uitgebreide familie $\square$ Ander (beskryf asb.)

\section{Jaarlikse huishoudelike inkomste (in Rand):}

$\square$ minder as 40000

tussen 40000 en 90000

tussen 90000 en 150000

meer as 150000 
In u eie woorde, beskryf asb. wat julle gesin as 'n eenheid gehelp het (bv. kwaliteite/ eienskappe van die gesin, hulpbronne) om aan te pas nadat die gesinslid met skisofrenie gediagnoseer is: (indien nodig, moet asb. nie huiwer om meer papier/spasie te gebruik nie) 


\section{APPENDIX C Informed Consent}

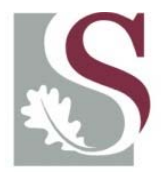

\section{UNIVERSITEIT•STELLENBOSCH•UNIVERSITY \\ jou kennisvennoot - your knowledge partner \\ STELLENBOSCH UNIVERSITY \\ CONSENT TO PARTICIPATE IN RESEARCH}

\section{RESILIENCE IN FAMILIES IN WHICH A FAMILY MEMBER HAS BEEN DIAGNOSED WITH SCHIZOPHRENIA}

You are invited to participate in a research study conducted by Melanie Bishop (BSc Honours Psychology) of the Department of Psychology at Stellenbosch University. The research results will contribute to the research thesis in order to fulfil the requirements for the MSc (Psychology) degree. You were selected as a possible participant in this study because you have a family member who has been diagnosed with schizophrenia.

\section{PURPOSE OF THE STUDY}

The study will look at resilience in families in which a family member has been diagnosed with schizophrenia. Resilience refers to ways in which a family is able to adapt successfully and move forward, despite traumatic and stressful life events. The researcher believes that your participation in this study will help other families who have similar experiences.

\section{PROCEDURES}

If you volunteer to participate in this study, we would ask you to do the following things:

1) Be willing to complete a biographical questionnaire.

a. This questionnaire will not take longer than 10 minutes to complete.

b. The questions refer to the structure of the household, your age, gender, relationship status, race, religion, language, annual income, education, area where you live, age of diagnosed individual, as well as when the individual was diagnosed and his/her age at that stage.

2) Be willing to complete a set of questionnaires about a range of processes within the family, such as the bond between family members, routines and activities maintained within the family; the family's support system(s); interaction between family members and the community; how the family deals with problems; and the importance of friends to the family.

These will take no longer than 30 minutes to complete, and they will be available in English and Afrikaans.

3) The researcher will be available to answer questions if you are uncertain about any aspect relating to the completion of the questionnaires.

4) After completing all the forms, you must post them to the researcher (the researcher will provide each participant with an envelope and stamps for postage).

\section{POTENTIAL RISKS AND DISCOMFORT}

Some of the items in the questionnaires may possibly cause some discomfort. You are in control of the process, in other words you have no obligation to continue or to complete any of the questionnaires if you are not able to do so, or if they cause discomfort. You may refuse to answer some of the questions. Please contact the researcher if you feel uncomfortable or feel the need to discuss issues related to your discomfort. The researcher will then refer you to an available professional in your area. Alternatively, you could contact FAMSA (0214477951, http://www.famsa.org.za) - an organisation dedicated to the development of families.

\section{POTENTIAL BENEFITS TO SUBJECTS AND/OR TO SOCIETY}

Academics, health professionals, every person who assists and helps families in which a member has been diagnosed with schizophrenia, as well as families with the same experiences will potentially benefit from this research. The researcher also hopes that any 'participant' in this research will truly 'participate'. In other words, that you as a participant will feel free to contact the researcher regarding any uncertainties, to find out how the research is developing, to give opinions and eventually ask to read the completed thesis. 


\section{PAYMENT FOR PARTICIPATION}

Participants in this research project will receive no payment.

\section{CONFIDENTIALITY}

Any information that is obtained in connection with this study and that can be identified with you will remain confidential and will be disclosed only with your permission, or as required by law. The completed questionnaires will be stored safely by the researcher and only she and her supervisor will have access to them. Your contact information will only be available to the researcher. To ensure confidentiality and anonymity, a code will be assigned to each questionnaire. The researcher will be the only person who will know which contact information and code corresponds to which questionnaire.

\section{PARTICIPATION AND WITHDRAWAL}

You may choose whether or not to be part of this study. If you volunteer to be part of this study, you may withdraw at any time without consequences of any kind. You may also refuse to answer any questions you do not want to answer and still remain in the study. The investigator may withdraw you from this research if circumstances arise that warrant doing so.

\section{IDENTITY OF INVESTIGATORS}

If you have any questions or concerns about the research, please feel free to contact the researcher or her supervisor. Their contact details are as follows:

Researcher: Melanie Bishop

Cell: 0824854951

E-mail: 15059448@sun.ac.za
Supervisor: Prof. A.P. Greeff

Tel. (work): (021) 8083464

E-mail: apg@sun.ac.za

\section{RIGHTS OF RESEARCH PARTICIPANTS}

You may withdraw your consent at any time and discontinue participation without penalty. You are not waiving any legal claims, rights or remedies because of your participation in this research study. If you have questions regarding your rights as a research subject, contact Ms Maléne Fouché [mfouche@sun.ac.za; 021808 4622], Division for Research Development, Stellenbosch University.

\section{SIGNATURE OF RESEARCH PARTICIPANT}

The information above was described to me, by in [Afrikaans/English/Xhosa/other] and I am in command of this language or it was satisfactorily translated to me. I was given the opportunity to ask questions and these questions were answered to my satisfaction. I hereby consent voluntarily to participate in this study. I have been given a copy of this form.

Name of Participant

Signature of Participant

Date

\section{SIGNATURE OF INVESTIGATOR}

I declare that I explained the information given in this document to $\mathrm{He} / \mathrm{she}$ was encouraged and given ample time to ask me any questions. This conversation was conducted in Afrikaans/English/Xhosa/other and no translator was used/this conversation was translated into by 


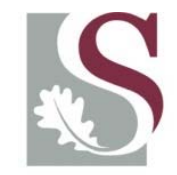

UNIVERSITEIT•STELLENBOSCH•UNIVERSITY

jou kennisvennoot your knowledge partner

\section{UNIVERSITEIT STELLENBOSCH INWILLIGING OM DEEL TE NEEM AAN NAVORSING}

\section{VEERKRAGTIGHEID IN GESINNE WAARVAN 'N GESINSLID MET SKISOFRENIE GEDIAGNOSEER} IS

U word genooi om deel te neem aan navorsing gedoen deur Melanie Bishop (BSc Honneurs Sielkunde) van die Departement Sielkunde aan die Universiteit Stellenbosch. Die navorsingsresultate sal gebruik word om 'n navorsingstesis te voltooi ter vervulling van die graad MSc (Sielkunde). $\mathrm{U}$ is as moontlike deelnemer aan die studie gekies omdat u gesin 'n lid het wat met skisofrenie gediagnoseer is.

\section{DOEL VAN DIE STUDIE}

In hierdie studie word daar gekyk na die veerkragtigheid van gesinne waarin 'n lid met skisofrenie gediagnoseer is. Veerkragtigheid verwys na die maniere waarop gesinne daarin slaag om aan te beweeg met hul lewens, ten spyte van traumatiese en stresvolle gebeurtenisse. Die navorser glo dat u bydrae tot die studie ander gesinne kan help wat soortgelyke ervarings het.

\section{PROSEDURES}

Indien $\mathrm{u}$ inwillig om aan die studie deel te neem, vra ons dat $\mathrm{u}$ die volgende doen:

1) Bereid wees om 'n biografiese vraelys te voltooi.

a. Dié vraelys behoort nie langer as tien minute te neem om te voltooi nie.

b. Die vrae sal betrekking hê op die samestelling van u gesin, u ouderdom, geslag, huwelikstatus, bevolkingsgroep, godsdiens, huistaal, maandelikse huishoudelike inkomste, opvoedkundige kwalifikasies, woonarea, die ouderdom van u gesinslid wat gediagnoseer is, sowel as sy/haar ouderdom met diagnose en wanneer die diagnose gedoen is.

2) Bereid wees om 'n stel vraelyste te voltooi oor ' $n$ verskeidenheid van prosesse in die gesin, soos die binding tussen gesinslede; roetines en aktiwiteite van die gesin; die gesin se ondersteuningsisteem/sisteme; interaksie tussen gesinslede en die gemeenskap; hoe die gesin probleme hanteer; en die belangrikheid van vriende vir die gesin.

Die voltooiing van dié vraelyste behoort nie langer as 'n halfuur te neem nie en die vraelyste sal in Afrikaans en Engels beskikbaar wees.

3) Die navorser is deurentyd beskikbaar om u vrae te beantwoord indien $u$ onseker is oor enige aspekte m.b.t. die invul van die vraelyste.

4) U moet asb die vraelyste aan die navorser terug pos (die navorser sal koeverte en seëls verskaf).

\section{MOONTLIKE RISIKO'S EN ONGEMAKLIKHEID}

Sommige van die items in die vraelyste mag dalk ongemak veroorsaak. Wees egter gerus dat u die verloop van die proses bepaal, m.a.w. u het geen verpligting om met die voltooiing van die vraelyste voort te gaan nie. U mag ook weier om sekere van die vrae te beantwoord. Kontak asb. die navorser as u enige ongemak voel of die behoefte het om hierdie ongemak te bespreek. Die navorser sal u verwys na ' $n$ beskikbare professionele persoon in u area. Alternatiewelik kan u gerus kontak maak met FAMSA (021-4477851, http://www.famsa.org.za) - 'n organisasie wat professionele dienste lewer in die ontwikkleing van gesinne.

\section{MOONTLIKE VOORDELE VIR DEELNEMERS EN/OF DIE SAMELEWING}

Akademici, werkers in die geestesgesondheidsektor, alle mense wat gesinne bystaan om aan te pas nadat 'n gesinslid met skisofrenie gediagnoseer is, asook gesinne wat dieselfde ervarings beleef, behoort baat te vind by die uitslae van die studie. Voorts hoop die navorser dat 'n "deelnemer" aan 'n navorsingsprojek werklik daaraan mag "deelneem". In dié opsig is u welkom om my te kontak om te hoor hoe die studie verloop, om wenke te gee en u mag gerus ook vra om die voltooide tesis te lees. 


\section{VERGOEDING VAN DEELNAME}

Deelnemers aan hierdie navorsingsprojek sal geen vergoeding ontvang nie.

\section{VERTROULIKHEID}

Enige inligting wat deur middel van die navorsing verkry word en wat met $\mathrm{u}$ in verband gebring kan word, sal vertroulik bly en slegs met u toestemming bekend gemaak word, of soos deur die wet vereis. Die voltooide vraelyste sal veilig bewaar word deur die navorser en slegs sy en haar studieleier sal toegang hê daartoe. U kontakbesonderhede sal slegs aan die navorser bekend wees. Om vertroulikheid en anonimiteit te verseker, sal daar 'n kode aan elke vraelys geheg word. Die navorser sal die enigste persoon wees wat weet na watter vraelys die kodes en kontakbesonderhede verwys.

\section{DEELNAME EN ONTTREKKING}

$\mathrm{U}$ kan self besluit of $u$ aan die studie wil deelneem of nie. Indien $u$ inwillig om aan die studie deel te neem, mag $u$ te eniger tyd $u$ daaraan onttrek sonder enige nadelige gevolge. $U$ mag ook weier om bepaalde vrae te antwoord, maar nog steeds aan die studie deelneem.

\section{IDENTITEIT VAN ONDERSOEKERS}

Indien $\mathrm{u}$ enige vrae of besorgdheid omtrent die navorsing het, staan dit $\mathrm{u}$ vry om met die navorser of haar studieleier in verbinding te tree. Hulle kontakbesonderhede is soos volg:

Navorser: Melanie Bishop

Sel: 0824854951

E-pos: 15059448@sun.ac.za
Studieleier: Prof. A.P. Greeff

Kantoor tel: (021) 8083464

E-pos: apg@sun.ac.za

\section{REGTE VAN DEELNEMERS AAN NAVORSING}

$\mathrm{U}$ kan te eniger tyd $\mathrm{u}$ inwilliging terugtrek en $\mathrm{u}$ deelname beëindig sonder enige nadelige gevolge vir $\mathrm{u}$. Deur aan die navorsing deel te neem doen u geensins afstand van enige wetlike regte, eise of regsmiddel nie. Indien $\mathrm{u}$ vrae het oor u regte as navorsingsubjek, skakel met Maléne Fouché (mfouche@sun.ac.za; 021808 4622), Afdeling Navorsingsontwikkeling, Universiteit Stellenbosch.

\section{VERKLARING DEUR DEELNEMER}

Die bostaande inligting is aan my, , deur in

Afrikaans/English/Xhosa/ander verskaf en verduidelik en ek is dié taal magtig of dit is bevredigend vir my vertaal. Ek is die geleentheid gebied om vrae te stel en my vrae is tot my bevrediging beantwoord. Ek willig hiermee vrywillig in om deel te neem aan die studie. 'n Afskrif van hierdie vorm is aan my gegee.

Naam van deelnemer

Handtekening van deelnemer

Datum

\section{VERKLARING DEUR ONDERSOEKER}

Ek verklaar dat ek die inligting in hierdie dokument vervat verduidelik het aan $\mathrm{Hy} / \mathrm{sy}$ is aangemoedig en oorgenoeg tyd gegee om vrae aan my te stel. Dié gesprek is in Afrikaans/English/Xhosa/ander gevoer en geen vertaler is gebruik nie/die gesprek is in vertaal deur 


\section{APPENDIX D}

\section{Instructions}

Dear Participant,

Thank you for agreeing to participate in this research project.

Please sign the informed consent form and complete the biographical questionnaire. Please note that there is a question at the back of the biographical questionnaire which should be completed. There is also a set of questionnaires included in this package which should be completed.

Please read the instructions at the top of each questionnaire carefully and circle the number which best describe your family. There is no 'right' or 'wrong' answer and it is important that you answer all the questions. Don't think too much about an answer. On completion of all the questionnaires, please put everything into the same envelope given to you and send it via post to the researcher.

Please make sure that all the forms are completed by completing the checklist below before sending the information back to the researcher:

\begin{tabular}{|l|l|}
\hline \multicolumn{2}{|c|}{ Checklist } \\
\hline INFORMED CONSENT & \\
\hline BIOGRAPHICAL QUESTIONNAIRE AND QUESTION AT THE BACK & \\
\hline ALL QUESTIONNAIRES (printed back to back) & \\
\hline
\end{tabular}

If you have any questions or concerns about the research, please feel free to contact the researcher or her supervisor. Their contact details are as follows:

Researcher: Melanie Bishop

Cell: 0824854951

E-mail: 15059448@sun.ac.za
Supervisor: Prof. Awie Greeff

Tel. (work): (021) 8083464

E-mail: apg@sun.ac.za

Kindest regards, Melanie Bishop 


\section{Instruksies}

Geagte Deelnemer,

Baie dankie vir u bereidwilligheid om deel te neem aan hierdie studie.

$\mathrm{U}$ moet asb. die ingeligte toestemmingsbrief onderteken asook die biografiese vraelys voltooi. Maak seker dat u ook die vraag op die agterkant van die biografiese vraelys voltooi. Daarna moet $u$ asb. al die vraelyste voltooi wat in hierdie pakkie ingesluit is.

Lees asb. al die instruksies bo-aan die vraelyste noukeurig deur en omkring dié nommer wat die beste u gesin beskryf. Daar is geen 'regte' of 'verkeerde' antwoord nie en dit is belangrik dat $\mathrm{u}$ al die vrae beantwoord. Moenie te lank oor ' $n$ antwoord dink nie. Nadat $u$ al die vraelyste voltooi het, kan $\mathrm{u}$ al die dokumente in dieselfde koevert wat aan u gegee is plaas en per pos terugstuur aan die navorser.

$\underline{\text { Kontroleer asb. dat u al die dokumente voltooi het deur hierdie kontrole-lys na te gaan, }}$ voordat $\mathrm{u}$ die voltooide vorms terugstuur aan die navorser.

\begin{tabular}{|l|l|}
\hline \multicolumn{2}{|c|}{ Kontrole-lys } \\
\hline INGELIGTE TOESTEMMING & \\
\hline BIOGRAFIESE VRAELYS & \\
\hline ALLE VRAELYSTE (Voor en agterop elke blad gedruk) & \\
\hline
\end{tabular}

Indien $u$ enige vrae of besorgdheid omtrent die navorsing het, moet asb. nie huiwer om met die navorser of haar studieleier in verbinding te tree nie. Hulle kontakbesonderhede is soos volg:

Navorser: Melanie Bishop

Sel: 0824854951

E-pos: 15059448@sun.ac.za
Studieleier: Prof. Awie Greeff

Kantoor tel: (021) 8083464

E-pos: apg@sun.ac.za

Vriendelike Groete, Melanie Bishop 


\section{APPENDIX E}

Figures of results from the mixed model repeated measures ANOVA and the ANOVA

\section{A. Results from the mixed model repeated measures ANOVA}

Figure 5a Differences at the F-COPES subscale: Family mobilization

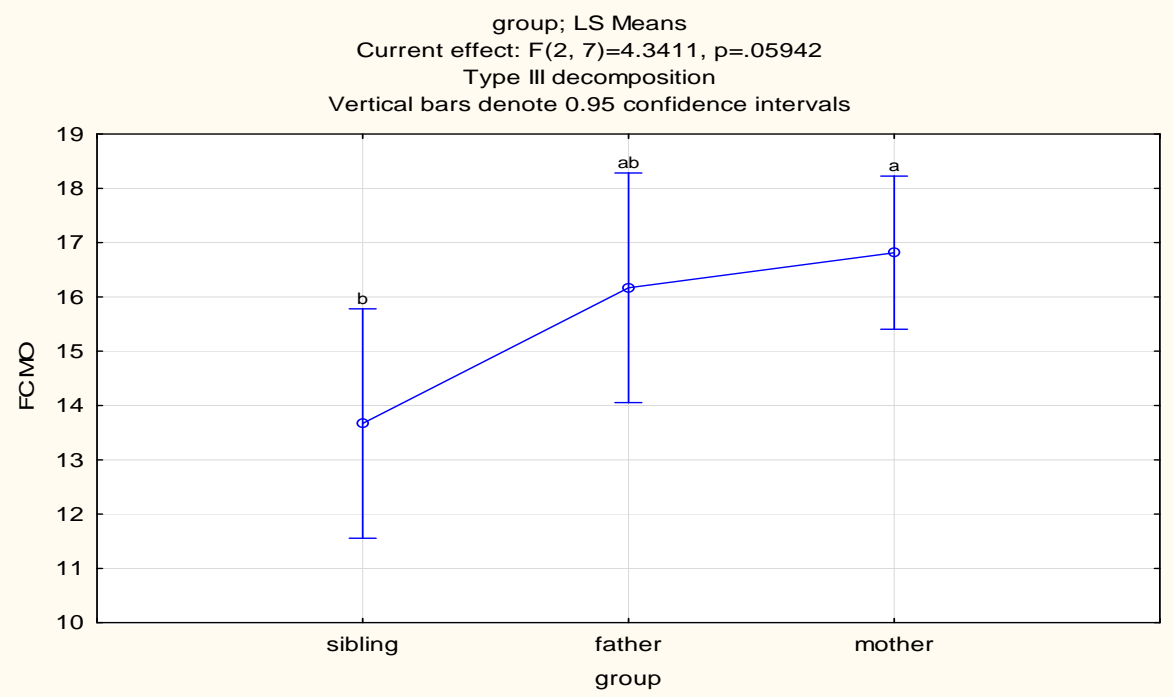

Figure $5 a$ The results of the mixed model repeated measures ANOVA shows significant differences between siblings and mothers in the F-COPES subscale: Family mobilization

Figure 5b.1 Differences at the FTRI Couple togetherness subscale

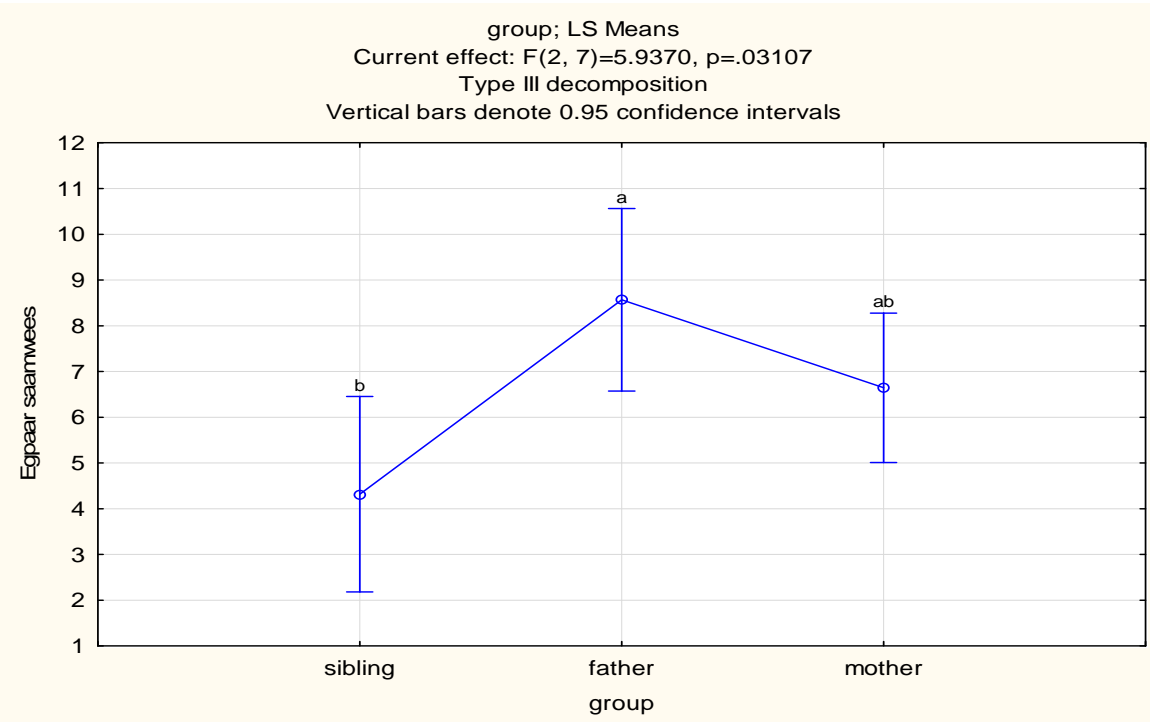

Figure 5b.1 The results of the mixed model repeated measures ANOVA shows significant differences between fathers and siblings with responses to the FTRI Couple togetherness subscale. 
Figure 5b.2 Differences at the FTRI Meals together subscale

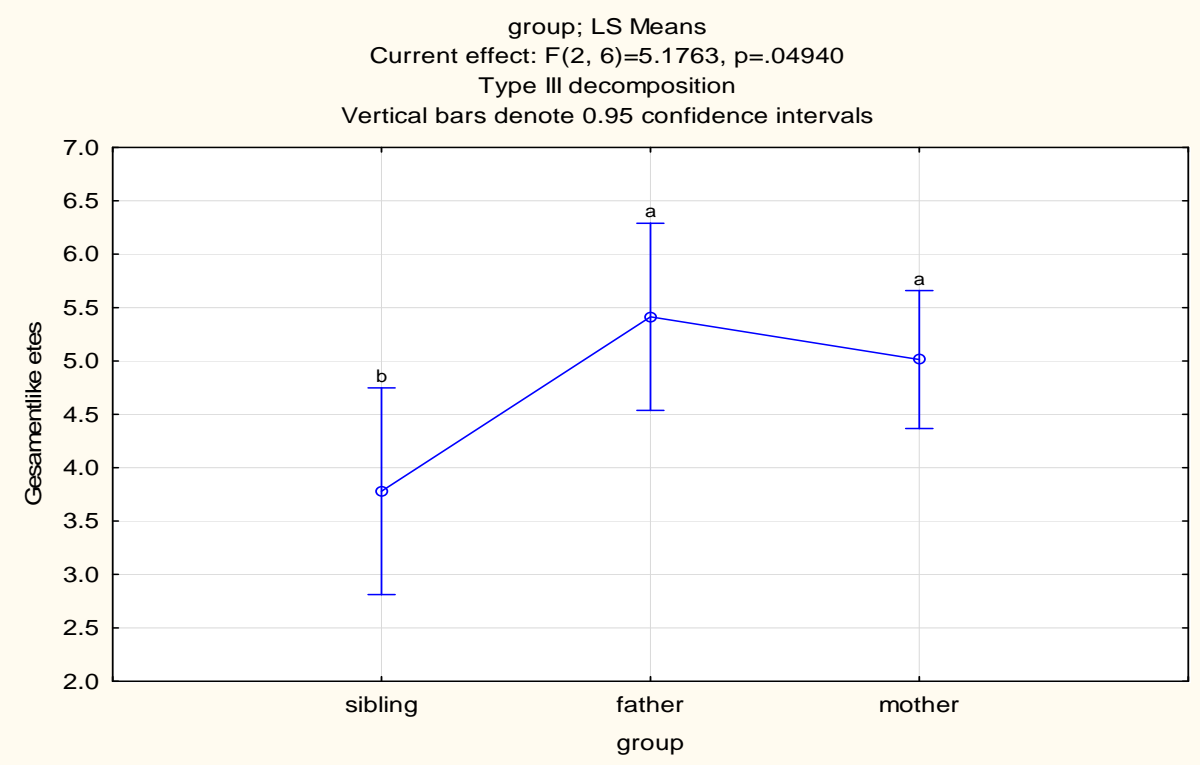

Figure 5b.2 The results of the mixed model repeated measures ANOVA shows significant differences between the groups' responses (mothers and siblings; and fathers and siblings) on the FTRI Meals together subscale.

Figure 5b.3 Differences at the FTRI Parent-child togetherness subscale

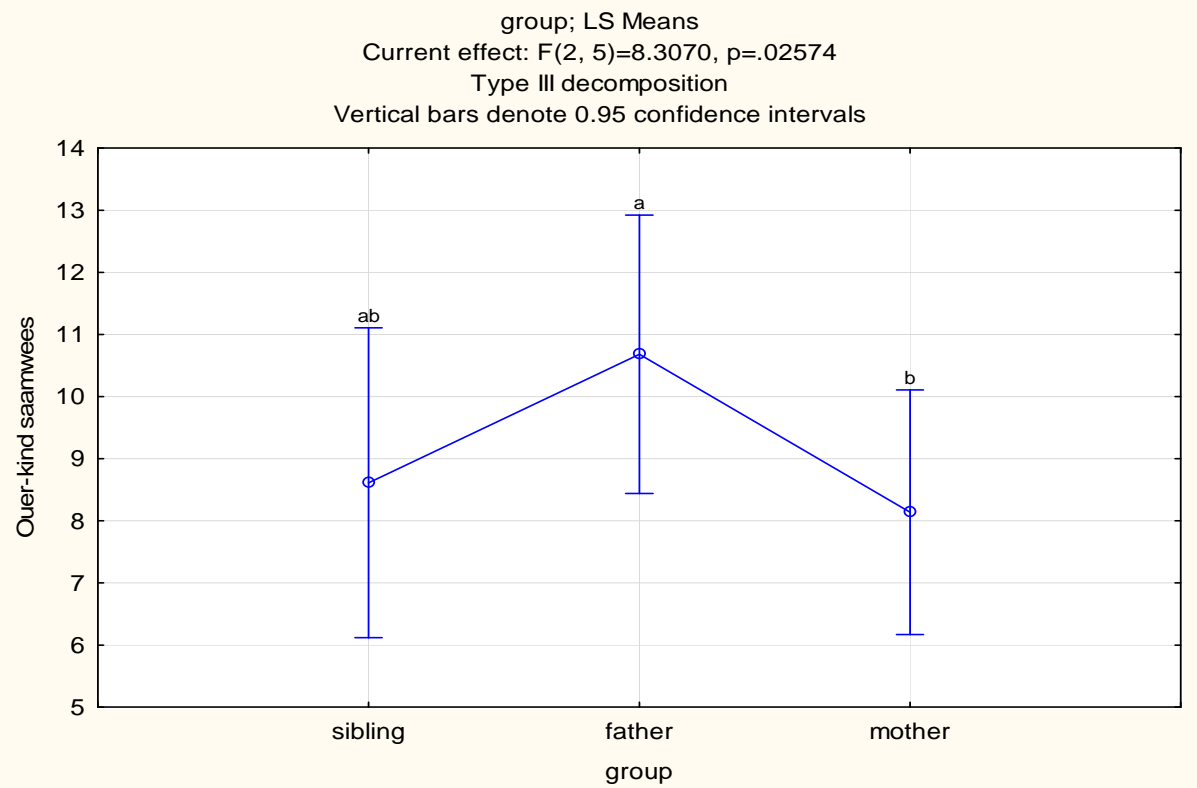

Figure $5 b .3$ The results of the mixed model repeated measures ANOVA shows significant differences between the mothers and fathers' responses on FTRI Parent-child togetherness subscale. 
Figure 5b.4 Differences at the FTRI: Family management subscale

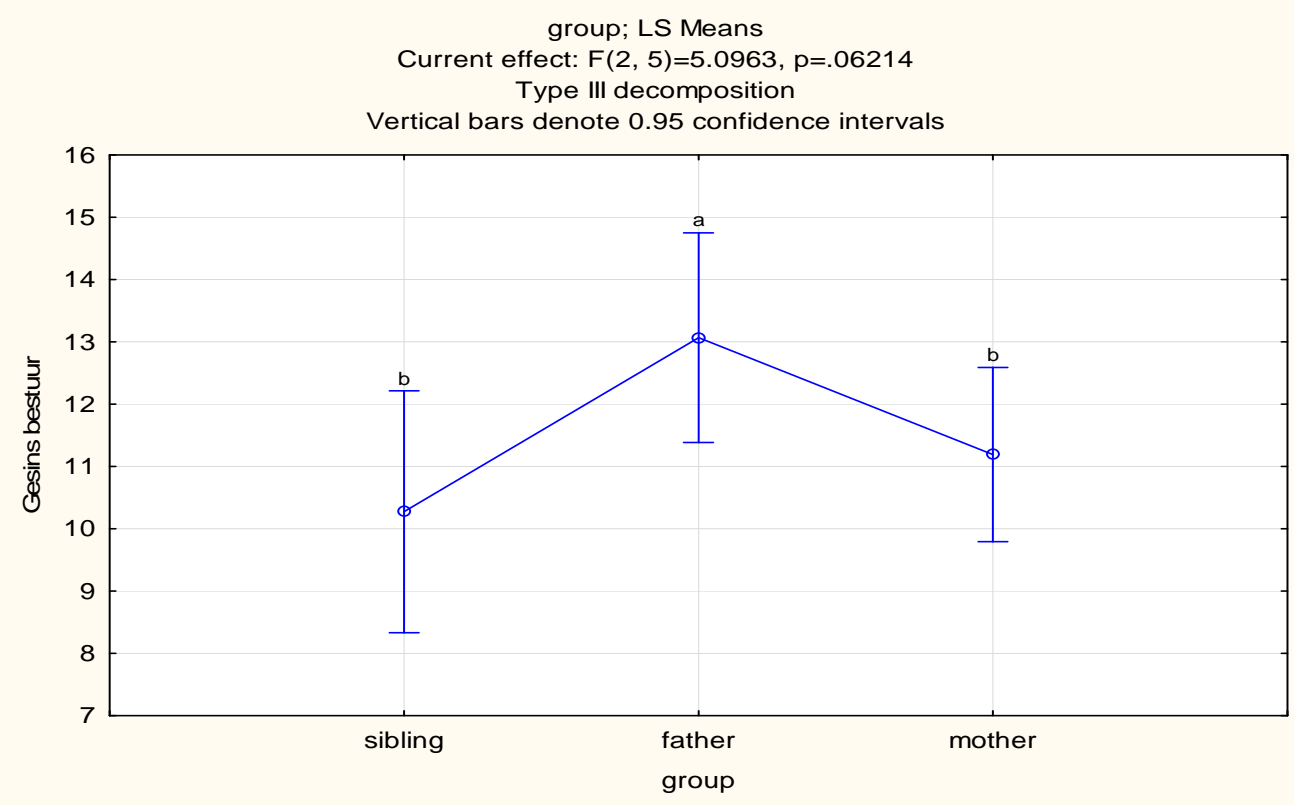

Figure $5 b .4$ The results of the mixed model repeated measures ANOVA shows significant differences between groups on the FTRI: Family management subscale.

\section{B. Results from the ANOVA}

Figure 1.1 Difference at the F-COPES Social support subscale

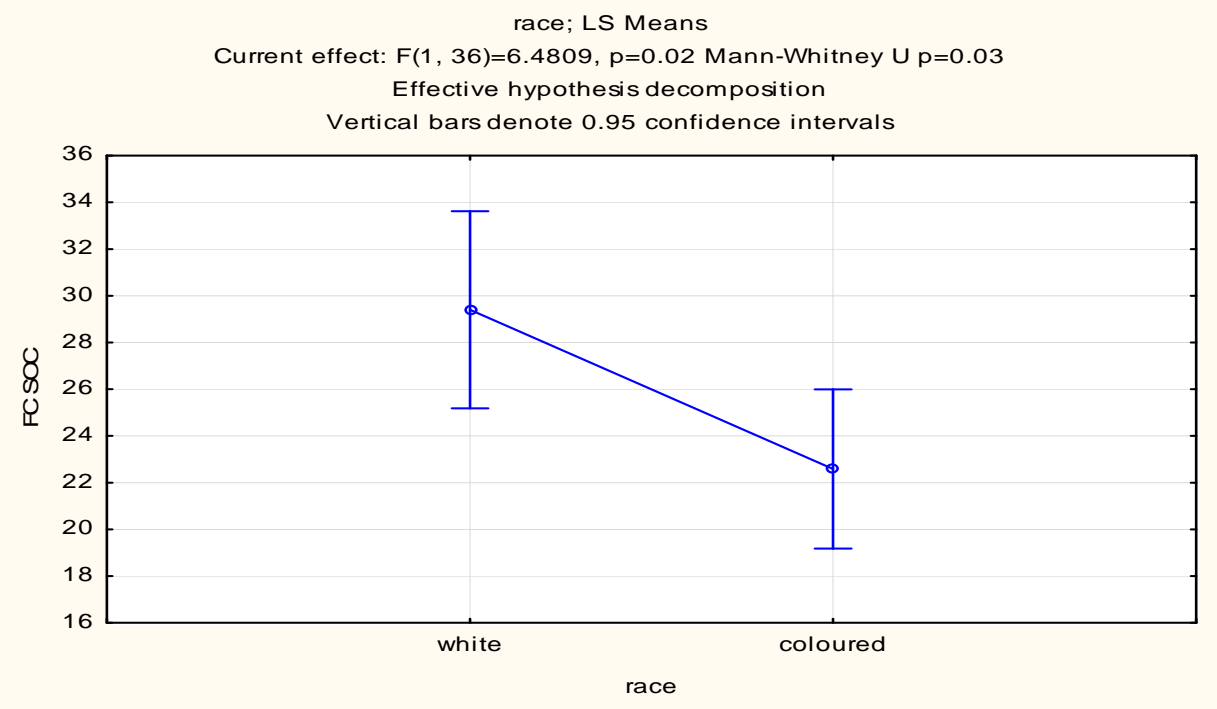

Figure 1.1 The results of the ANOVA shows significant difference between the white and coloured races (F-COPES Social support, $\mathrm{p}=0.02$ ). 
Figure 1.2 Difference between language groups at the F-COPES Reframing subscale

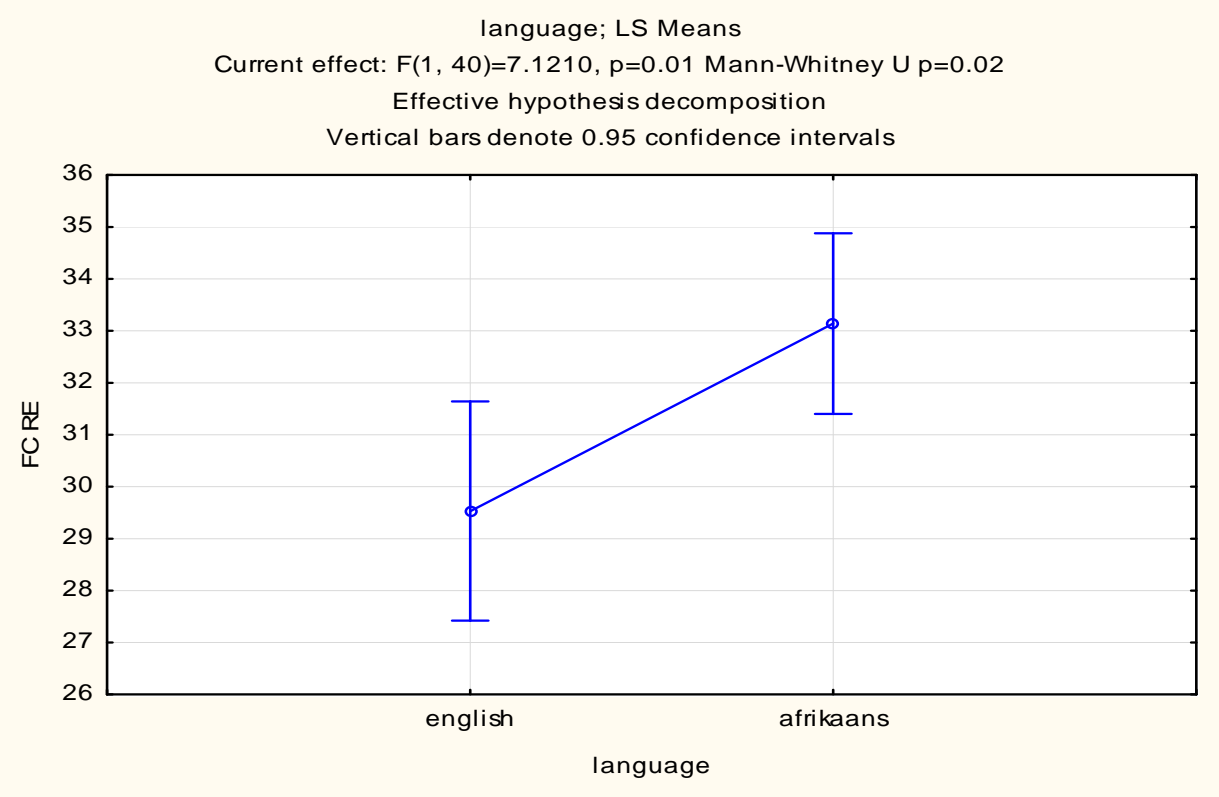

Figure 1.2 The results of the ANOVA shows a significant difference between the Afrikaans and English households (F-COPES Reframing, $\mathrm{p}=0.01$ ).

Figure 1.3.1 Difference between race groups at the F-COPES Spiritual support subscale

race; LS Means

Current effect: $F(1,36)=11.863, p=<0.01$ Mann-Whitney $U p<0.01$

Effective hypothesis decomposition

Vertical bars denote 0.95 confidence intervals

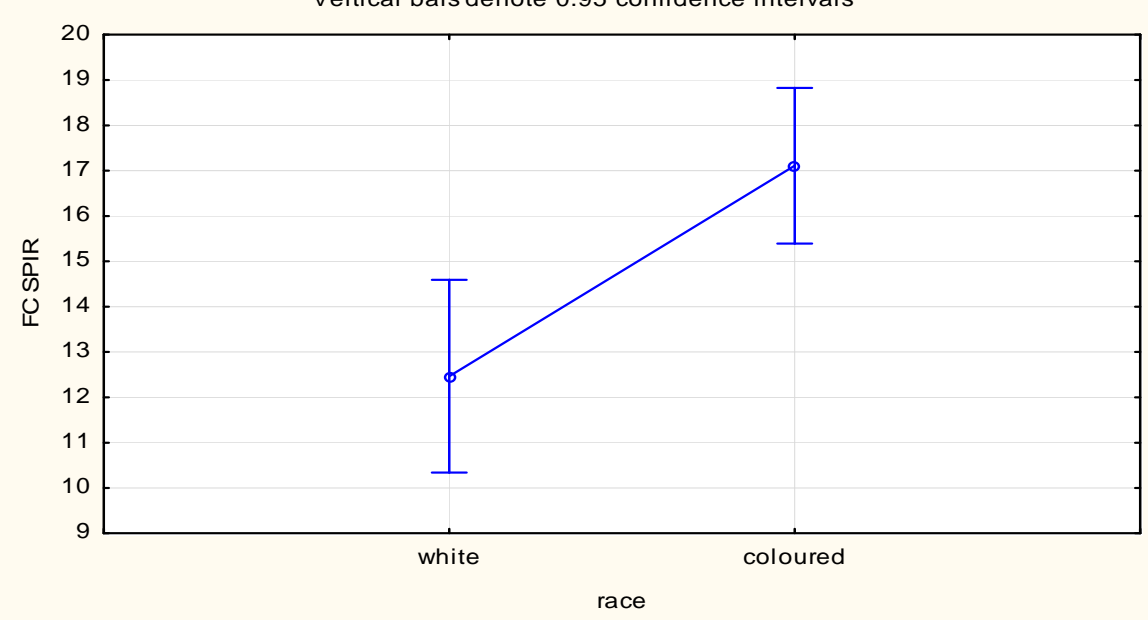

Figure 1.3.1 The results of the ANOVA shows a significant difference between white and coloured families (F-COPES Spiritual support, $\mathrm{p}<0.01$ ). 
Figure 1.3.2 Difference between language groups at the F-COPES Spiritual support subscale

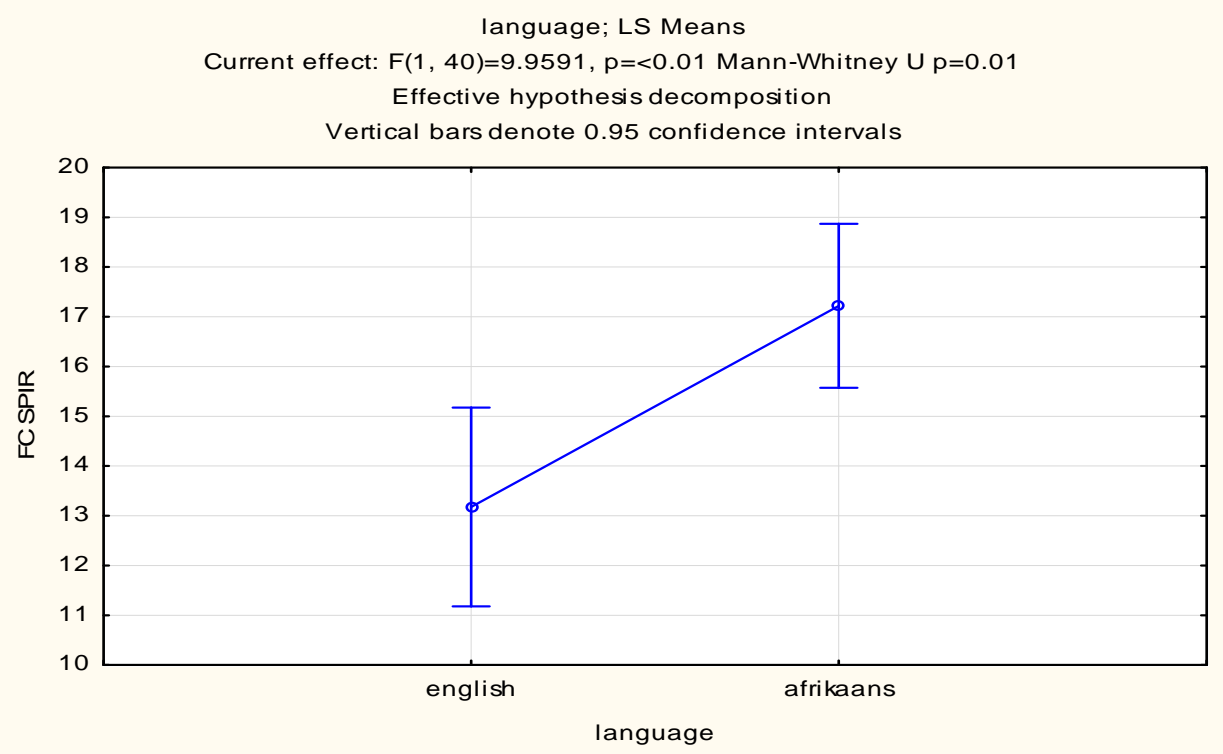

Figure 1.3.2 The results of the ANOVA shows a significant difference between English and Afrikaans speaking families (F-COPES Spiritual support, $\mathrm{p}<0.01$ ).

Figure 1.3.3 Differences between family structures at the F-COPES Spiritual support subscale

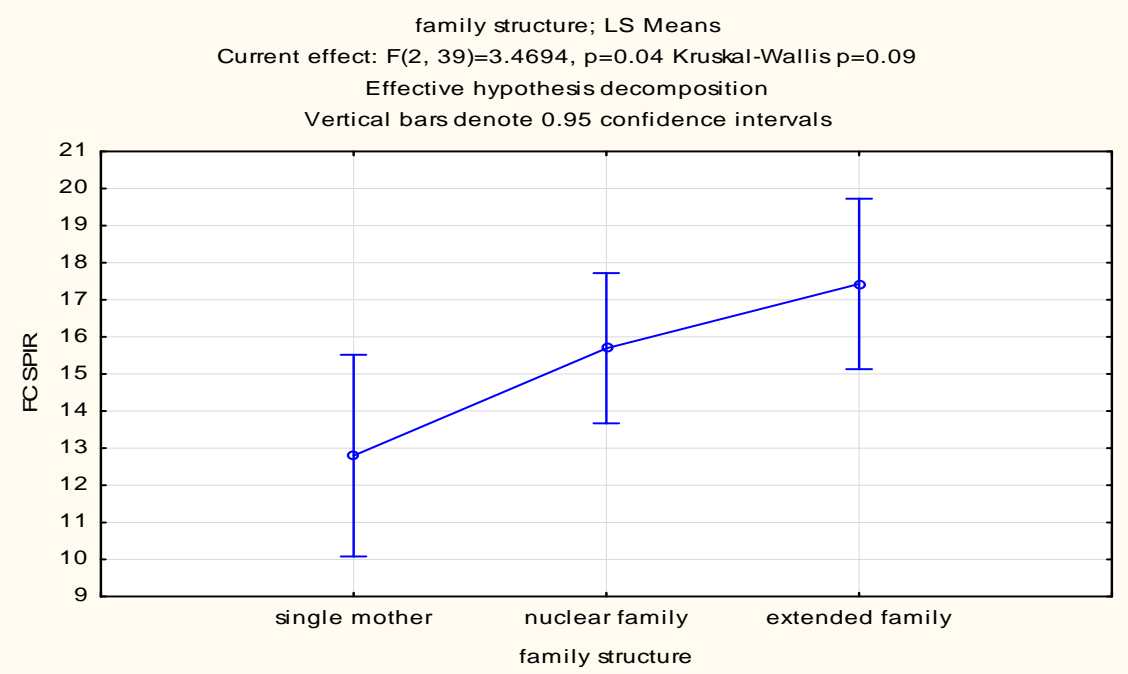

Figure 1.3.3 The results of the ANOVA shows significant difference between family structures (F-COPES Spiritual support, $\mathrm{p}=0.04$ ). LSD post-hoc testing revealed significant differences between the single mother households and the extended family $(p=0.01)$, with the extended family households having significantly higher scores than the single mother households. 
Figure 1.3.4 Differences between household income groups at the F-COPES Spiritual support subscale

income 2 groups; LS Means

Current effect: $F(1,40)=10.952, p=<0.01$ Mann-Whitney $U p<0.01$

Effective hypothesis decomposition

Vertical bars denote 0.95 confidence intervals

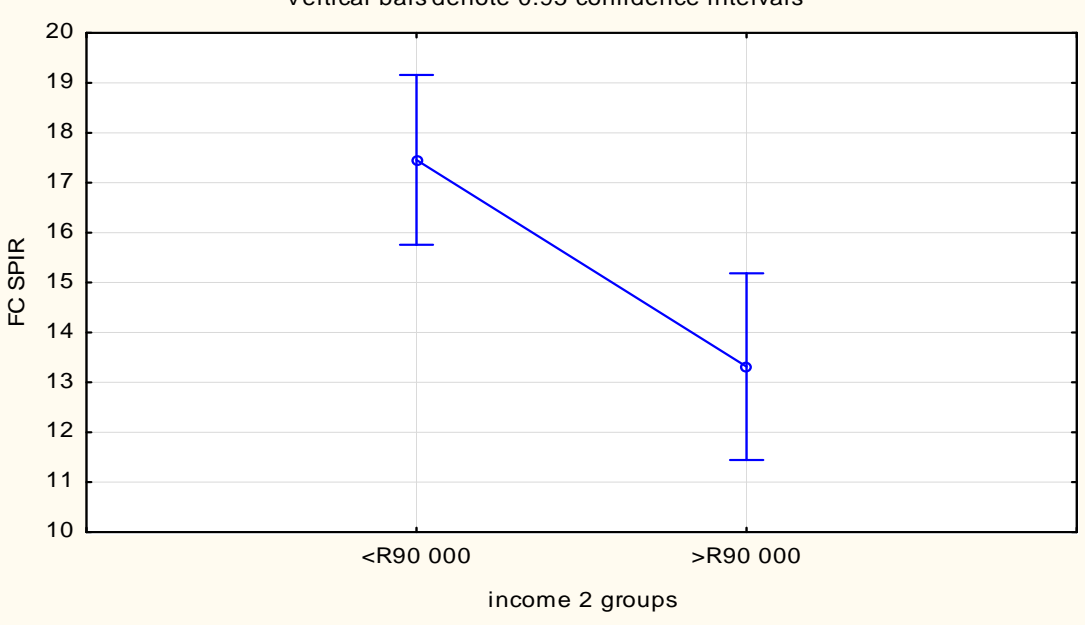

Figure 1.3.4 The results of the ANOVA shows significant difference between the two household income groups ( $<$ R90 000 and $>$ R90 000 per year) (F-COPES Spiritual support, $\mathrm{p}<0.01)$.

Figure 1.4 Difference between language groups at the F-COPES Family mobilization subscale

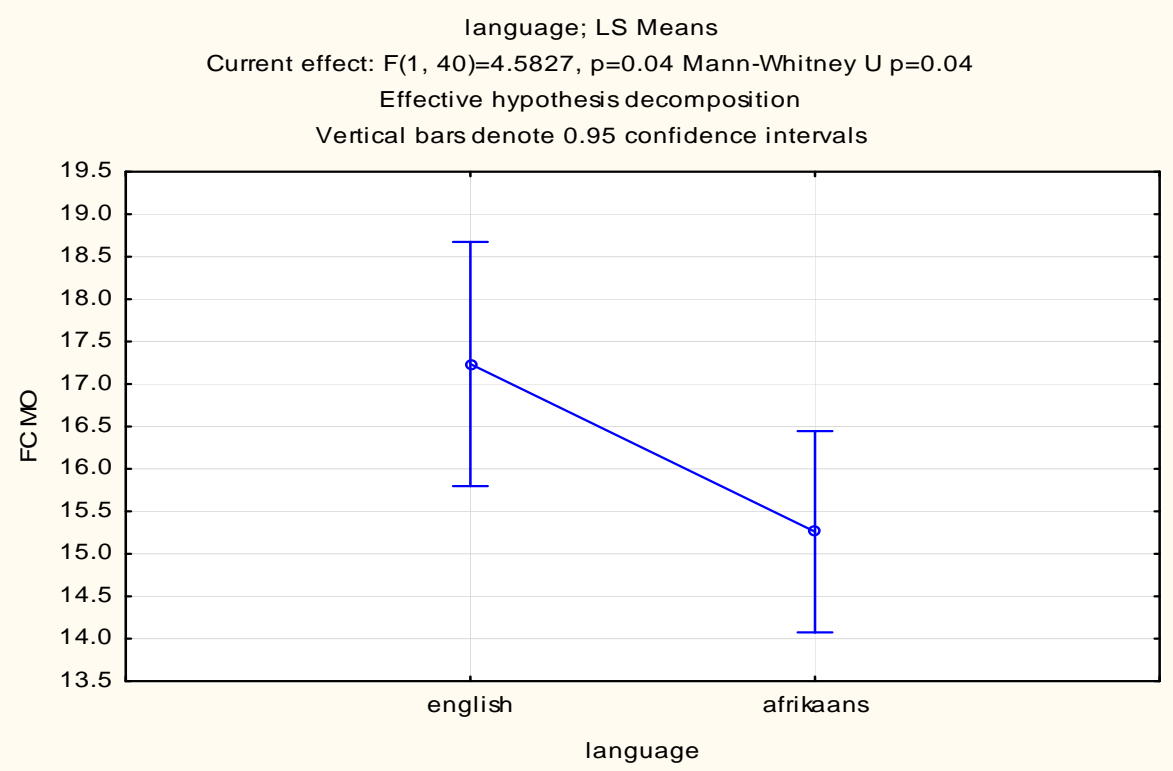

Figure 1.4 The results of the ANOVA shows significant difference between the two language groups (F-COPES: Family mobilization subscale, $p=0.04$ ). 
Figure 1.5.1 Differences between race groups at the F-COPES Passive appraisal subscale

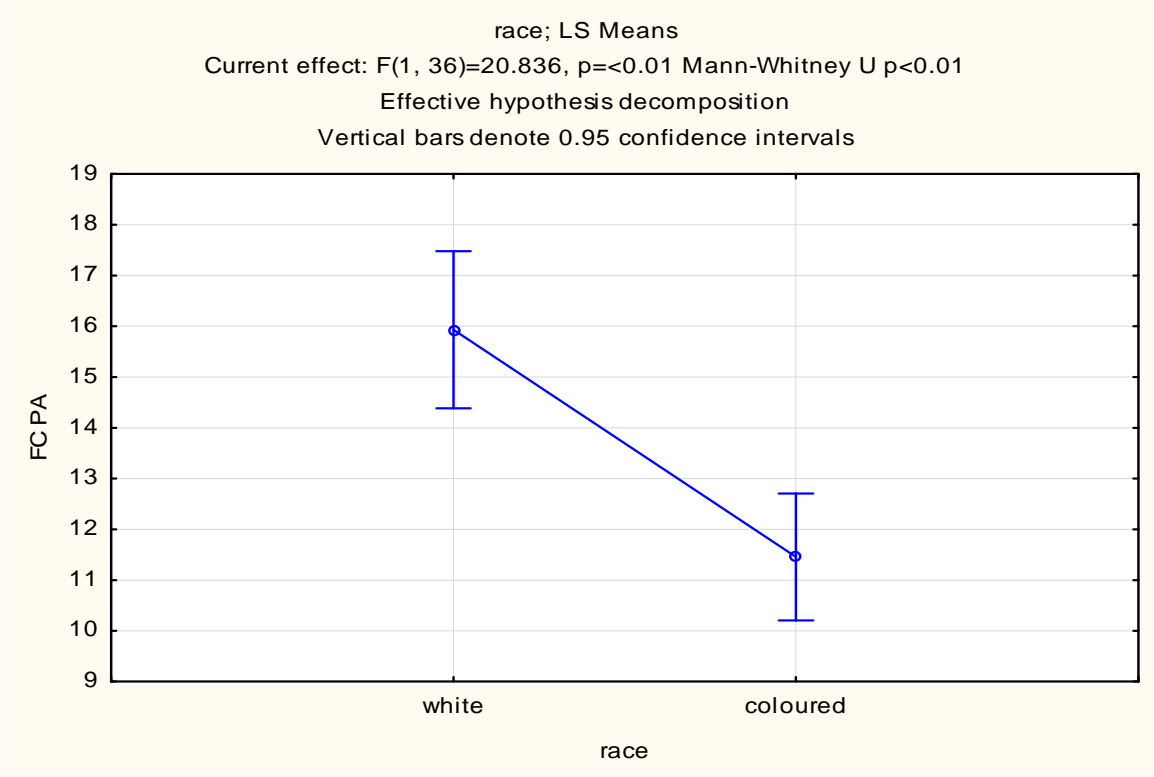

Figure 1.5.1 The results of the ANOVA shows a significant difference between the race groups, white and coloured (F-COPES Passive appraisal subscale, $\mathrm{p}<0.01$ ).

Figure: 1.5.2 Difference between language groups at the F-COPES Passive appraisal subscale

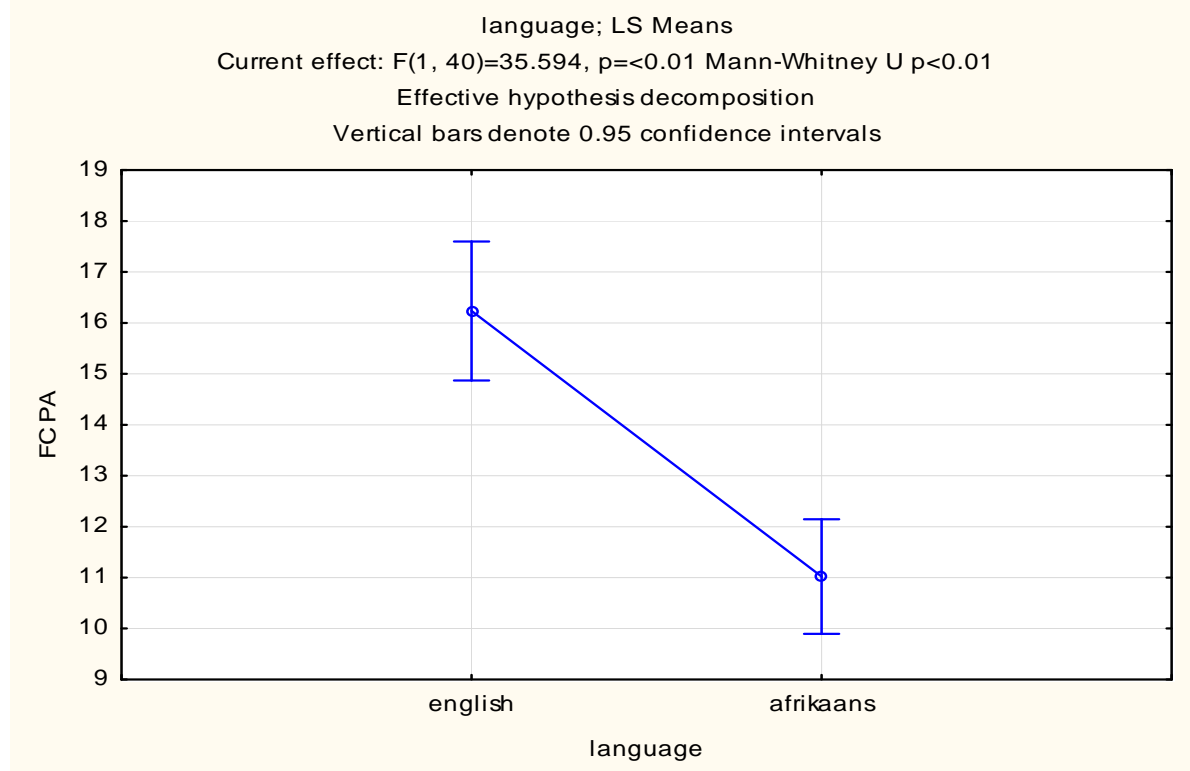

Figure: 1.5.2 The results of the ANOVA shows a significant difference between the two language groups (F-COPES Passive appraisal, $\mathrm{p}<0.01$ ). 
Figure 1.5.3 Difference between the income groups at F-COPES Passive appraisal subscale

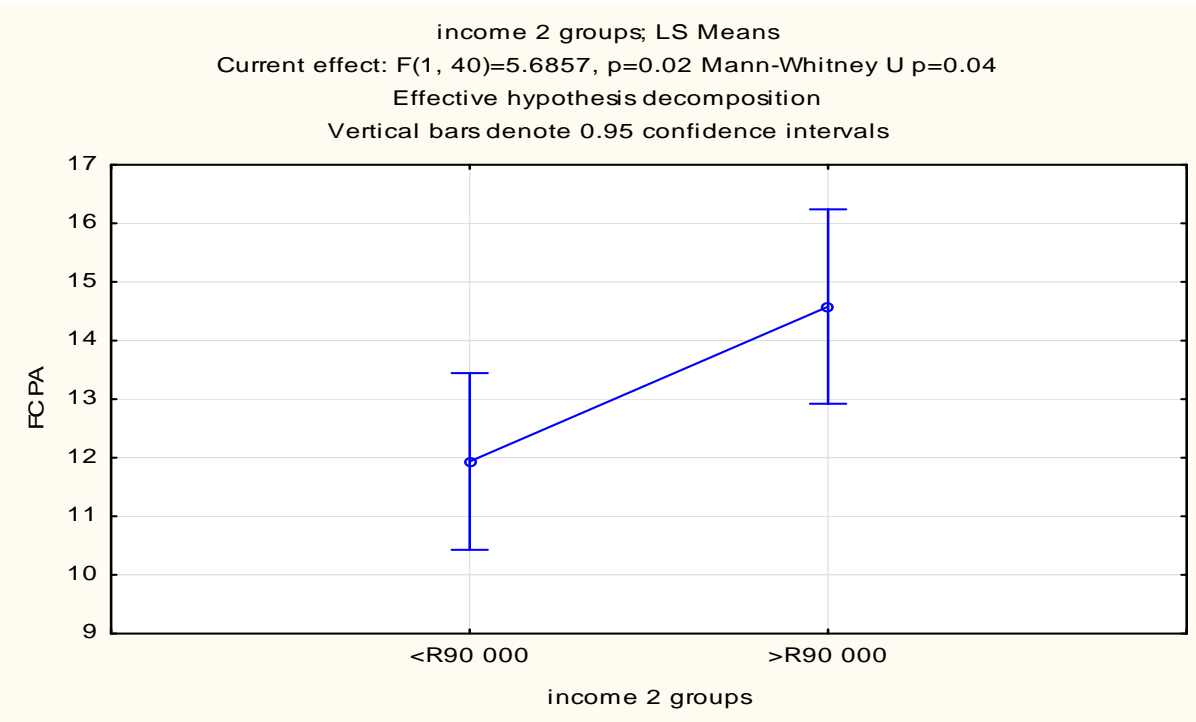

Figure 1.5.3 The results of the ANOVA shows significant difference between the two income groups were calculated (F-COPES Passive appraisal subscale, $\mathrm{p}=0.02$ ).

Figure 2 Differences between family structures at the FTRI Important

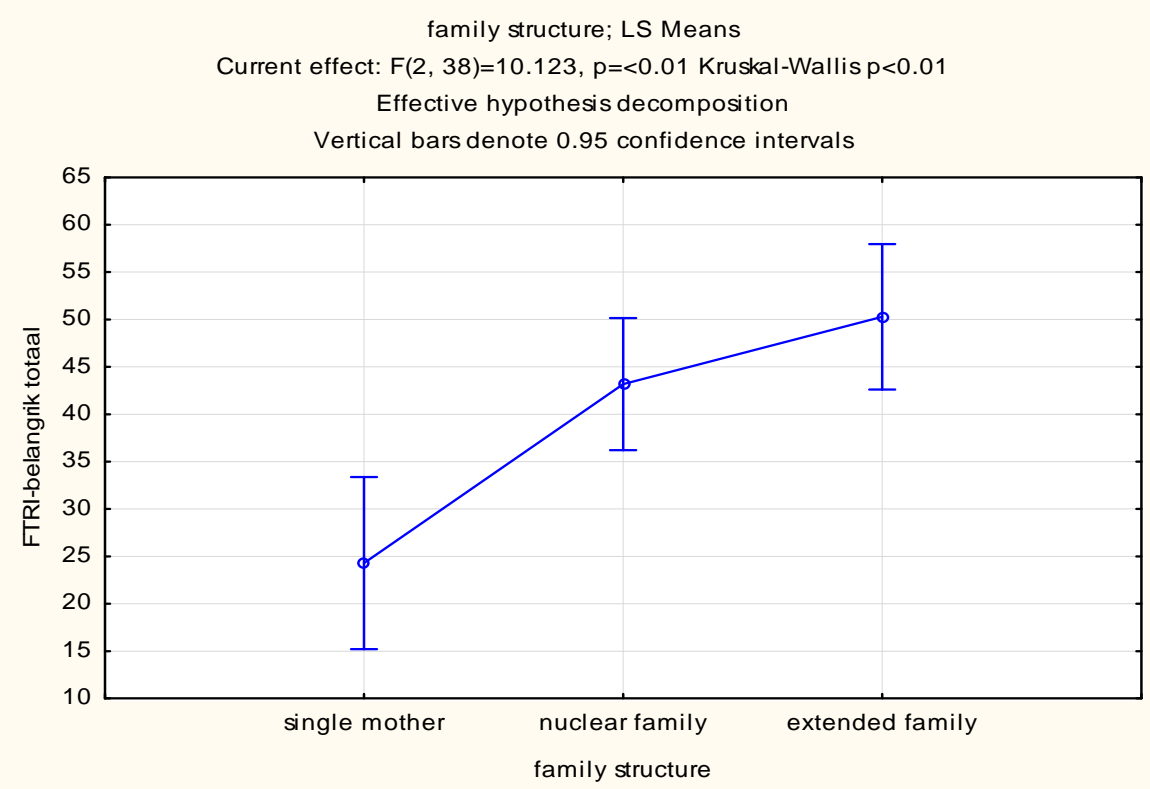

Figure 2 The results of the ANOVA shows significant difference between family structures. The LSD post- hoc testing revealed a significant difference between the single mother and nuclear families $(\mathrm{p}<0.01)$. Another significant difference with the post-hoc testing revealed a significant difference between the single mother and extended family household structures $(\mathrm{p}<0.001)$. 
Figure 3 Differences between language groups at the FPSC Incendiary subscale

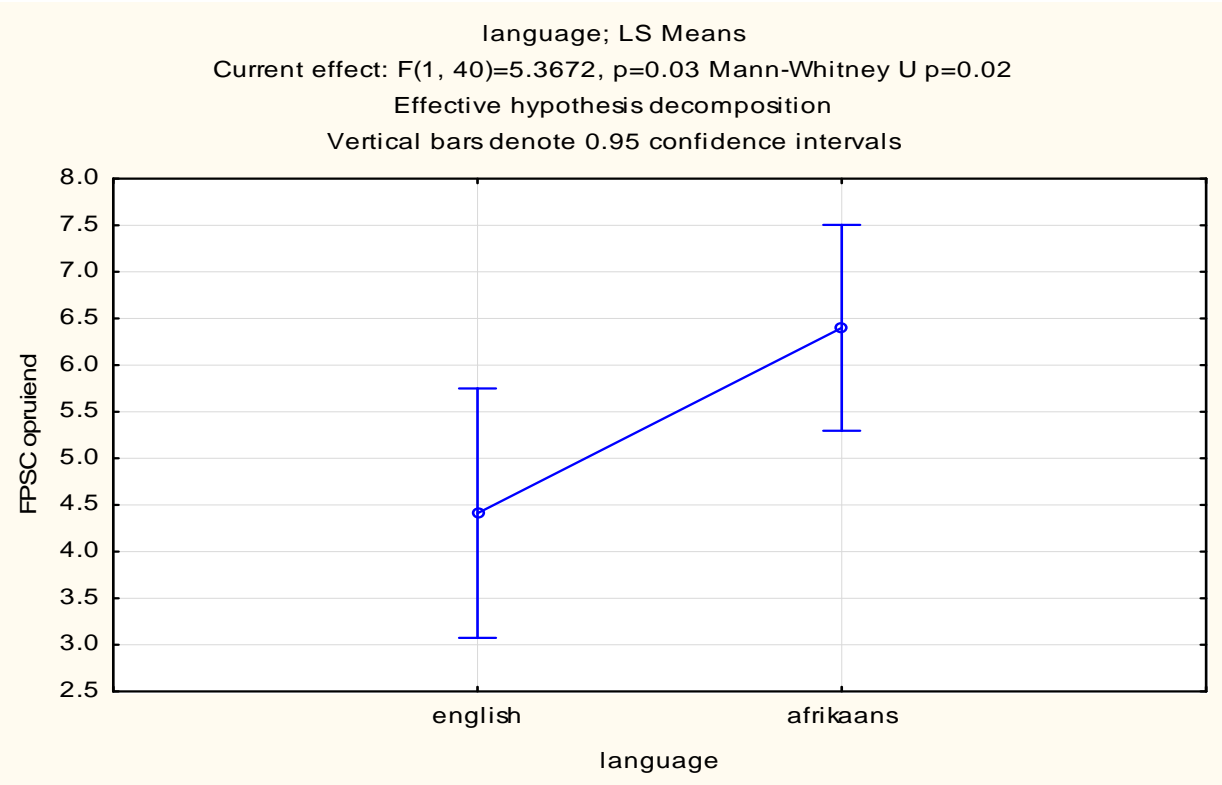

Figure 3 The results of the ANOVA shows a significant difference between the two language groups, with the Afrikaans households having a significantly higher score on this subscale than the English speaking participants (FPSC Incendiary, $p=0.03$ ).

Figure 4.1 Difference between language groups at the FHI Control subscale

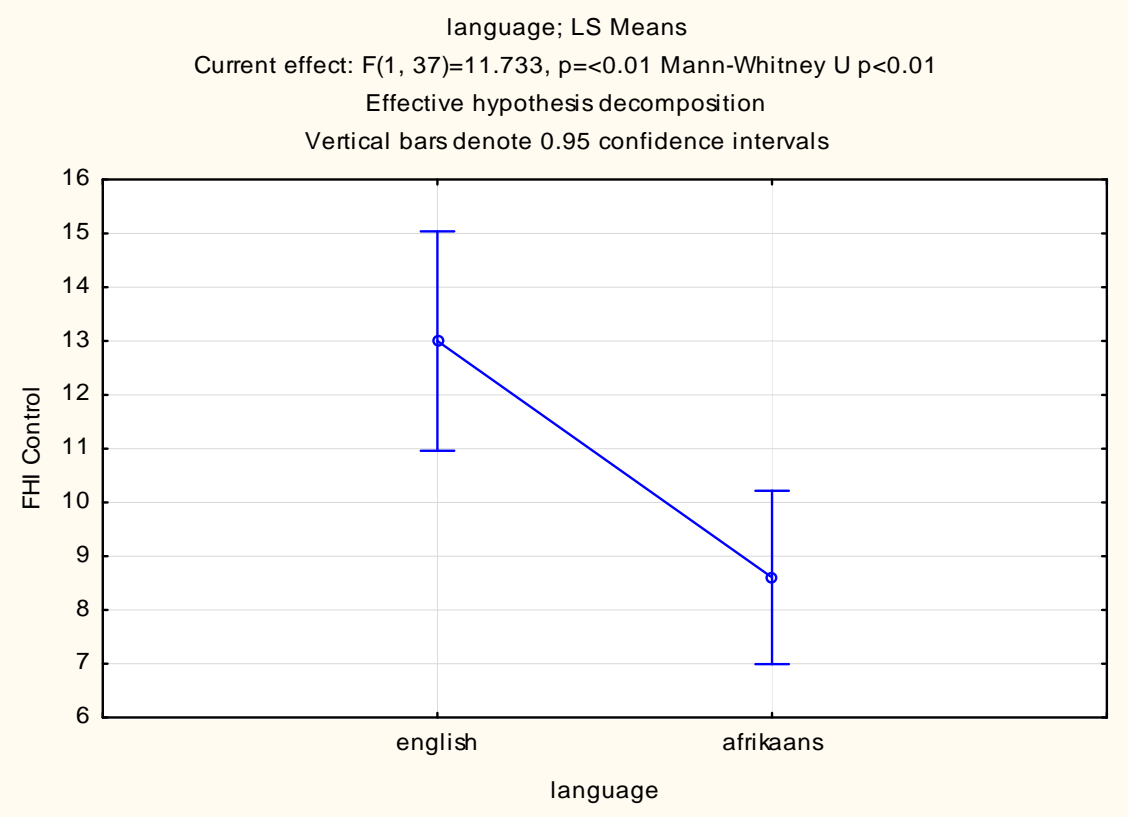

Figure 4.1 The results of the ANOVA shows a significant difference between the English and Afrikaans speaking families (FHI Control subscale, $p<0.01$ ). 
Figure 4.2 Differences between family structures at the FHI Control subscale

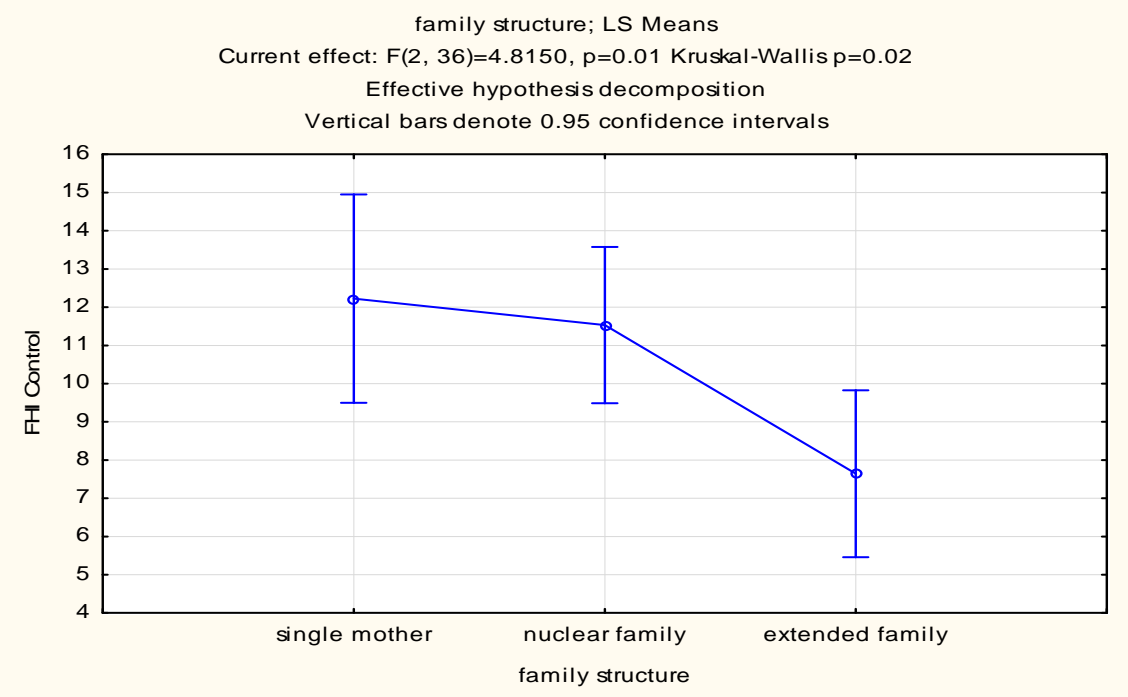

Figure 4.2 The results of the ANOVA shows significant differences between family structures (FHI Control subscale, $\mathrm{p}=0.01$ ). The LSD post-hoc testing revealed significant differences between the extended families and single mother families $(p=0.01)$, as well as between the extended families and nuclear families $(p=0.01)$. In both instances, the extended families revealed a significantly lower score on this subscale than the other two families.

Figure 4.3 Difference between income groups at the FHI Control subscale

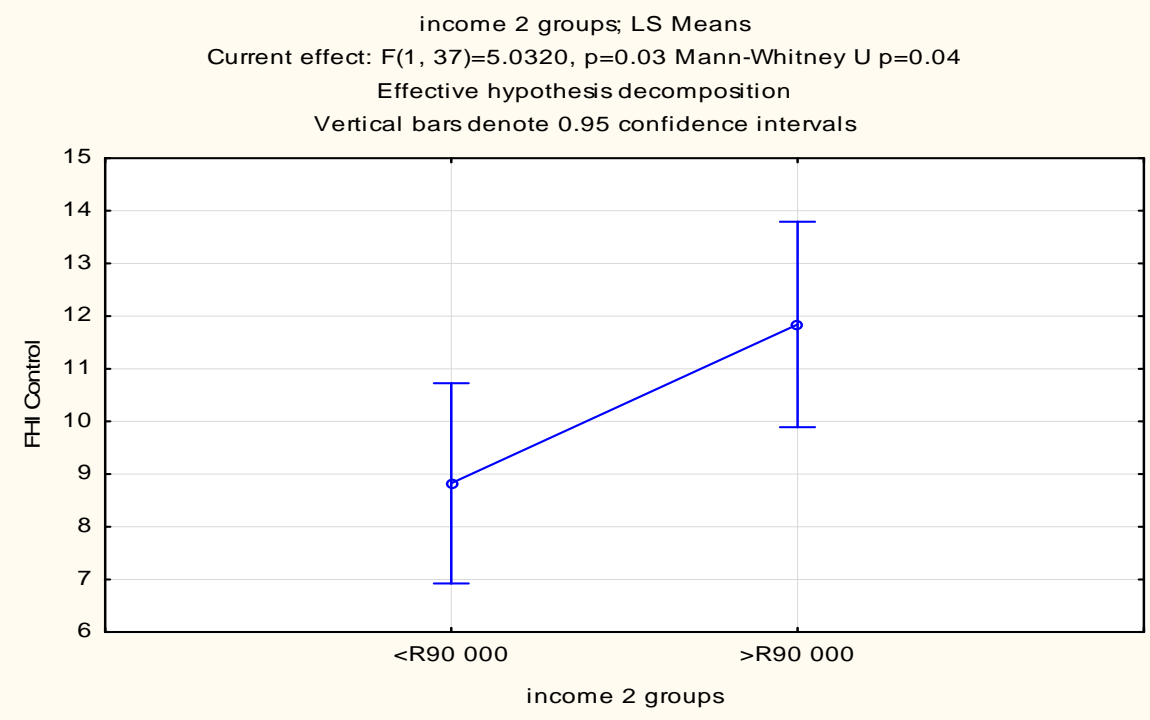

Figure 4.3 The results of the ANOVA shows a significant difference between the two income groups $(<\mathrm{R} 90000$ and $>$ R90 000 annual household income) at the FHI control subscale $(p=0.03)$. 
Figure 5.1.1 Difference between languages at the FACI8 Attachment subscale

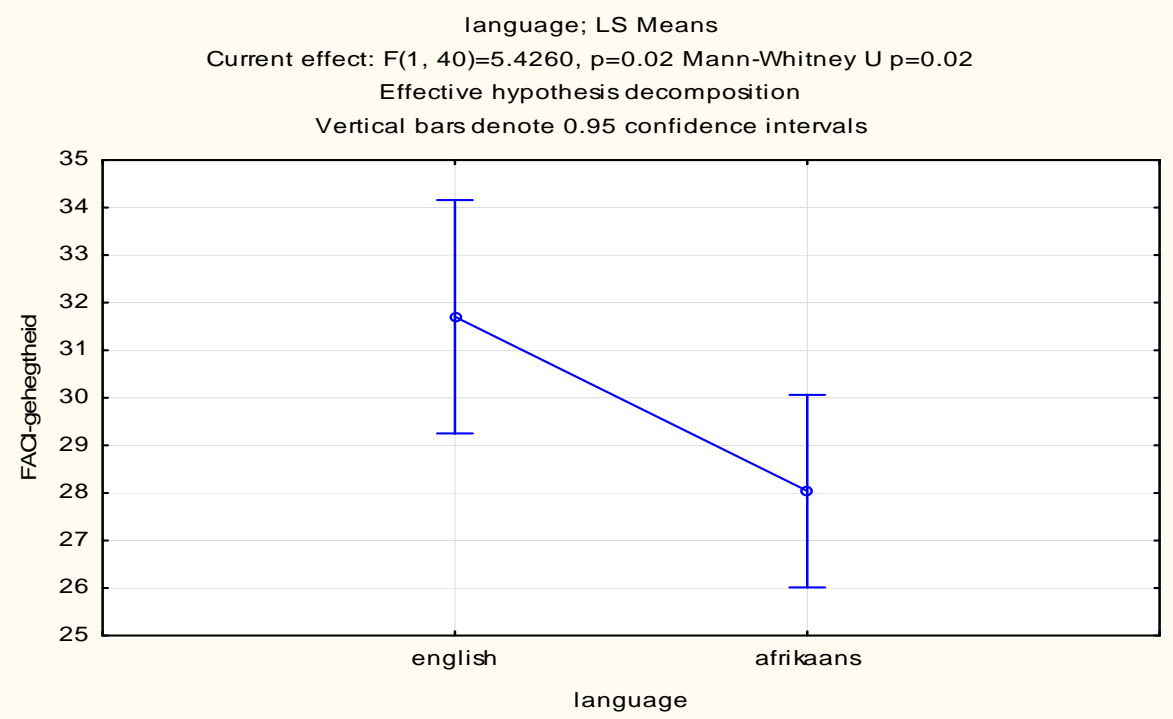

Figure 5.1.1 The results of the ANOVA shows a significant difference between the two language groups (FACI8 Attachment subscale, $\mathrm{p}=0.02$ ).

Figure 5.1.2 Difference between family structures at the FACI8 Attachment subscale

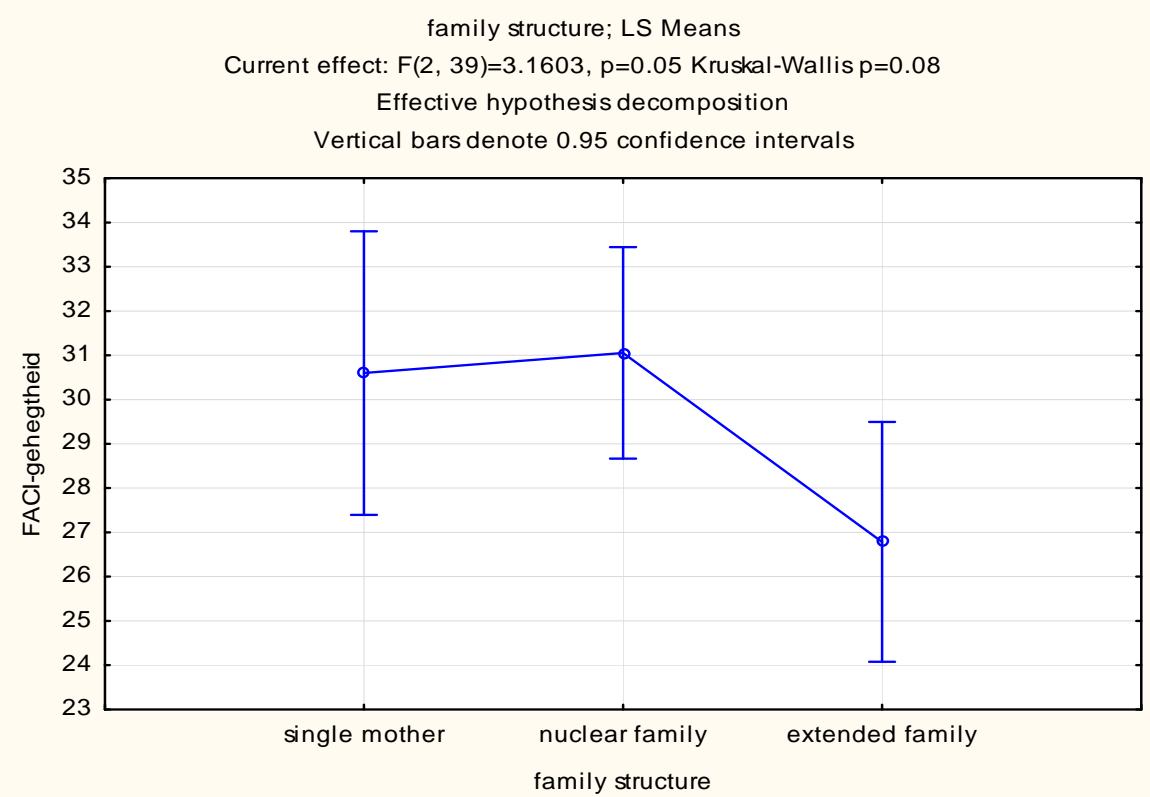

Figure 5.1.2 The results of the ANOVA shows significant difference between family structures (FACI8 Attachment subscale, $\mathrm{p}=0.05$ ). The LSD post-hoc testing revealed a significant difference between the responses of the nuclear households and the extended family structures $(p=0.05)$, with the nuclear families having a higher score than the extended families. 
Figure 5.1.3 Difference between the two income groups at the FACI8 Attachment subscale

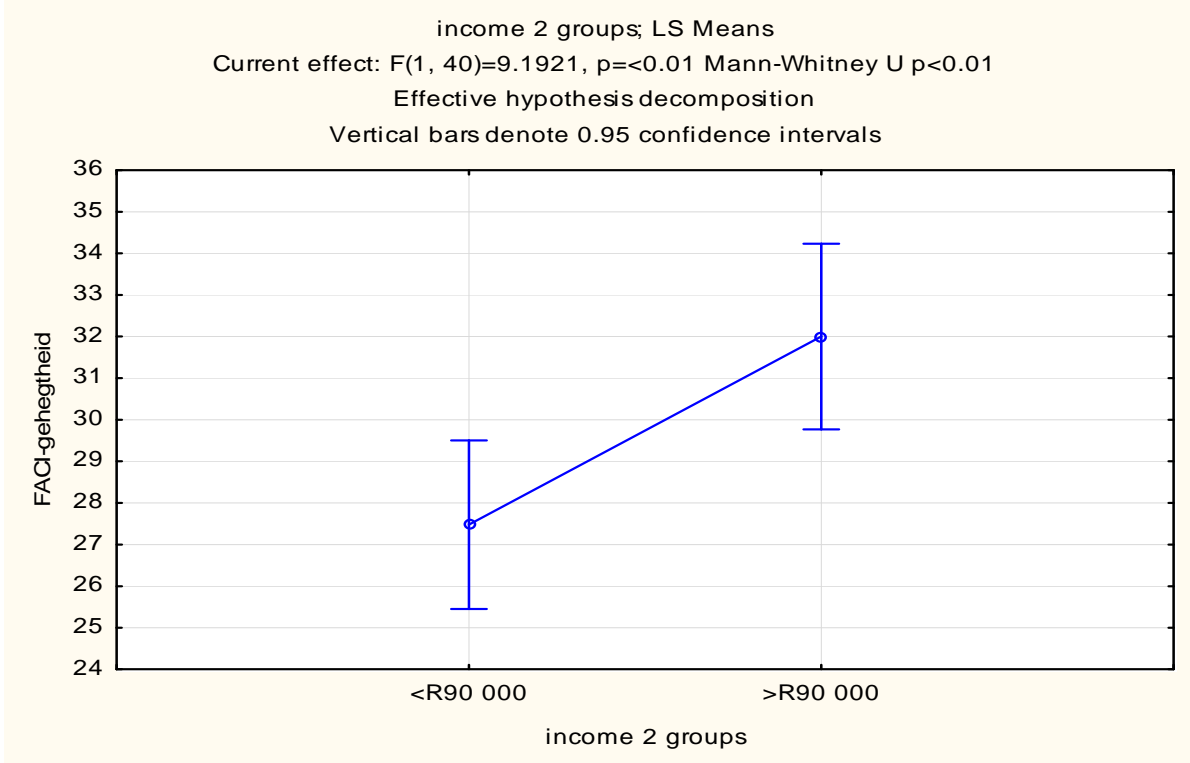

Figure 5.1.3 The results of the ANOVA shows a significant difference between the two income groups $(<\mathrm{R} 90000$ and $>$ R90 000 per year) at the FACI8 attachment subscale $(\mathrm{p}<0.01)$.

Figure 5.2 Difference between the two income groups at the FACI8 Total scale

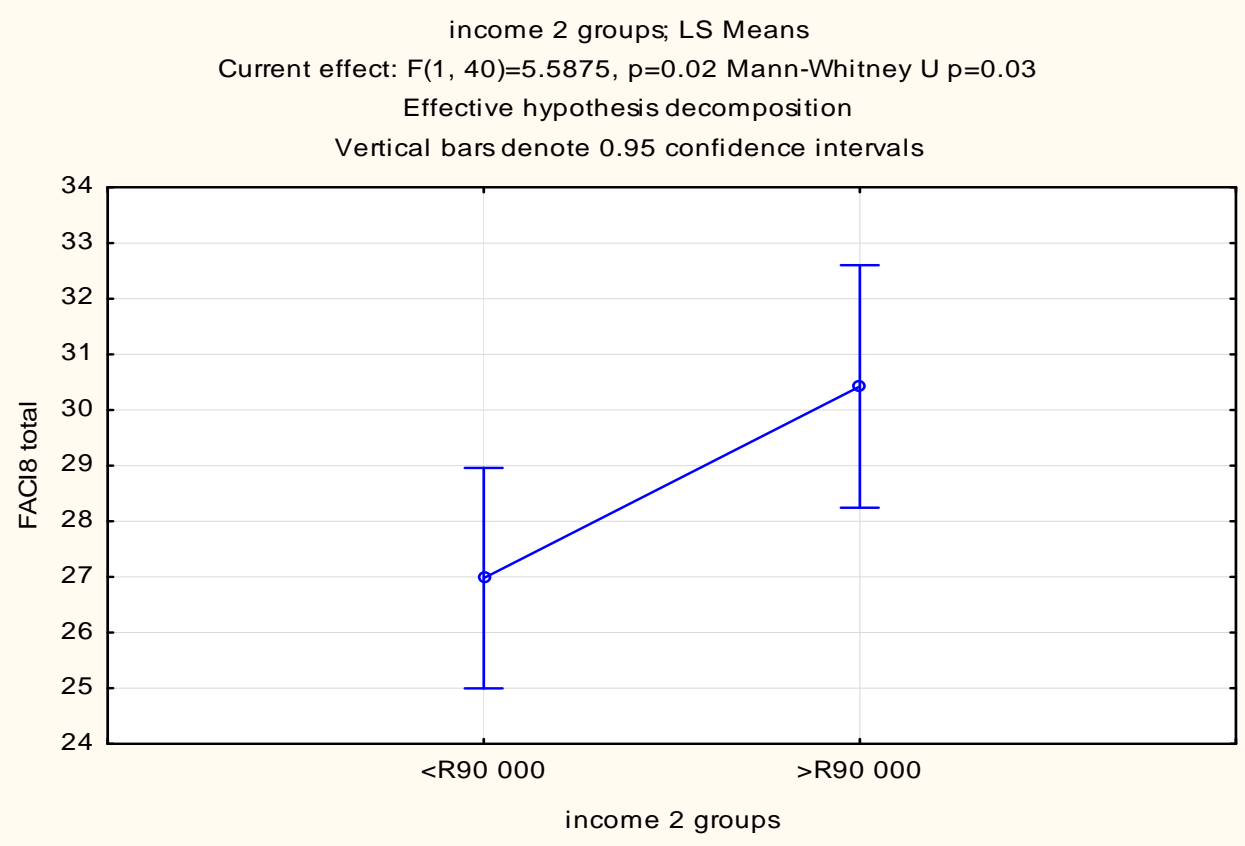

Figure 5.2 The results of the ANOVA shows a significant difference between the two income groups $(<\mathrm{R} 90000$ and $>$ R90 000 per year $)$ at FACI8 total $(\mathrm{p}=0.02)$. 